Estudos de métodos numéricos para a simulação de escoamentos viscoelásticos com superfície livre

Rafael Alves Figueiredo 

SERVIÇO DE PÓS-GRADUAÇÃO DO ICMC-USP

Data de Depósito:

Assinatura:

\title{
Estudos de métodos numéricos para a simulação de escoamentos viscoelásticos com superfície livre
}

\section{Rafael Alves Figueiredo}

Orientador: Prof. Dr. José Alberto Cuminato

\begin{abstract}
Dissertação apresentada ao Instituto de Ciências Matemáticas e de Computação - ICMC-USP, como parte dos requisitos para obtenção do título de Mestre em Ciências - Ciências de Computação e Matemática Computacional. EXEMPLAR DE DEFESA
\end{abstract}

USP - São Carlos

Julho de 2011 
Ficha catalográfica elaborada pela Biblioteca Prof. Achille Bassi e Seção Técnica de Informática, ICMC/USP, com os dados fornecidos pelo(a) autor(a)

Alves Figueiredo, Rafael
Estudo de Métodos Numéricos para a Simulação de
Escoamentos Viscoelásticos com Superficie Livre /
Rafael Alves Figueiredo; orientador José Alberto
Cuminato -- São Carlos, 2011.
60 p.
Dissertação (Mestrado - Programa de Pós-Graduação en
Ciências de Computação e Matemática Computacional) --
Instituto de Ciências Matemáticas e de Computação,
Universidade de São Paulo, 2011.
1. método de diferenças finitas. 2. superfície
livre. modelo SxpP. 4. tridimensional. I. Alberto
Cuminato, José , orient. II. Título.


Dedico às pessoas que mais amo na vida:

minha família. 



\section{Agradecimentos}

A minha família por todo o apoio e incentivo na minha vida.

Ao professor José Alberto Cuminato pela oportunidade de desenvolver este trabalho.

Ao professor Cassio Machiaveli Oishi pelas discussões, auxílio no projeto e paciência.

A todos os professores do LCAD/ICMC-USP.

A todos os professores da faculdade de matemática da Universidade Federal de Uberlândia, em especial aos professores Alessandro Alves Santana, Márcio José Horta Dantas e Marcos Antônio da Câmara.

A todos os meus amigos, que me acompanharam e me apoiaram ao longo desse projeto, em especial aos amigos do LCAD.

Ao CNPq e a FAPESP pelo auxílio financeiro.

A todas as pessoas que contribuíram explícita e implicitamente no desenvolvimento desse trabalho.

A Deus pela minha vida. 


\section{Resumo}

Neste projeto, é apresentado um método numérico com uma abordagem do tipo MAC para a simulação de escoamentos viscoelásticos incompressíveis tridimensionais com superfície livre governados pelo modelo de fluido SXPP. A formulação apresentada nesse trabalho é uma extensão dos resultados obtidos por Oishi et al. (2011), sobre o estudo de métodos numéricos para a simulação de escoamentos incompressíveis viscoelásticos com superfície livre a baixos números de Reynolds, para o caso bidimensional.

No contexto de problemas transientes, metodologias explícitas para solução numérica das equações governantes apresentam restrições de estabilidade muito severas para a definição do passo temporal, acarretando em um custo computacional relativamente alto. Sendo assim, utilizamos um método implícito para resolver a equação de conservação da quantidade de movimento, eliminando assim, a restrição de estabilidade parabólica e diminuindo significativamente o custo computacional. Mas tal estratégia acopla os campos de velocidade e pressão. Dessa forma, para desacoplar esses campos, foi utilizado uma abordagem que combina método de projeção com uma técnica implícita para o tratamento da pressão na superfície livre. A equação constitutiva foi resolvida pelo método de Runge-Kutta de segunda-ordem.

A validação do método numérico foi realizada utilizando refinamento da malha no escoamento em um canal. Como aplicação, apresentamos resultados numéricos sobre o problema do jato oscilante e do inchamento do extrudado.

Palavras-chave: método de diferenças finitas, superfície livre, modelo SXPP, tridimensional. 


\section{Abstract}

In this work, we present a numerical method with a MAC type approach to simulate tridimensional incompressible viscoelastic free surface flows governed by a SXPP (Single eXtended Pom-Pom) model. The formulation presented in this work is an extension to the work of Oishi et al. (2011). They have studied numerical methods for solving incompressible viscoelastic free surface flows with low Reynolds number, for the bidimensional case.

In the context of transient problems, explicit methodologies for the numerical solution of the governing equations present severe stability constraints for defining the time step, what highly increases the computational cost. Due to this fact, an implicit method is used to solve the momentum equation, eliminating the parabolic stability constraint and decreasing significantly the computational cost. However, this strategy couples velocity and pressure fields. To decouples this fields, it was used an approach that combines a projection method and an implicit technique for the treatment of the pressure at the free surface. The constitutive equation is solved by a second-order Runge-Kutta method.

The numerical method validation was achieved by a mesh refinement for a flow in a channel. As applications, numerical results of the die-swell problem and the jet buckling phenomenon are presented.

Keywords: finite difference method, free surface, SXPP model, tridimensional. 


\section{Sumário}

1 Introdução

2 Equações governantes e condições auxiliares $\quad 5$

2.1 Introdução . . . . . . . . . . . . . . . . . . . . . . . . 5

2.2 Adimensionalização das equações governantes e constitutiva . . . . . . . . . . . 7

2.3 Condições iniciais e de contorno . . . . . . . . . . . . . . . . . . . . . 10

2.3 .1 Fronteira rígida . . . . . . . . . . . . . . . . . 11

2.3.2 Fronteira de entrada do fluido . . . . . . . . . . . . . . . . . 13

2.3.3 Fronteira de saída do fluido . . . . . . . . . . . . . . . . . . . 13

2.3.4 Superfície livre . . . . . . . . . . . . . . . . . . . . 13

3 Método numérico para solução do modelo SXPP 15

3.1 Introdução . . . . . . . . . . . . . . . . . . . . . . . . . 15

3.2 Metodologia GENSMAC . . . . . . . . . . . . . . . . . . . 16

3.3 Método de projeção . . . . . . . . . . . . . . . . . . . . 19

3.4 Formulação implícita da metologia GENSMAC-SXPP . . . . . . . . . . . . . . 20

3.5 Tratamento da condição de contorno para a pressão ao longo da superfície livre . . . 22

3.6 Sistemas lineares . . . . . . . . . . . . . . . . . . . . 24

3.7 Algoritmo computacional . . . . . . . . . . . . . . . . . . 24

3.8 Cálculo do passo temporal . . . . . . . . . . . . . . . . . . . 25

4 Discretização Espacial $\quad 27$

4.1 Contribuição não-newtoniana em células $[\mathbf{F}]$ e $[\mathbf{S}] \ldots \ldots \ldots$

4.2 Contribuição não-newtoniana em células $[\mathbf{B}] \ldots \ldots \ldots$. . . . . . . . . . . . 31

5 Resultados $\quad 37$

5.1 Verificação do método numérico . . . . . . . . . . . . . . . . . 37

5.2 Aplicações . . . . . . . . . . . . . . . . . . . . . . . 40 
5.2.1 Inchamento do extrudado . . . . . . . . . . . . . . . . . . 40

5.2 .2 Jato oscilante . . . . . . . . . . . . . . . . . . . . 45

6 Considerações finais $\quad 51$

$\begin{array}{ll}\text { Referências Bibliográficas } & 60\end{array}$ 


\section{Lista de Figuras}

2.1 Exemplo de molécula polimérica para o modelo Pom-Pom (Martins, 2009). . . . . . . . . . 6

2.2 Ilustração das fronteiras envolvidas nesse trabalho . . . . . . . . . . . . . . . . . 11

3.1 Representação da célula $C_{i, j, k}$, utilizada no método GENSMAC: as velocidades $u, v$ e $w$ nas faces da célula e a pressão $p$ e a contribuição não newtoniana $T$ no centro da célula. . . . . . 16

3.2 (a) representa a classificação das células para a simulação do escoamento representado em (b). 17

3.3 Superfície planar paralela ao plano $x y$, extraído de Oishi (2008) . . . . . . . . . . . 18

3.4 Superfície planar paralela inclinada $45^{\circ}$, extraído de Oishi (2008) . . . . . . . . . . . . 18

3.5 Superfície planar paralela inclinada $60^{\circ}$, extraído de Oishi (2008). . . . . . . . . . . . . 19

4.1 Ilustração de uma fronteira rígida paralela ao plano $x y \ldots \ldots$. . . . . . . . . . . . 32

4.2 Ilustração de uma fronteira rígida com quina, paralela aos plano $x y$ e $y z \ldots$. . . . . . . . 34

4.3 Ilustração de uma fronteira rígida com quina, paralela aos plano $x y, x z$ e $y z \ldots . . . . .35$

5.1 Ilustração do domínio para simulação do escoamento em um tubo. . . . . . . . . . . . . . 37

5.2 Solução numérica do escoamento em um tubo com o modelo SXPP. Comparação entre as soluções obtidas com as malhas $M 1, M 2$ and $M 3$ em relação à solução obtida com a malha M4. a) w,b) $\left.\left.\left.T^{z z}, c\right) T^{y z}, d\right) T^{y y}, e\right) \lambda \ldots \ldots \ldots \ldots \ldots$

5.3 Definição do domínio para simulação do inchamento do extrudado. . . . . . . . . . . . 41

5.4 Convergência da superfície livre em uma seção transversal $y=0.015$ nas malhas $M 5, M 6 \mathrm{e}$ M7 em diferentes tempos. . . . . . . . . . . . . . . . . . . . 41

5.5 Resultado numérico do inchamento do extrudado: velocidade na direção y na malha $M 7 \mathrm{em}$ diferentes tempos. . . . . . . . . . . . . . . . . . . . . 42

5.6 Razão de inchamento $\times$ influência de $\alpha \ldots \ldots$. . . . . . . . . . . . . . . . 43

5.7 Razão de inchamento $\times$ influência de $\beta \ldots \ldots \ldots$. . . . . . . . . . . . . 43

5.8 Razão de inchamento $\times$ influência de $\ldots \ldots \ldots$. . . . . . . . . . . . . 44

5.9 Razão de inchamento $\times$ influência de $Q \ldots \ldots \ldots$. . . . . . . . . . . . . . . . 44

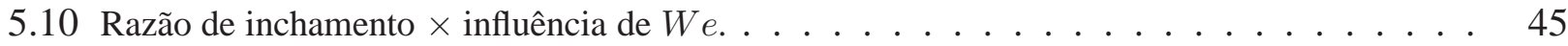


5.11 Razão de inchamento $\times$ influência de $R e . \ldots . \ldots . \ldots$. . . . . . . . . . . 45

5.12 Geometria do jato oscilante. . . . . . . . . . . . . . . . . . . 46

5.13 Jato oscilante nos tempos $t=2 s, t=5 s$ e $t=9 s$ para os seguintes parâmetros: $R e=6$, $W e=0.1, \alpha=0.5, \beta=0.9, \gamma=0.1$ e $Q=1 \ldots \ldots \ldots \ldots$. . . . . . . 47

5.14 Jato oscilante nos tempos $t=2 s, t=5 s$ e $t=9 s$ para os seguintes parâmetros: $R e=6$, $W e=0.1, \alpha=0.01, \beta=0.3, \gamma=0.8$ e $Q=8 \ldots \ldots \ldots \ldots \ldots \ldots$

5.15 Jato oscilante nos tempos $t=2 s, t=5 s$ e $t=9 s$ para os seguintes parâmetros: $R e=5$, $W e=0.1, \alpha=0.08, \beta=0.3, \gamma=0.7$ e $Q=7 \ldots \ldots \ldots \ldots \ldots$

5.16 Jato oscilante nos tempos $t=2 s, t=5 s$ e $t=9 s$ para os seguintes parâmetros: $R e=4$, $W e=0.1, \alpha=0.5, \beta=0.9, \gamma=0.1$ e $Q=1 \ldots \ldots \ldots \ldots$

5.17 Jato oscilante nos tempos $t=2 s, t=5 s$ e $t=9 s$ para os seguintes parâmetros: $R e=2$, $W e=0.1, \alpha=0.5, \beta=0.9, \gamma=0.1$ e $Q=1 \ldots \ldots \ldots \ldots$ 


\section{Lista de Tabelas}

5.1 Erros nas malhas $M 1, M 2$ e $M 3$ para o escoamento em um tubo com fluido SXPP.

40

5.2 Ocorrência de oscilação para o problema do jato oscilante, com diversos parâmetros do modelo SXPP e com $W e=0.1$. 


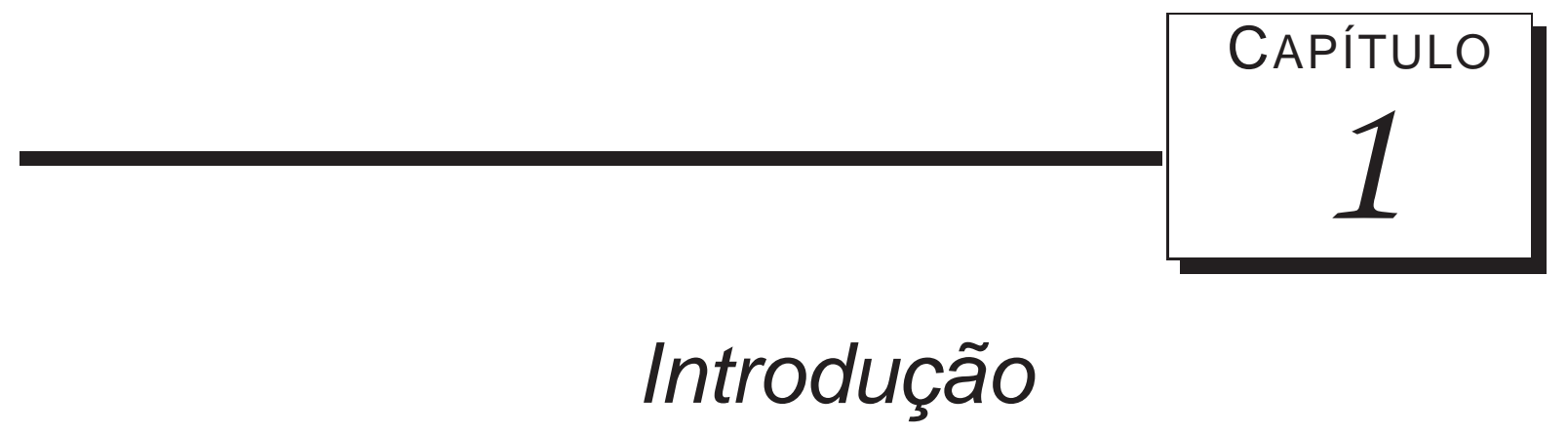

Escoamentos com fluidos viscoelásticos estão presentes em muitas aplicações industriais, assim, entender como esses escoamentos se comportam, é de interesse econômico e tecnológico. Várias equações constitutivas que descrevem fluidos viscoelásticos podem ser encontradas em Bird et al. (1987). Porém, nenhuma dessas equações descrevem de forma satisfatória o correto comportamento elongacional e de cisalhamento. Para eliminar tal falha, surgiu recentemente o modelo Pom-Pom, proposto por McLeish and Larson (1998). Na tentativa de superar alguns problemas do modelo original, foram propostos vários modelos, como XPP (eXtended Pom-Pom), proposto por Verbeeten et al. (2001) e Clemeur et al. (2003), SIPP (Single Improved Pom-Pom), DIPP (Double Improved Pom-Pom), SXPP (Single eXtended Pom-Pom), DXPP (Double eXtended Pom-Pom), $\lambda^{2}$ XPP, mXPP (modified eXtended Pom-Pom) e Semi-Linear SXPP. Alguns autores têm realizado diversos estudos para obtenção da solução numérica para esse modelo de fluido, como pode ser visto em Bishko et al. (1999); Rubio and Wagner (2000); Wapperom and Keunings (2001); Verbeeten et al. (2002); Bogaerds et al. (2002); Clemeur et al. (2004); Verbeeten et al. (2004); Aboubacar et al. (2005); van Os and Phillips (2005); Aguayo et al. (2006); Soulages et al. (2006); Aguayo et al. (2007); Inkson and Phillips (2007), e mais recentemente em Puangkird et al. (2009); Inkson et al. (2009); Favero et al. (2010); Baltussen et al. (2010b); Wang et al. (2010).

Todos os trabalhos mencionados acima investigaram escoamentos bidimensionais. Um dos primeiros trabalhos na literatura sobre o comportamento reológico do modelo XPP em três dimensões foi proposto por Sirakov et al. (2005). Usando um método de elementos finitos, os autores estudaram o fluxo do polímero em uma contração, além de uma comparação dos resultados numéricos com resultados experimentais. Dressler and Edwards (2006) analisaram o modelo Pom-Pom em um tubo, enquanto Khorsand et al. (2011) introduziram um método de volumes finitos para investigar a equação do modelo SXPP em um tubo. Mais recentemente, Tenchev et al. (2011) mostrou alguns resultados 
em três dimensões de um escoamento ao redor de um cilindro e em uma contração. Nesse artigo, os problemas foram modelados para um fluido XPP e os resultados numéricos foram obtidos com um método de elementos finitos.

Além disso, uma dificuldade adicional aparece quando escoamentos com o modelo XPP envolvem superfície livre. Nesse caso, uma técnica eficiente para representar a interface e um método preciso para resolver as equações constitutivas precisão ser combinados na simulação numérica. Baltussen et al. (2010a) também analisaram o comportamento do modelo XPP em um problema do tipo fountain flow.

Um problema comum em reologia computacional, envolvendo superfície livre, é o fenômeno do inchamento do extrudado. Recentemente, alguns trabalhos foram publicados descrevendo o comportamento do modelo XPP para este problema. Em uma visão bidimensional, Russo and Phillips (2010) apresentaram um método espectral para simular tal fenômeno, enquanto Oishi et al. (2011) propuseram um esquema de diferenças finitas para estudar a influência dos parâmetros do modelo XPP sobre a razão de inchamento. Para o caso tridimensional, existem poucos trabalhos que descrevem o problema do inchamento do extrudado. Por exemplo, Debbaut and Marchal (2008) modelaram numericamente esse problema utilizando o software POLYFLOW, enquanto Aloku and Yuan (2010) simularam a convecção dupla do modelo Pom-Pom em um processo de formação de espuma em uma extrusão. Um estudo recente do inchamento do extrudado axissimétrico com o modelo XPP, utilizando uma formulação lagrangiana-euleriana arbitrária de elementos finitos, foi apresentado por Ganvir et al. (2011). Os resultados numéricos obtidos por Ganvir et al. (2011) estão em boa concordância com os resultados experimentais.

Uma questão desafiadora consiste em descrever um método preciso para resolver escoamentos viscoelásticos com a presença de superfície livre. Este fato tem mobilizado vários pesquisadores em reologia computacional e muito progresso tem sido obtido para esses problemas. Em particular, para o modelo XPP alguns resultados foram apresentados: Yang et al. (2010) simularam o processo de enchimento de um molde que combina um método Level-Set e o método de volumes finitos em uma malha não deslocada; Jiang et al. (2011) estudaram o fenômeno do impacto de gotas de líquido em superfícies sólidas utilizando um método SPH (Smoothed Particle Hidrodynamic) melhorado; Qiang et al. (2011) apresentaram resultados recentes de escoamentos bifásicos gás-liquido utilizando métodos Level-Set/SIMPLEC.

No entanto, no contexto do método MAC (Marker-And-Cell), utilizando diferenças finitas e uma malha deslocada, soluções numéricas em três dimensões de escoamentos com superfície livre de polímero ramificado recebeu relativamente pouca atenção, e tanto quanto sabemos, este é o primeiro trabalho que apresenta resultados para o modelo SXPP. Dentro deste contexto, esse trabalho apresenta um método numérico para simular escoamentos com superfície livre, permitindo o estudo dos problemas que não poderiam ser estudados antes. A técnica numérica implementada neste trabalho é uma extensão do método implícito para escoamentos viscoelásticos descrito em Oishi et al. (2011). Tal técnica foi implementada no ambiente de simulação FreeFlow (Castelo et al., 2000). 
Assim, nesse trabalho foi utilizado um método numérico robusto e um modelo confiável para a equação constitutiva, que são cruciais para a simulação de escoamentos com fluidos viscoelásticos.

O método numérico utilizado foi verificado utilizando refinamento da malha em um canal. Como aplicação e estudo do comportamento desse modelo para o caso tridimensional com superfície livre, foi analisada a influência dos parâmetros do modelo nos problemas do jato oscilante e do inchamento do extrudado. Mais detalhes sobre o estudo e desenvolvimento desse trabalho, podem ser encontrados ao longo da dissertação. 
CAPÍTULO

\section{Equações governantes e condições auxiliares}

Neste capítulo serão apresentadas as equações que modelam o escoamento de um fluido viscoelástico com superfície livre, assim como as condições iniciais e de contorno.

\subsection{Introdução}

Todos os escoamentos considerados neste trabalho são incompressíveis e isotérmicos, ou seja, a densidade e a temperatura são constantes. Dessa forma, as equações de conservação da massa e de conservação do momento para fluidos viscoelásticos são dadas por:

$$
\begin{gathered}
\rho\left(\frac{\partial \mathbf{u}}{\partial t}+\nabla \cdot(\mathbf{u u})\right)=\nabla \cdot \sigma+\rho \mathbf{g}, \\
\nabla \cdot \mathbf{u}=0,
\end{gathered}
$$

sendo $t$ o tempo e $\mathbf{x}$ o vetor posição, $\mathbf{u}=\mathbf{u}(\mathbf{x}, t)$ é o campo de velocidade, $p=p(\mathbf{x}, t)$ é a pressão, $\rho$ é a densidade do fluido, que é constante por hipótese, $\mathbf{g}=\mathbf{g}(\mathbf{x}, t)$ é o campo gravitacional e $\sigma=\sigma(\mathbf{x}, t)$ é o tensor de tensões. O tensor $\sigma$ pode ser decomposto da seguinte forma

$$
\sigma=\tau-p \mathbf{I}
$$

em que I é a matriz identidade $3 \times 3$ e $\tau=\tau(\mathbf{x}, t)=\left[\begin{array}{ccc}\tau^{x x} & \tau^{x y} & \tau^{x z} \\ \tau^{y x} & \tau^{y y} & \tau^{y z} \\ \tau^{z x} & \tau^{z y} & \tau^{z z}\end{array}\right]$ é o tensor de tensão extra, que é simétrico (Bird et al., 1987). 
Adotou-se a formulação EVSS (Elastic-Viscous Split Stress) (Rajagopalan et al., 1990) para decompor o tensor $\sigma$ em uma parte newtoniana (viscosa) e outra parte não-newtoniana (elástica). $\mathrm{O}$ emprego dessa formulação permite escrever o tensor $\sigma$ da seguinte forma

$$
\sigma=-p \mathbf{I}+2 \mu_{S} D+T
$$

em que $\mu_{S}$ é a viscosidade do solvente, $D$ é o tensor taxa de deformação, dado por

$$
D=\frac{1}{2}\left(\nabla \mathbf{u}+(\nabla \mathbf{u})^{\mathrm{T}}\right)
$$

sendo que $(\nabla \mathbf{u})^{\mathrm{T}}$ é o transposto do tensor gradiente de velocidade $\nabla \mathbf{u}$, e $T$ é o tensor do polímero, o qual é definido pela equação constitutiva característica do modelo do fluido.

Neste trabalho é estudado o modelo SXPP (Single eXtended Pom Pom) (Verbeeten et al., 2001), que é derivado do modelo Pom-Pom (McLeish and Larson, 1998). Este modelo representa a molécula polimérica na forma de um tubo, que constitui sua coluna vertebral. Além disso, nos extremos desta molécula, existe um dado número de ramificações (braços), como pode ser visto na figura 2.1.

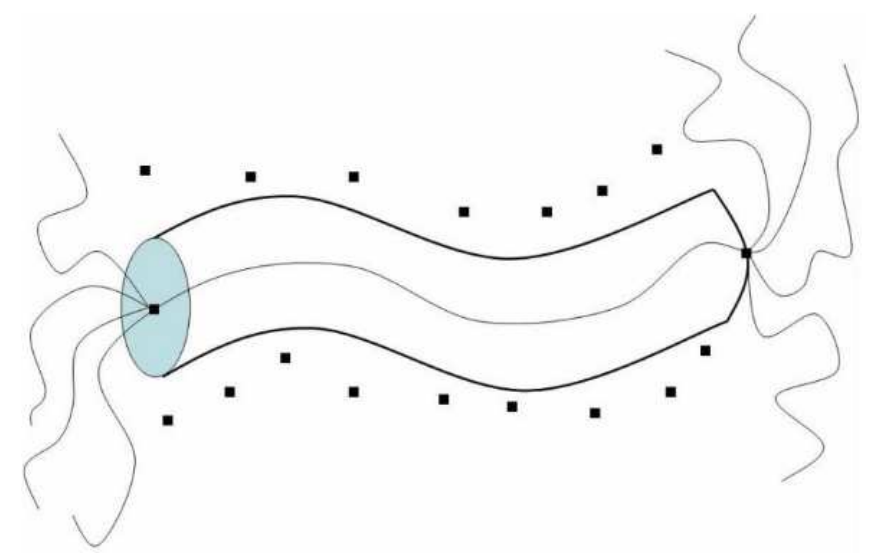

Figura 2.1: Exemplo de molécula polimérica para o modelo Pom-Pom (Martins, 2009).

A equação constitutiva do modelo SXPP é dada por

$$
f(\lambda, T) T+\lambda_{1} \stackrel{\nabla}{T}+G_{0}(f(\lambda, T)-1) \mathbf{I}+\frac{\alpha}{G_{0}}(T \cdot T)=2 \mu_{P} D,
$$

em que $f(\lambda, T)$ é uma variável auxiliar, dada por

$$
f(\lambda, T)=2 \frac{\lambda_{1}}{\lambda_{2}}\left(1-\frac{1}{\lambda}\right) e^{Q_{0}(\lambda-1)}+\frac{1}{\lambda^{2}}\left[1-\frac{\alpha}{3 G_{0}^{2}} \operatorname{tr}(T \cdot T)\right]
$$

e $\lambda=\lambda(T)$ é a extensão relativa da coluna vertebral da molécula polimérica, descrita pela equação

$$
\lambda(T)=\sqrt{1+\frac{1}{3 G_{0}}|\operatorname{tr}(T)|} .
$$


Além disso, $\stackrel{\nabla}{T}$ representa a derivada contravariante de $T$, definida por

$$
\stackrel{\nabla}{T}=\frac{\partial T}{\partial t}+\nabla \cdot(\mathbf{u} T)-(\nabla \mathbf{u}) \cdot T-T \cdot(\nabla \mathbf{u})^{T} .
$$

Nas equações (2.6) - (2.8), $\lambda_{1}$ e $\lambda_{2}$ são os tempos de relaxação do modelo, $\mu_{P}=G_{0} \lambda_{1}$ a viscosidade do polímero, $G_{0}$ o módulo da relaxação linear, $\alpha$ a anisotropia do material e $Q$ o número de ramificações em cada extremidade da molécula polimérica, tal que, $Q Q_{0}=2$ (Aboubacar et al., 2005).

\subsection{Adimensionalização das equações governantes e cons- titutiva}

Todas as equações apresentadas anteriormente modelam um escoamento incompressível, isotérmico e viscoelástico e estão na forma dimensional. Entretanto, computacionalmente é mais vantajoso trabalhar com a forma adimensional dessas equações. Assim, para adimensionalizar as equações governantes e constitutiva é necessário introduzir as variáveis adimensionais (acrescidas do índice $*$ )

$$
\begin{aligned}
& \mathbf{x}^{*}=\frac{\mathbf{x}}{L}, \quad \mathbf{u}^{*}=\frac{\mathbf{u}}{U}, \quad t^{*}=\frac{U}{L} t, \quad \mathbf{g}^{*}=\frac{\mathbf{g}}{g} \\
& p^{*}=\frac{p}{\rho U^{2}}, \quad \tau^{*}=\frac{\tau}{\rho U^{2}}, \quad T^{*}=\frac{T}{\rho U^{2}}, \quad \stackrel{\nabla}{T^{*}}=\frac{L}{\rho U^{3}} \stackrel{\nabla}{T},
\end{aligned}
$$

em que $L$ é a escala de comprimento, $U$ a escala de velocidade e $g$ a escala de aceleração de campo.

Para preservar a similaridade entre a forma dimensional e a adimensional do modelo SXPP, é necessário definir alguns parâmetros importantes relacionados às equações de Navier-Stokes e a equação constitutiva.

- Número de Reynolds (Re)

$$
R e=\frac{\rho U L}{\mu},
$$

sendo

$$
\mu=\mu_{S}+\mu_{P}
$$

a viscosidade total, dada pela soma da viscosidade do solvente $\left(\mu_{S}\right)$ com a viscosidade do polímero $\left(\mu_{P}\right)$.

- Número de Weissemberg $(W e)$

$$
W e=\frac{\lambda_{1} U}{L}=\frac{\lambda_{1}}{\left(\frac{L}{U}\right)} .
$$

Como $\lambda_{1}$ é uma das constantes temporais de um fluido viscoelástico e $\frac{L}{U}$ é a escala de tempo característica do escoamento, quanto maior $W e$, menor a escala de tempo do escoamento, o que diminui o tempo de relaxação da molécula polimérica. Assim, quanto maior $W e$, maior a viscoelasticidade. 
- Número de Froude (Fr)

$$
F r=\frac{U}{\sqrt{g L}},
$$

estabelece a razão entre as forças inerciais e as forças de campo (Fortuna, 2000).

- Parâmetro $\beta$

$$
\beta=\frac{\mu_{S}}{\mu}, \quad \beta \in(0,1),
$$

é o parâmetro de razão de viscosidade.

\section{- Parâmetro $\gamma$}

$$
\gamma=\frac{\lambda_{2}}{\lambda_{1}}
$$

que representa a razão entre o tempo de relaxamento do estiramento da coluna vertebral e tempo de relaxamento da orientação.

Para obter as equações governantes e constitutiva na forma adimensional, basta substituir os parâmetros adimensionais nas equações (2.1) - (2.9). Assim, a forma adimensional dessas equações é apresentada a seguir. Por simplicidade, omitiu-se o sinal “*” das variáveis.

$$
\begin{gathered}
\nabla \cdot \mathbf{u}=0 \\
\frac{\partial \mathbf{u}}{\partial t}+\nabla \cdot(\mathbf{u u})=\nabla \cdot \sigma+\frac{1}{F r^{2}} \mathbf{g}, \\
\sigma=-p \mathbf{I}+\frac{2 \beta}{R e} D+T \\
f(\lambda, T) T+W e \stackrel{\nabla}{T}+\frac{1-\beta}{R e W e}(f(\lambda, T)-1) \mathbf{I}+\alpha \frac{\operatorname{Re} W e}{1-\beta} T \cdot T=2 \frac{1-\beta}{R e} D,
\end{gathered}
$$

em que

$$
\begin{gathered}
f(\lambda, T)=\frac{2}{\gamma}\left(1-\frac{1}{\lambda}\right) e^{Q_{o}(\lambda-1)}+\frac{1}{\lambda^{2}}\left[1-\frac{\alpha}{3}\left(\frac{\operatorname{Re} W e}{1-\beta}\right)^{2} \operatorname{tr}(T \cdot T)\right], \\
\lambda=\sqrt{1+\frac{1}{3}\left(\frac{\operatorname{Re} W e}{1-\beta}\right)|\operatorname{tr}(T)| .}
\end{gathered}
$$

Da mesma forma, seguem as equações $(2.11),(2.12)$ e (2.14), em coordenadas cartesianas

$$
\frac{\partial u}{\partial x}+\frac{\partial v}{\partial y}+\frac{\partial w}{\partial z}=0
$$




$$
\begin{aligned}
& \frac{\partial u}{\partial t}+\frac{\partial\left(u^{2}\right)}{\partial x}+\frac{\partial(u v)}{\partial y}+\frac{\partial(u w)}{\partial z}= \\
& \quad-\frac{\partial p}{\partial x}+\frac{\beta}{R e}\left(\frac{\partial^{2} u}{\partial x^{2}}+\frac{\partial^{2} u}{\partial y^{2}}+\frac{\partial^{2} u}{\partial z^{2}}\right)+\frac{\partial T^{x x}}{\partial x}+\frac{\partial T^{x y}}{\partial y}+\frac{\partial T^{x z}}{\partial z}+\frac{1}{F r^{2}} g^{x}, \\
& \frac{\partial v}{\partial t}+\frac{\partial(u v)}{\partial x}+\frac{\partial\left(v^{2}\right)}{\partial y}+\frac{\partial(v w)}{\partial z}= \\
& \quad-\frac{\partial p}{\partial y}+\frac{\beta}{R e}\left(\frac{\partial^{2} v}{\partial x^{2}}+\frac{\partial^{2} v}{\partial y^{2}}+\frac{\partial^{2} v}{\partial z^{2}}\right)+\frac{\partial T^{x y}}{\partial x}+\frac{\partial T^{y y}}{\partial y}+\frac{\partial T^{y z}}{\partial z}+\frac{1}{F r^{2}} g^{y},
\end{aligned}
$$

$$
\begin{aligned}
\frac{\partial w}{\partial t}+\frac{\partial(u w)}{\partial x}+ & \frac{\partial(v w)}{\partial y}+\frac{\partial\left(w^{2}\right)}{\partial z}= \\
& -\frac{\partial p}{\partial z}+\frac{\beta}{R e}\left(\frac{\partial^{2} w}{\partial x^{2}}+\frac{\partial^{2} w}{\partial y^{2}}+\frac{\partial^{2} w}{\partial z^{2}}\right)+\frac{\partial T^{x z}}{\partial x}+\frac{\partial T^{y z}}{\partial y}+\frac{\partial T^{z z}}{\partial z}+\frac{1}{F r^{2}} g^{z}
\end{aligned}
$$

$$
\begin{aligned}
\frac{\partial T^{x x}}{\partial t} & =2 \xi \frac{\partial u}{\partial x}+2\left(\frac{\partial u}{\partial x} T^{x x}+\frac{\partial u}{\partial y} T^{x y}+\frac{\partial u}{\partial z} T^{x z}\right)-\left(\frac{\partial\left(u T^{x x}\right)}{\partial x}+\frac{\partial\left(v T^{x x}\right)}{\partial y}+\frac{\partial\left(w T^{x x}\right)}{\partial z}\right) \\
& -\frac{1}{W e}\left\{f(\lambda, T) T^{x x}+\xi(f(\lambda, T)-1)+\frac{\alpha}{\xi}\left[\left(T^{x x}\right)^{2}+\left(T^{x y}\right)^{2}+\left(T^{x z}\right)^{2}\right]\right\},
\end{aligned}
$$

$$
\begin{aligned}
\frac{\partial T^{y y}}{\partial t} & =2 \xi \frac{\partial v}{\partial y}+2\left(\frac{\partial v}{\partial x} T^{x y}+\frac{\partial v}{\partial y} T^{y y}+\frac{\partial v}{\partial z} T^{y z}\right)-\left(\frac{\partial\left(u T^{y y}\right)}{\partial x}+\frac{\partial\left(v T^{y y}\right)}{\partial y}+\frac{\partial\left(w T^{y y}\right)}{\partial z}\right) \\
& -\frac{1}{W e}\left\{f(\lambda, T) T^{y y}+\xi(f(\lambda, T)-1)+\frac{\alpha}{\xi}\left[\left(T^{x y}\right)^{2}+\left(T^{y y}\right)^{2}+\left(T^{y z}\right)^{2}\right]\right\},
\end{aligned}
$$

$$
\begin{aligned}
\frac{\partial T^{z z}}{\partial t} & =2 \xi \frac{\partial w}{\partial z}+2\left(\frac{\partial w}{\partial x} T^{x z}+\frac{\partial w}{\partial y} T^{y z}+\frac{\partial w}{\partial z} T^{z z}\right)-\left(\frac{\partial\left(u T^{z z}\right)}{\partial x}+\frac{\partial\left(v T^{z z}\right)}{\partial y}+\frac{\partial\left(w T^{z z}\right)}{\partial z}\right) \\
& -\frac{1}{W e}\left\{f(\lambda, T) T^{z z}+\xi(f(\lambda, T)-1)+\frac{\alpha}{\xi}\left[\left(T^{x z}\right)^{2}+\left(T^{y z}\right)^{2}+\left(T^{z z}\right)^{2}\right]\right\}
\end{aligned}
$$




$$
\begin{aligned}
\frac{\partial T^{x y}}{\partial t} & =\xi\left(\frac{\partial u}{\partial y}+\frac{\partial v}{\partial x}\right)+\frac{\partial u}{\partial x} T^{x y}+\frac{\partial u}{\partial y} T^{y y}+\frac{\partial u}{\partial z} T^{y z}+\frac{\partial v}{\partial x} T^{x x}+\frac{\partial v}{\partial y} T^{x y}+\frac{\partial v}{\partial z} T^{x z} \\
& -\left(\frac{\partial\left(u T^{x y}\right)}{\partial x}+\frac{\partial\left(v T^{x y}\right)}{\partial y}+\frac{\partial\left(w T^{x y}\right)}{\partial z}\right) \\
& -\frac{1}{W e}\left\{f(\lambda, T) T^{x y}+\frac{\alpha}{\xi}\left[T^{x x} T^{x y}+T^{x y} T^{y y}+T^{x z} T^{y z}\right]\right\} \\
\frac{\partial T^{x z}}{\partial t} & =\xi\left(\frac{\partial u}{\partial z}+\frac{\partial w}{\partial x}\right)+\frac{\partial u}{\partial x} T^{x z}+\frac{\partial u}{\partial y} T^{y z}+\frac{\partial u}{\partial z} T^{z z}+\frac{\partial w}{\partial x} T^{x x}+\frac{\partial w}{\partial y} T^{x y}+\frac{\partial w}{\partial z} T^{x z} \\
& -\left(\frac{\partial\left(u T^{x z}\right)}{\partial x}+\frac{\partial\left(v T^{x z}\right)}{\partial y}+\frac{\partial\left(w T^{x z}\right)}{\partial z}\right) \\
& -\frac{1}{W e}\left\{f(\lambda, T) T^{x z}+\frac{\alpha}{\xi}\left[T^{x x} T^{x z}+T^{x y} T^{y z}+T^{x z} T^{z z}\right]\right\} \\
\frac{\partial T^{y z}}{\partial t} & =\xi\left(\frac{\partial v}{\partial z}+\frac{\partial w}{\partial y}\right)+\frac{\partial v}{\partial x} T^{x z}+\frac{\partial v}{\partial y} T^{y z}+\frac{\partial v}{\partial z} T^{z z}+\frac{\partial w}{\partial x} T^{x y}+\frac{\partial w}{\partial y} T^{y y}+\frac{\partial w}{\partial z} T^{y z} \\
& -\left(\frac{\partial\left(u T^{y z}\right)}{\partial x}+\frac{\partial\left(v T^{y z}\right)}{\partial y}+\frac{\partial\left(w T^{y z}\right)}{\partial z}\right) \\
& \frac{1}{W e}\left\{f(\lambda, T) T^{y z}+\frac{\alpha}{\xi}\left[T^{x y} T^{x z}+T^{y y} T^{y z}+T^{y z} T^{z z}\right]\right\}
\end{aligned}
$$

em que

$$
\xi=\frac{1-\beta}{R e W e}
$$

Portanto, a equação da continuidade (2.11), a equação de Navier-Stokes (2.12) e as equações que definem a contribuição não-newtoniana (2.14), (2.15) e (2.16) são as equações adimensionais para escoamentos incompressíveis, isotérmicos e viscoelásticos do modelo SXPP. A partir dessa seção, serão utilizadas somente as equações adimensionais.

A seguir serão apresentadas as principais condições iniciais e de contorno utilizadas nesse trabalho.

\subsection{Condições iniciais e de contorno}

Para resolver as equações (2.11), (2.12) e (2.14), é necessário impor condições auxiliares para as componentes da velocidade $u, v$ e $w$, pressão $p$ e a contribuição não-newtoniana $T$, para que a solução numérica preserve as características físicas do escoamento. Existem basicamente dois tipos 
de condições auxiliares:

- Condições iniciais - São escolhidas de forma que sejam compatíveis com as equações governantes, pois fornecem informações sobre o estado inicial do problema sendo condições importantes para a convergência do método numérico. A especificação de um campo inicial de velocidade $\mathbf{u}_{0}$ deve satisfazer a equação da continuidade (2.11) (Fortuna, 2000). A pressão e a contribuição não-newtoniana são escolhidas de forma compatível com o campo de velocidade, sendo, geralmente, consideradas nulas no instante inicial $t_{0}$ (Batchelor, 1967; Fortuna, 2000; Bird et al., 1987).

- Condições de contorno - Especificam o que ocorre no limiar da região espacial de definição do problema, isto é, fornecem informações físicas em todo tempo $t$ das variáveis dependentes nas fronteiras da região que limita o escoamento. Para os escoamentos estudados nesse trabalho, existem basicamente quatro tipos de condições de fronteira (vide figura 2.2). Essas condições de contorno são definidas nas subseções a seguir.

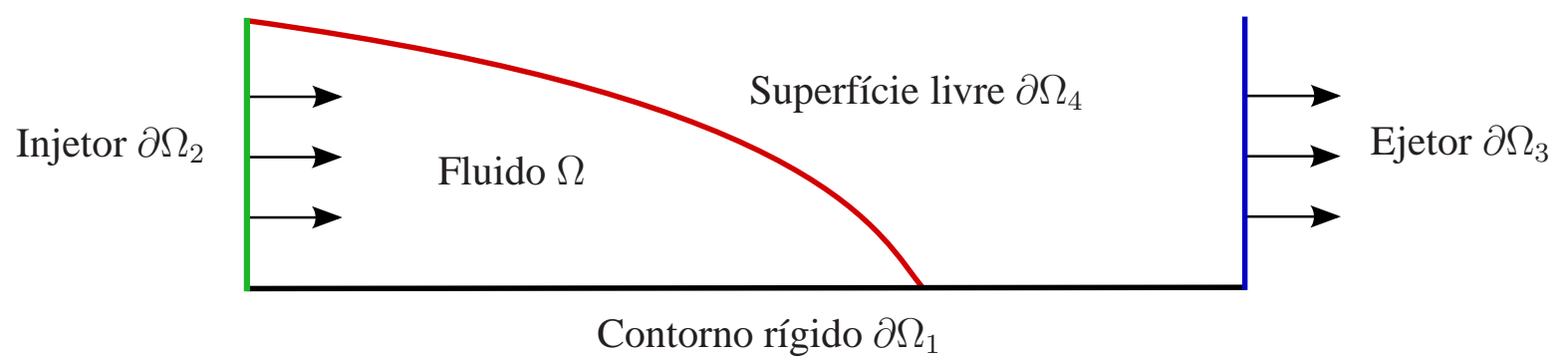

Figura 2.2: Ilustração das fronteiras envolvidas nesse trabalho.

\subsubsection{Fronteira rígida}

Simula a situação em que não poderá haver fluxo de massa na direção normal. Assim, sendo $\mathbf{u}_{\vec{n}}$ a componente normal de velocidade na fronteira, devemos ter

$$
\mathbf{u}_{\vec{n}}=0
$$

Além disso, é necessário especificar as velocidades tangenciais $\mathbf{u}_{t_{1}}$ e $\mathbf{u}_{t_{2}}$ ao longo da fronteira $\partial \Omega_{1}$. Existem dois casos, apresentados a seguir:

- Condição de aderência nula (free-slip) - É usada para impor condição de simetria, ou quando os efeitos da condição de aderência não são desejáveis. Neste caso, é conveniente impor que a taxa de variação da componente da velocidade paralela à fronteira seja nula ao longo da direção normal, ou seja,

$$
\frac{\partial \mathbf{u}_{t_{1}}}{\partial \vec{n}}=0 \quad \text { e } \frac{\partial \mathbf{u}_{t_{2}}}{\partial \vec{n}}=0 .
$$


Essa condição permite que o fluido deslize livremente sobre a superfície da fronteira $\partial \Omega_{1}$, sem atrito.

- Condição de aderência completa (no-slip) - Esta condição parte do pressuposto de que o fluido irá aderir à fronteira $\partial \Omega_{1}$, ou seja, significa que o fluido deve ficar "colado" à fronteira $\partial \Omega_{1}$. Logo, é apropriado definir as velocidades tangenciais do fluido, como sendo

$$
\mathbf{u}_{\overrightarrow{t_{1}}}=0 \quad \text { e } \quad \mathbf{u}_{t_{2}}=0
$$

A condição de aderência completa é a única condição de contorno para fronteira rígida utilizada nesse trabalho.

Para obter uma condição de contorno para $T$ em $\partial \Omega_{1}$, existem três situações a serem consideradas. Na primeira, são considerados contornos rígidos paralelos ao plano $x y$. Pelas condições de impermeabilidade e aderência completa, segue que

$$
u=v=w=0 \quad \Rightarrow \quad \frac{\partial u}{\partial x}=\frac{\partial v}{\partial x}=\frac{\partial w}{\partial x}=0 \quad \text { e } \quad \frac{\partial u}{\partial y}=\frac{\partial v}{\partial y}=\frac{\partial w}{\partial y}=0,
$$

e pela equação da continuidade,

$$
\frac{\partial u}{\partial x}=\frac{\partial v}{\partial y}=0 \quad \Rightarrow \quad \frac{\partial w}{\partial z}=0
$$

Portanto, por (2.14), segue que

$$
\begin{aligned}
& \frac{\partial T^{x x}}{\partial t}=2 \frac{\partial u}{\partial z} T^{x z}-\frac{1}{W e}\left\{f(\lambda, T) T^{x x}+\xi(f(\lambda, T)-1)+\frac{\alpha}{\xi}\left[\left(T^{x x}\right)^{2}+\left(T^{x y}\right)^{2}+\left(T^{x z}\right)^{2}\right]\right\} \\
& \frac{\partial T^{y y}}{\partial t}=2 \frac{\partial v}{\partial z} T^{y z}-\frac{1}{W e}\left\{f(\lambda, T) T^{y y}+\xi(f(\lambda, T)-1)+\frac{\alpha}{\xi}\left[\left(T^{x y}\right)^{2}+\left(T^{y y}\right)^{2}+\left(T^{y z}\right)^{2}\right]\right\} \\
& \frac{\partial T^{z z}}{\partial t}=-\frac{1}{W e}\left\{f(\lambda, T) T^{z z}+\xi(f(\lambda, T)-1)+\frac{\alpha}{\xi}\left[\left(T^{x z}\right)^{2}+\left(T^{y z}\right)^{2}+\left(T^{z z}\right)^{2}\right]\right\} \\
& \frac{\partial T^{x y}}{\partial t}=\frac{\partial u}{\partial z} T^{y z}+\frac{\partial v}{\partial z} T^{x z}-\frac{1}{W e}\left\{f(\lambda, T) T^{x y}+\frac{\alpha}{\xi}\left[T^{x x} T^{x y}+T^{y y} T^{x y}+T^{x z} T^{y z}\right]\right\} \\
& \frac{\partial T^{x z}}{\partial t}=\frac{\partial u}{\partial z}\left(T^{z z}+\xi\right)-\frac{1}{W e}\left\{f(\lambda, T) T^{x z}+\frac{\alpha}{\xi}\left[T^{x x} T^{x z}+T^{x y} T^{y z}+T^{x z} T^{z z}\right]\right\} \\
& \frac{\partial T^{y z}}{\partial t}=\frac{\partial v}{\partial z}\left(T^{z z}+\xi\right)-\frac{1}{W e}\left\{f(\lambda, T) T^{y z}+\frac{\alpha}{\xi}\left[T^{x y} T^{x z}+T^{y y} T^{y z}+T^{y z} T^{z z}\right]\right\}
\end{aligned}
$$

Para o segundo e o terceiro casos, são considerados contornos rígidos paralelos ao plano $x z \mathrm{e}$ contornos rígidos paralelos ao plano yz. Analogamente ao primeiro caso, pelas condições de impermeabilidade e aderência completa, é fácil obter as condições dos contornos rígidos paralelos aos planos $x z$ e $y z$. 


\subsubsection{Fronteira de entrada do fluido}

As condições de contorno na região $\partial \Omega_{2}$ são dadas por

$$
\begin{aligned}
& \mathbf{u}_{\vec{n}}=u_{\text {inflow }}, \\
& \mathbf{u}_{\vec{t}_{1}}=0 \\
& \mathbf{u}_{t_{2}}=0
\end{aligned}
$$

sendo $u_{\text {inflow }}$ a velocidade de entrada do fluido no domínio. Se $u_{\text {inflow }}$ for constante, de acordo com Mompean and Deville (1997), a contribuição não-newtoniana $T$ é considerada nula, pois considera-se que um fluido prestes a entrar no domínio está livre de perturbações. Por outro lado, se $u_{\text {inflow }}$ é parabólica a contribuição não-newtoniana $T$ é definida como no modelo de fluido Oldroyd-B (Oishi et al., 2011; Aboubacar et al., 2005).

Assim, para um perfil de velocidade constante

$$
T=0
$$

enquanto que, para um perfil de velocidade parabólico na direção $z$

$$
\begin{aligned}
& T^{x x}=T^{y y}=T^{x y}=0 \\
& T^{x z}=\frac{1}{R e}\left(1-\frac{\lambda_{2}}{\lambda_{1}}\right) \frac{\partial w}{\partial x} \\
& T^{y z}=\frac{1}{R e}\left(1-\frac{\lambda_{2}}{\lambda_{1}}\right) \frac{\partial w}{\partial y} \\
& T^{z z}=2 \frac{W e}{R e}\left(1-\frac{\lambda_{2}}{\lambda_{1}}\right)\left[\left(\frac{\partial w}{\partial x}\right)^{2}+\left(\frac{\partial w}{\partial y}\right)^{2}\right] .
\end{aligned}
$$

\subsubsection{Fronteira de saída do fluido}

As condições de contorno na região $\partial \Omega_{3}$ são dadas pela condição de Neumann homogênea para a velocidade e para a contribuição não-newtoniana, respectivamente, desta forma

$$
\begin{array}{cc}
\frac{\partial \mathbf{u}_{t_{1}}}{\partial \vec{n}}=0, & \frac{\partial \mathbf{u}_{t_{2}}}{\partial \vec{n}}=0, \quad \text { e } \frac{\partial \mathbf{u}_{\vec{n}}}{\partial \vec{n}}=0, \\
\frac{\partial \mathbf{T}}{\partial \vec{n}} & =0 .
\end{array}
$$

\subsubsection{Superfície livre}

Em $\partial \Omega_{4}$, supondo uma atmosfera externa passiva (sem influência de tensão superficial), por Batchelor (1967), é necessário impor condições para os campos de velocidade e pressão nessa fronteira. Tais condições são dadas por 


$$
\begin{aligned}
& \vec{n} \cdot(\sigma \cdot \vec{n})=0, \\
& \overrightarrow{t_{1}} \cdot(\sigma \cdot \vec{n})=0, \\
& \overrightarrow{t_{2}} \cdot(\sigma \cdot \vec{n})=0,
\end{aligned}
$$

sendo $\vec{n}=\left(n_{x}, n_{y}, n_{z}\right)^{\mathrm{T}}$ o versor normal e $\overrightarrow{t_{1}}=\left(m_{1 x}, m_{1 y}, m_{1 z}\right)^{\mathrm{T}}$ e $\overrightarrow{t_{2}}=\left(m_{2 x}, m_{2 y}, m_{2 z}\right)^{\mathrm{T}}$ os versores tangentes à região $\partial \Omega_{4}$ do fluido.

Por outro lado, substituindo a equação (2.13) em (2.37) - (2.39), obtêm-se, respectivamente, as seguintes equações, na forma cartesiana

$$
\begin{aligned}
p= & n_{x}^{2} T^{x x}+n_{y}^{2} T^{y y}+n_{z}^{2} T^{z z}+2\left(n_{x} n_{y} T^{x y}+n_{x} n_{z} T^{x z}+n_{y} n_{z} T^{y z}\right)+\frac{2 \beta}{R e}\left[n_{x}^{2} \frac{\partial u}{\partial x}\right. \\
+ & \left.n_{y}^{2} \frac{\partial v}{\partial y}+n_{z}^{2} \frac{\partial w}{\partial z}+n_{x} n_{y}\left(\frac{\partial u}{\partial y}+\frac{\partial v}{\partial x}\right)+n_{x} n_{z}\left(\frac{\partial u}{\partial z}+\frac{\partial w}{\partial x}\right)+n_{y} n_{z}\left(\frac{\partial v}{\partial z}+\frac{\partial w}{\partial y}\right)\right], \\
& \frac{2 \beta}{R e}\left[n_{x} m_{1 x} \frac{\partial u}{\partial x}+n_{y} m_{1 y} \frac{\partial v}{\partial y}+n_{z} m_{1 z} \frac{\partial w}{\partial z}+\left(n_{x} m_{1 y}+n_{y} m_{1 x}\right)\left(\frac{\partial u}{\partial y}+\frac{\partial v}{\partial x}\right)\right. \\
+ & \left.\left(n_{x} m_{1 z}+n_{z} m_{1 x}\right)\left(\frac{\partial u}{\partial z}+\frac{\partial w}{\partial x}\right)+\left(n_{y} m_{1 z}+n_{z} m_{1 y}\right)\left(\frac{\partial v}{\partial z}+\frac{\partial w}{\partial y}\right)\right] \\
= & -\left[n_{x} m_{1 x} T^{x x}+n_{y} m_{1 y} T^{y y}+n_{z} m_{1 z} T^{z z}\right. \\
& \left.+\left(n_{x} m_{1 y}+n_{y} m_{1 x}\right) T^{x y}+\left(n_{x} m_{1 z}+n_{z} m_{1 x}\right) T^{x z}+\left(n_{y} m_{1 z}+n_{z} m_{1 y}\right) T^{y z}\right], \\
& \frac{2 \beta}{R e}\left[n_{x} m_{2 x} \frac{\partial u}{\partial x}+n_{y} m_{2 y} \frac{\partial v}{\partial y}+n_{z} m_{2 z} \frac{\partial w}{\partial z}+\left(n_{x} m_{2 y}+n_{y} m_{2 x}\right)\left(\frac{\partial u}{\partial y}+\frac{\partial v}{\partial x}\right)\right. \\
+ & \left.\left(n_{x} m_{2 z}+n_{z} m_{2 x}\right)\left(\frac{\partial u}{\partial z}+\frac{\partial w}{\partial x}\right)+\left(n_{y} m_{2 z}+n_{z} m_{2 y}\right)\left(\frac{\partial v}{\partial z}+\frac{\partial w}{\partial y}\right)\right] \\
= & -\left[n_{x} m_{2 x} T^{x x}+n_{y} m_{2 y} T^{y y}+n_{z} m_{2 z} T^{z z}\right. \\
& \left.+\left(n_{x} m_{2 y}+n_{y} m_{2 x}\right) T^{x y}+\left(n_{x} m_{2 z}+n_{z} m_{2 x}\right) T^{x z}+\left(n_{y} m_{2 z}+n_{z} m_{2 y}\right) T^{y z}\right] .
\end{aligned}
$$

Por fim, para a contribuição não-newtoniana em $\partial \Omega_{4}$ é empregada a condição de Neumann homogênea (Tomé et al., 2002)

$$
\frac{\partial T}{\partial \vec{n}}=0
$$

Dessa forma, definimos as condições de fronteira para resolver as equações (2.11), (2.12) e (2.14), de acordo com o problema de interesse, segundo a formulação do modelo SXPP.

No capítulo seguinte serão apresentados a metodologia utilizada para resolver numericamente escoamentos envolvendo o modelo SXPP e o algoritmo computacional. 


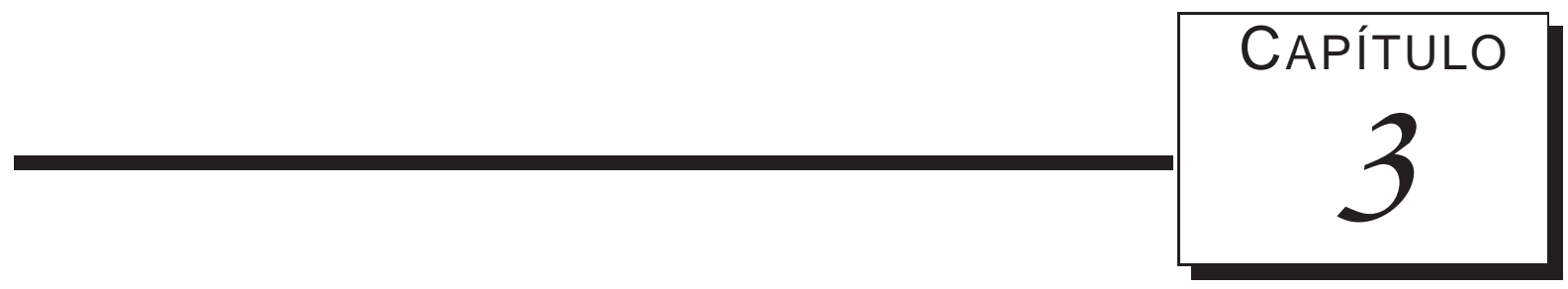

\section{Método numérico para solução do modelo SXPP}

\subsection{Introdução}

Muito esforço tem sido dedicado nas últimas décadas para obtenção numérica da solução de escoamentos com diversos modelos de fluidos, inclusive fluidos viscoelásticos. Uma dificuldade adicional surge quando esses escoamentos envolvem superfícies livres, pois a posição desse tipo de contorno é conhecida apenas no instante inicial $t=t_{0}$, sendo necessário determinar a sua posição a cada passo de tempo. Para superar tal dificuldade, surgiram vários métodos na literatura, a maioria influenciada pelo método Marker-And-Cell (MAC) (Harlow and Welch, 1965). Tal método originou vários outros métodos, sendo importante destacar o método Simplified Marker-And-Cell (SMAC), que modifica o método original dividindo o ciclo computacional em duas partes: inicialmente, calcula-se um campo de velocidade previsor, seguido do cálculo de um potencial auxiliar para a correção do campo de pressão.

Estendendo a aplicabilidade do método SMAC para domínios arbitrários em duas dimensões, surge o método GENeralized Simplified Marker-And-Cell (GENSMAC) proposto por Tomé (1993).

Em adição, Oishi et al. (2011) modificou o algoritmo do GENSMAC para simular escoamentos viscoelásticos com o modelo SXPP em duas dimensões. Assim, motivado pelo trabalho de Oishi et al. (2011) e pela proposta desse trabalho, é apresentada a seguir a metodologia GENSMAC no caso tridimensional para simular o modelo SXPP. 


\subsection{Metodologia GENSMAC}

O método GENSMAC, diferente do método MAC, utiliza partículas marcadoras apenas na superfície livre e não em todo domínio. Tal fato resulta em uma economia no uso de memória e uma redução no tempo de processamento nas simulações numéricas. Para isso são utilizados dois tipos de malha, uma malha fixa (euleriana) e outra malha móvel (lagrangeana). A malha fixa é composta por células deslocadas (staggered grid), nas quais as velocidades são definidas nas faces da célula e as outras propriedades do fluido, como a pressão e a contribuição não newtoniana, são definidas no centro da célula (vide figura 3.1). Na malha móvel são armazenas as partículas marcadas, onde a superfície livre é representada. A movimentação da malha móvel é determinada pela convecção das partículas, através da solução da equação

$$
\frac{d \mathbf{x}}{d t}=\mathbf{u}(\mathbf{x}, t)
$$

para cada partícula, sendo $\mathrm{x}$ a posição da partícula na malha fixa.

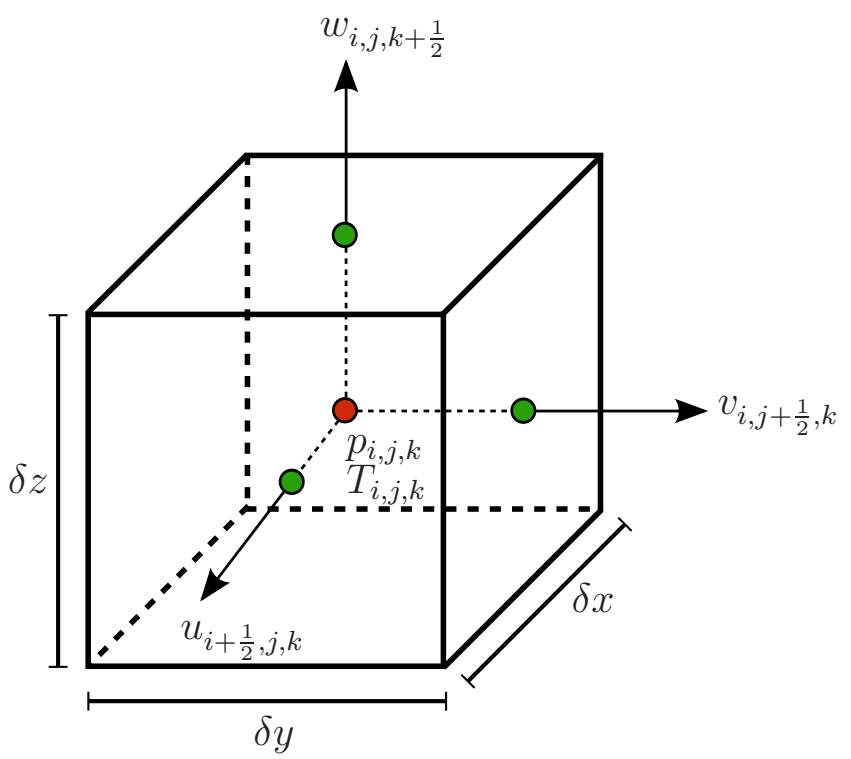

Figura 3.1: Representação da célula $C_{i, j, k}$, utilizada no método GENSMAC: as velocidades $u, v$ e $w$ nas faces da célula e a pressão $p$ e a contribuição não newtoniana $T$ no centro da célula.

Na malha fixa, a posição da superfície livre e dos demais tipos de fronteira é determinada por uma estratégia de identificação das células, baseada na seguinte classificação:

- Células de fronteira [B] (boundary): determinam a configuração do contorno rígido;

- Células do injetor [I] (inflow): definem a entrada de fluido;

- Células do ejetor [O] (outflow): definem a saída de fluido;

- Células vazias [E] (empty): definem células que não têm fluido em seu interior; 
- Células de superfície livre [S] (surface): são células que possuem fluido em seu interior e apresentam interface em contato com célula [E];

- Células cheias [F] (full): denotam células cheias de fluido e que não apresentam contato com células do tipo [E].

A figura 3.2, extraída de Tomé et al. (1999), ilustra um exemplo de identificação de malha de um escoamento em um dado tempo, comparado com a foto de um escoamento real, em que a classificação das células é baseada no problema físico. Sem perda de generalidade as células vazias não são identificadas.

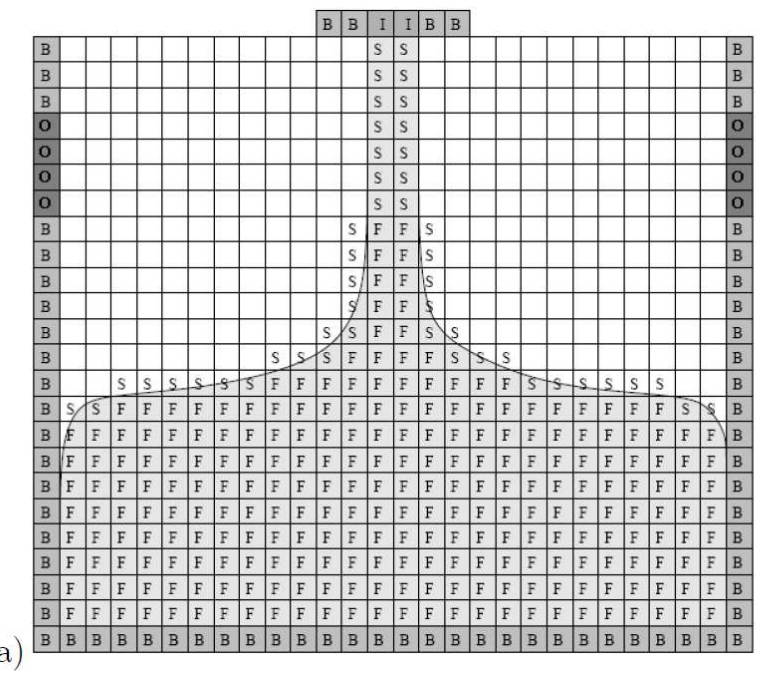

(b)

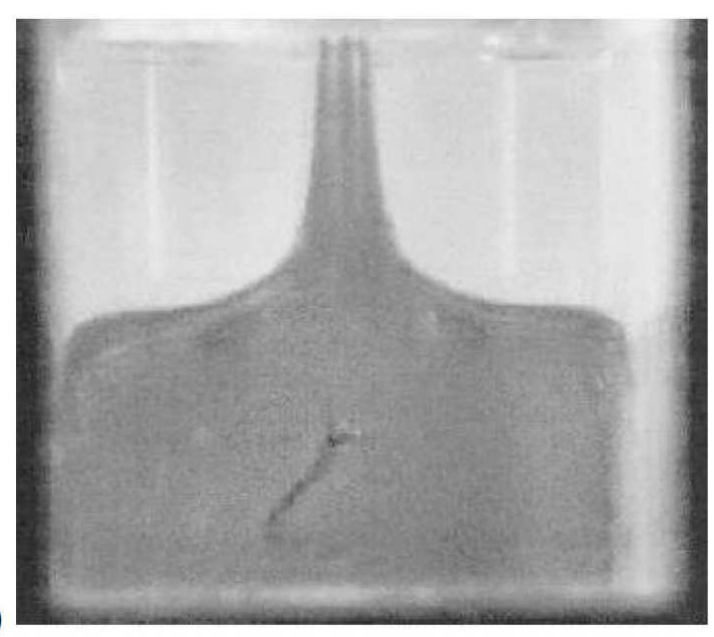

Figura 3.2: (a) representa a classificação das células para a simulação do escoamento representado em (b).

A cada ciclo computacional faz-se necessário uma nova classificação das células do domínio, devido à movimentação da superfície livre. Tal atualização verifica apenas a classificação das células na vizinhança de [S] e é feita de acordo com Oliveira (1999), Castelo et al. (2000) e Martins (2009), pelos seguintes passos:

- Células do tipo $[\mathbf{E}]$ e $[\mathbf{F}]$ que contêm partícula marcadora são classificadas com $[\mathbf{S}]$;

- Células do tipo $[\mathbf{S}]$ sem interface comum com célula tipo $[\mathbf{E}]$ se tornam tipo [F];

- Células tipo [S] sem partícula marcadora se tornam tipo [E] e todas as grandezas que estavam definidas nestas novas células [E] passam a ser desconsideradas;

- Células tipo $[\mathbf{S}]$ sem interface comum com célula tipo $[\mathbf{E}]$ se tornam tipo $[\mathbf{F}]$;

- Células tipo [F] com interface comum com célula tipo [E] se tornam tipo [S].

Para aplicar as condições de fronteiras (2.37), (2.38) e (2.39) na superfície livre, são utilizadas as ideias propostas por Tomé et al. (2001), que consiste em aproximar o versor normal $\vec{n}$ no centro da 
célula do tipo $[\mathbf{S}]$ considerando as células vizinhas. Supondo uma malha refinada o suficiente para que a célula do tipo $[\mathbf{S}]$ tenha no máximo três faces em contato com células do tipo [E] e nenhuma delas paralelas entre si, são considerados três casos, apresentados a seguir.

No primeiro caso, considera-se apenas uma face da célula do tipo [S] em contato com célula do tipo [E]. Nesse caso, são consideradas superfícies planas paralelas aos eixos coordenados, como mostrado na figura 3.3. Assim, o versor normal à superfície livre $\vec{n}$ pode ser definido como $( \pm 1,0,0)$, $(0, \pm 1,0)$ ou $(0,0, \pm 1)$, dependendo da posição da célula [E] em relação a célula $[\mathbf{S}]$.

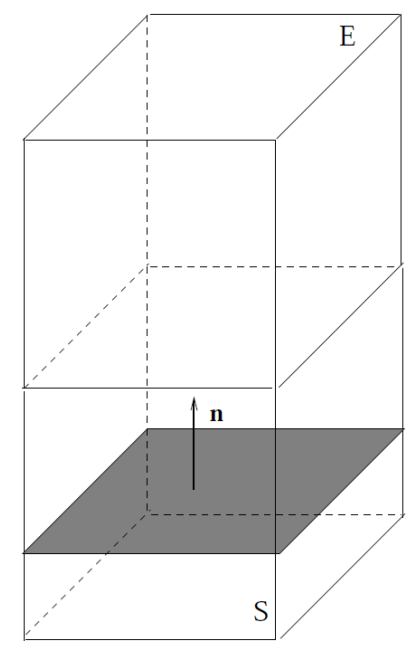

Figura 3.3: Superfície planar paralela ao plano $x y$, extraído de Oishi (2008).

No segundo caso, considera-se duas faces da célula $[\mathbf{S}]$ em contato com células $[\mathbf{E}]$. Nesse caso, são consideradas superfícies planas inclinadas com um ângulo de $45^{\circ}$, vide figura 3.4. Dessa forma, $\vec{n}$ pode ser definido como $\left( \pm \frac{\sqrt{2}}{2}, \pm \frac{\sqrt{2}}{2}, 0\right),\left( \pm \frac{\sqrt{2}}{2}, 0, \pm \frac{\sqrt{2}}{2}\right)$ ou $\left(0, \pm \frac{\sqrt{2}}{2}, \pm \frac{\sqrt{2}}{2}\right)$, dependendo da posição das células $[\mathbf{E}]$ em relação a célula $[\mathbf{S}]$.

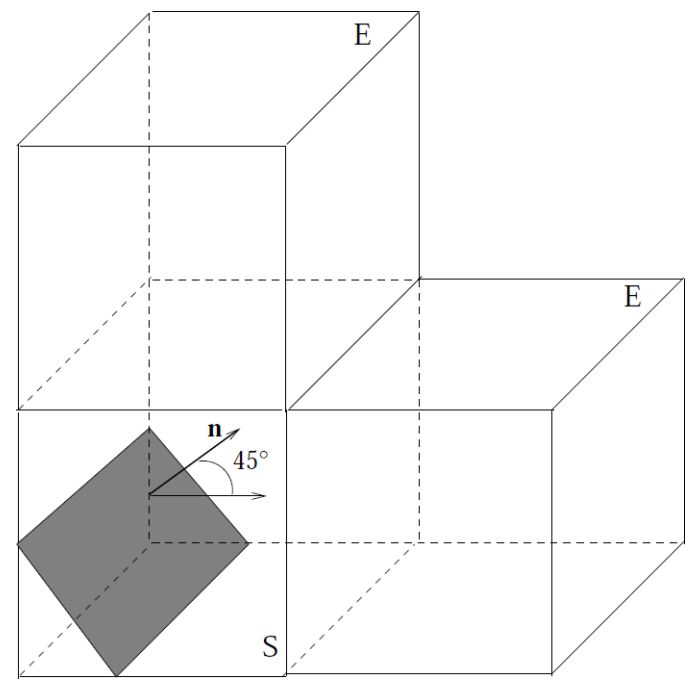

Figura 3.4: Superfície planar paralela inclinada $45^{\circ}$, extraído de Oishi (2008). 
Já no último caso, considera-se três faces da célula $[\mathbf{S}]$ em contato com células [E]. Nesse caso, são consideradas superfícies planas inclinadas com um ângulo de $60^{\circ}$, vide figura 3.5. Por fim, $\vec{n}$ pode ser definido como $\left( \pm \frac{\sqrt{3}}{3}, \pm \frac{\sqrt{3}}{3}, \pm \frac{\sqrt{3}}{3}\right)$, dependendo da distribuição das células [E] em relação a célula $[\mathbf{S}]$.

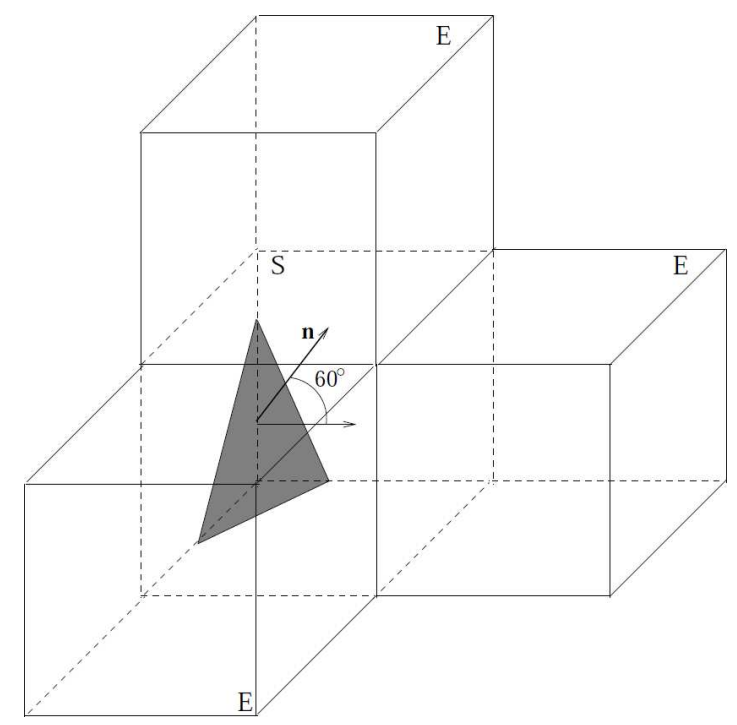

Figura 3.5: Superfície planar paralela inclinada $60^{\circ}$, extraído de Oishi (2008).

Observação 1 : No caso em que células do tipo [S] possuem faces paralelas em contato com células do tipo [E], não é possível obter informações sobre o versor normal $\vec{n}$ em relação à superfície livre. Uma possivel solução para esse problema pode ser o refinamento da malha.

\subsection{Método de projeção}

Devido à restrição de incompressibilidade, a solução numérica do sistema de equações (2.11)(2.12), acopla os campos de velocidade e pressão. Tal fato ocorre porque a pressão em escoamentos incompressíveis tem como objetivo garantir que a equação da continuidade seja satisfeita em cada passo de tempo. Existem alguns métodos na literatura que resolvem esse sistema de forma acoplada. Porém, esses métodos apresentam algumas dificuldades computacionais devido ao tamanho e à não-linearidade do sistema obtido.

Afim de evitar esses problemas causados pelos métodos acoplados, é utilizada a estratégia do desacoplamento dos campos de velocidade e pressão. Essa estratégia de desacoplamento, também conhecida como método de projeção, foi proposta por Chorin $(1967,1968)$ como um eficiente método para resolver as equações de Navier-Stokes incompressíveis. O método de projeção é fundamentado no Teorema da Decomposição de Helmholts-Hodge (TDHH), o qual será apresentado a seguir.

Teorema 1 (Decomposição de Helmholtz-Hodge) Seja $\Omega$ uma região com fronteira suave $\partial \Omega$ e $\widetilde{\boldsymbol{u}}$ 
um campo vetorial definido em $\Omega$. Nestes termos, $\widetilde{\boldsymbol{u}}$ pode ser decomposto na forma

$$
\widetilde{\boldsymbol{u}}=\mathbf{u}+\nabla \psi
$$

de forma única, sendo $\psi$ um campo escalar também definido em $\Omega$. O campo vetorial $\mathbf{u}$ é solenoidal e paralelo a $\partial \Omega$, isto é,

$$
\nabla \cdot \mathbf{u}=0
$$

e, ao longo de $\partial \Omega$,

$$
\mathbf{u} \cdot \vec{n}=0
$$

sendo que $\vec{n}$ é o vetor normal exterior a $\partial \Omega$.

Mais detalhes sobre o TDHH podem ser encontrados em Chorin and Marsden (2000).

A essência do método de projeção para resolver escoamentos incompressíveis consiste em aproximar um valor para a pressão e utilizar a equação da quantidade de movimento (2.12) para definir um campo de velocidade intermediária $\widetilde{\mathbf{u}}$, que em muitos casos não é solenoidal. Essa estratégia desacopla os campos de velocidade e pressão.

No entanto, é necessário corrigir o valor da pressão. Para isso, aplica-se o TDHH, em seguida o divergente na equação (3.2) e, finalmente, impõe-se a equação da continuidade (2.11). Assim, obtém-se a equação de Poisson

$$
\nabla^{2} \psi=\nabla \cdot \widetilde{\mathbf{u}}
$$

sendo que sua solução determina a correção da pressão $\psi$.

Nesse ponto, como $\widetilde{\mathbf{u}}$ e $\psi$ são conhecidos, u pode ser extraído pela equação (3.2). Mais detalhes sobre o método de projeção utilizado no GENSMAC pedem ser encontrados na próxima seção.

\subsection{Formulação implícita da metologia GENSMAC-SXPP}

Em problemas transientes, metodologias explícitas apresentam restrições de estabilidade parabólica rigorosas para a definição do passo temporal. Esta restrição é calculada em função do número de Reynolds, e como para escoamentos com fluidos viscoelásticos o número de Reynolds é, geralmente, baixo $(R e<1)$, o custo computacional torna-se relativamente alto.

Modificações recentes na metodologia GENSMAC tratam os termos difusivos com esquemas implícitos e os termos convectivos da equação da quantidade de movimento com esquemas explícitos. Essas modificações são denominadas de esquema semi-implícito e foram propostas por Oishi (2004); Oishi et al. (2006a,b). Mais recentemente, estendendo os trabalhos anteriores, Oishi et al. (2008) propôs modificações no GENSMAC para simular escoamentos com superfície livre a baixos números de Reynolds. Tais modificações combinam o método de projeção com uma técnica implícita para o tratamento da pressão na superfície livre. Assim, considerando a proposta inicial desse trabalho, é 
adotada a estratégia proposta por Oishi et al. (2008) para simular escoamentos viscoelásticos com o modelo SXPP em três dimensões.

É importante ressaltar, como observado por Martins (2009) e Oishi et al. (2011), para o caso bidimensional, que a formulação do GENSMAC-SXPP utilizada nesse trabalho, nada altera a estratégia proposta por Oishi et al. (2008). Isso ocorre devido ao fato de que, na equação de conservação da quantidade de movimento, a contribuição não-newtoniana $T$ é inserida na forma de um termo fonte, que é calculada explicitamente no tempo, como veremos a seguir. Além disso, $T$ merece atenção especial, com relação a aproximação nos contornos rígidos, pelas não-linearidades presentes no modelo SXPP. Detalhes sobre as aproximações de $T$ serão explicados no próximo capítulo.

Por simplicidade, a equação (2.14), que define a contribuição não-newtoniana para o modelo SXPP, será reescrita na forma de uma equação diferencial ordinária

$$
\frac{\partial T}{\partial t}=F(\mathbf{u}, T)
$$

sendo que, por (2.27),

$$
\begin{aligned}
F(\mathbf{u}, T)= & 2 \xi D-\left\{\nabla \cdot(\mathbf{u} T)-\left[(\nabla \mathbf{u}) \cdot T+T \cdot(\nabla \mathbf{u})^{\mathrm{T}}\right]\right\} \\
& -\frac{1}{W e}\left\{f(\lambda, T) T+\xi(f(\lambda, T)-1) \mathbf{I}+\frac{\alpha}{\xi} T \cdot T\right\} .
\end{aligned}
$$

Assim, seguindo a estratégia de solução proposta por Oishi et al. (2008) e estendendo o trabalho de Oishi et al. (2011) para o caso tridimensional, a formulação do GENSMAC-SXPP utilizada nesse trabalho será apresentada a seguir.

Para eliminar a restrição de estabilidade parabólica, causada pela integração temporal da equação da quantidade de movimento na formulação explícita, é utilizado o método de Crank-Nicolson. Nesse caso, as aproximações discretas no tempo para as equações (2.11) e (2.12) são escritas como

$$
\nabla \cdot \mathbf{u}^{(n+1)}=0
$$

$\mathrm{e}$

$$
\frac{\mathbf{u}^{(n+1)}-\mathbf{u}^{(n)}}{\delta t}+\nabla \cdot(\mathbf{u u})^{(n)}+\nabla p^{(n+1)}=\frac{\beta}{2 R e}\left[\nabla^{2} \mathbf{u}^{(n)}+\nabla^{2} \mathbf{u}^{(n+1)}\right]+\nabla \cdot T^{\left(n+\frac{1}{2}\right)}+\frac{1}{F r^{2}} \mathbf{g}^{(n)},
$$

sendo que

$$
\nabla \cdot T^{\left(n+\frac{1}{2}\right)}=\frac{1}{2}\left(\nabla \cdot \widetilde{T}^{(n+1)}+\nabla \cdot T^{(n)}\right)
$$

O tensor $\widetilde{T}^{(n+1)}$ é calculado utilizando o método de Runge-Kutta de segunda ordem (RK21) (Butcher, 2003; Lambert, 1973) para integrar a equação (3.6). O esquema RK21 é aplicado em duas etapas. Na primeira etapa é calculado o tensor previsor $\widetilde{T}^{(n+1)}$, da forma 


$$
\frac{\widetilde{T}^{(n+1)}-T^{(n)}}{\delta t}=F\left(\mathbf{u}^{(n)}, T^{(n)}\right)
$$

Na segunda etapa, $T^{(n+1)}$ é calculado de forma semelhante à Regra do Trapézio, por

$$
\frac{T^{(n+1)}-T^{(n)}}{\delta t}=\frac{1}{2}\left[F\left(\mathbf{u}^{(n)}, T^{(n)}\right)+F\left(\mathbf{u}^{(n+1)}, \widetilde{T}^{(n+1)}\right)\right] .
$$

Essa estratégia de calcular o tensor previsor evita que valores defasados no tempo dessa grandeza sejam utilizados em partes do algoritmo computacional (Martins, 2009; Oishi et al., 2011).

Seguindo o procedimento de solução do GENSMAC, o cálculo da velocidade intermediária $\widetilde{\mathbf{u}}$ utilizada no método de projeção, é determinado resolvendo (3.9), por

$$
\frac{\widetilde{\mathbf{u}}^{(n+1)}-\widetilde{\mathbf{u}}^{(n)}}{\delta t}+\nabla \cdot(\mathbf{u u})^{(n)}+\nabla \widetilde{p}^{(n+1)}=\frac{\beta}{2 R e}\left[\nabla^{2} \widetilde{\mathbf{u}}^{(n)}+\nabla^{2} \widetilde{\mathbf{u}}^{(n+1)}\right]+\nabla \cdot T^{\left(n+\frac{1}{2}\right)}+\frac{1}{F r^{2}} \mathbf{g}^{(n)}
$$

em que $\widetilde{\mathbf{u}}^{(n)}=\mathbf{u}^{(n)}$ e $\widetilde{p}^{(n+1)}=p^{(n)}$ é uma aproximação para $p^{(n+1)}$. Em vários casos, $p^{(n+1)} \neq p^{n}$, dessa forma $\widetilde{\mathbf{u}}$ não satisfaz a equação da continuidade. Assim, é necessário calcular uma correção para a pressão.

Para obter a equação para correção da pressão, aplica-se o TDHH e substitui-se a equação (3.2) em (3.13). Por fim, compara-se a expressão resultante com a equação (3.9). Dessa forma, segue que

$$
p^{(n+1)}=\widetilde{p}^{(n+1)}+\frac{\psi^{(n+1)}}{\delta t}-\frac{\beta}{2 R e} \nabla^{2} \psi^{(n+1)},
$$

em que $\psi^{(n+1)}$ é obtido pelo cálculo da equação de Poisson

$$
\nabla^{2} \psi^{(n+1)}=\nabla \cdot \widetilde{\mathbf{u}}^{(n+1)}
$$

obtida, como vista na seção anterior, pela aplicação do TDHH.

Conhecendo o valor de $\psi^{(n+1)}$ é possível corrigir a pressão e atualizar o campo de velocidades $\mathbf{u}^{(n+1)}$, através da equação (3.2), já que $\widetilde{\mathbf{u}}^{(n+1)}$ é conhecido.

Assim, calculado $\mathbf{u}^{(n+1)}$, encerramos um ciclo computacional, calculando $T^{(n+1)}$ por (3.12).

\subsection{Tratamento da condição de contorno para a pressão ao longo da superfície livre}

Seguindo a estratégia de solução de Oishi et al. (2008), a condição de contorno ao longo da superfície livre (2.40) é tratada de forma implícita. Dessa forma, a equação (2.40) é reescrita na forma discreta como 


$$
\begin{aligned}
p^{(n+1)}= & \left.n_{x}^{2} T^{x x}\right|^{(n+1)}+\left.2 n_{x} n_{y} T^{x y}\right|^{(n+1)}+\left.2 n_{x} n_{z} T^{x z}\right|^{(n+1)}+\left.n_{y}^{2} T^{y y}\right|^{(n+1)} \\
& +\left.2 n_{y} n_{z} T^{y z}\right|^{(n+1)}+\left.n_{z}^{2} T^{z z}\right|^{(n+1)}+\frac{2 \beta}{R e}\left[n_{x}^{2} \frac{\partial u}{\partial x}+n_{x} n_{y}\left(\frac{\partial u}{\partial y}+\frac{\partial v}{\partial x}\right)\right. \\
& \left.+n_{x} n_{z}\left(\frac{\partial u}{\partial z}+\frac{\partial w}{\partial x}\right)+n_{y}^{2} \frac{\partial v}{\partial y}+n_{y} n_{z}\left(\frac{\partial v}{\partial z}+\frac{\partial w}{\partial y}\right)+n_{z}^{2} \frac{\partial w}{\partial z}\right]^{(n+1)} .
\end{aligned}
$$

Pode ser observado que a equação (3.16) acopla os campos de velocidade e pressão. A estratégia para desacoplar esses campos consiste em substituir a equação (3.14) na equação (3.16). Dessa forma, obtém-se

$$
\begin{aligned}
\widetilde{p}^{(n+1)}+ & \frac{\psi^{(n+1)}}{\delta t}-\frac{\beta}{2 R e} \nabla^{2} \psi^{n+1}= \\
\left.n_{x}^{2} T^{x x}\right|^{(n+1)}+\left.2 n_{x} n_{y} T^{x y}\right|^{(n+1)}+\left.2 n_{x} n_{z} T^{x z}\right|^{(n+1)}+\left.n_{y}^{2} T^{y y}\right|^{(n+1)} & \\
& +\left.2 n_{y} n_{z} T^{y z}\right|^{(n+1)}+\left.n_{z}^{2} T^{z z}\right|^{(n+1)}+\frac{2 \beta}{R e}\left[n_{x}^{2} \frac{\partial u}{\partial x}+n_{x} n_{y}\left(\frac{\partial u}{\partial y}+\frac{\partial v}{\partial x}\right)\right. \\
& \left.+n_{x} n_{z}\left(\frac{\partial u}{\partial z}+\frac{\partial w}{\partial x}\right)+n_{y}^{2} \frac{\partial v}{\partial y}+n_{y} n_{z}\left(\frac{\partial v}{\partial z}+\frac{\partial w}{\partial y}\right)+n_{z}^{2} \frac{\partial w}{\partial z}\right]^{(n+1)}
\end{aligned}
$$

Tal substituição desacopla os campos de velocidade e pressão. Mas observe que, na etapa do cálculo de $\psi$ no ciclo computacional apresentado anteriormente, nem o campo de velocidade $\mathbf{u}^{(n+1)}$ nem o tensor $T^{(n+1)}$ são conhecidos.

Para resolver esse problema, aplica-se a equação (3.2) na equação (3.17) e aproxima-se $T^{(n+1)}$ por $\widetilde{T}^{(n+1)}$. Dessa forma obtém-se

$$
\begin{aligned}
& \widetilde{p}^{(n+1)}+\frac{\psi^{(n+1)}}{\delta t}-\frac{\beta}{2 R e} \nabla^{2} \psi^{n+1}= \\
& \left.\quad n_{x}^{2} \widetilde{T}^{x x}\right|^{(n+1)}+\left.2 n_{x} n_{y} \widetilde{T}^{x y}\right|^{(n+1)}+\left.2 n_{x} n_{z} \widetilde{T}^{x z}\right|^{(n+1)}+\left.n_{y}^{2} \widetilde{T}^{y y}\right|^{(n+1)} \\
& +\left.2 n_{y} n_{z} \widetilde{T}^{y z}\right|^{(n+1)}+\left.n_{z}^{2} \widetilde{T}^{z z}\right|^{(n+1)}+\frac{2 \beta}{R e}\left[n_{x}^{2} \frac{\partial}{\partial x}\left(\widetilde{u}-\frac{\partial \psi}{\partial x}\right)\right. \\
& +n_{x} n_{y}\left(\frac{\partial}{\partial y}\left(\widetilde{u}-\frac{\partial \psi}{\partial x}\right)+\frac{\partial}{\partial x}\left(\widetilde{v}-\frac{\partial \psi}{\partial y}\right)\right)+n_{x} n_{z}\left(\frac{\partial}{\partial z}\left(\widetilde{u}-\frac{\partial \psi}{\partial x}\right)+\frac{\partial}{\partial x}\left(\widetilde{w}-\frac{\partial \psi}{\partial z}\right)\right) \\
& \left.+n_{y}^{2} \frac{\partial}{\partial y}\left(\widetilde{v}-\frac{\partial \psi}{\partial y}\right)+n_{y} n_{z}\left(\frac{\partial}{\partial z}\left(\widetilde{v}-\frac{\partial \psi}{\partial y}\right)+\frac{\partial}{\partial y}\left(\widetilde{w}-\frac{\partial \psi}{\partial z}\right)\right)+n_{z}^{2} \frac{\partial}{\partial z}\left(\widetilde{w}-\frac{\partial \psi}{\partial z}\right)\right]^{(n+1)} .
\end{aligned}
$$

Assim, isolando $\psi^{(n+1)}$ no lado esquerdo da equação (3.18), obtemos a condição de contorno para $\psi$ na superfície livre. Mais detalhes, como as equações para $\psi$ correspondentes a cada tipo de aproximação da superfície livre, podem ser encontrados em Oishi (2008) e Oishi et al. (2008). 


\subsection{Sistemas lineares}

O uso de métodos implícitos para resolver as equações de conservação da quantidade de movimento (3.13) e da condição de contorno para a pressão ao longo da superfície livre (3.18) requer a solução de dois sistemas lineares a cada passo de tempo.

No sistema Freeflow, vários métodos estão implementados para resolver tais sistemas lineares, sendo que todos esses métodos foram implementados por diferentes usuários do sistema. Além da precisão na solução desses sistemas lineares, existe também a preocupação com o custo computacional.

Sendo assim, para contribuir com o sistema Freeflow e resolver os sistemas resultantes das equações (3.13) e (3.18), é utilizada uma ferramenta muito robusta chamada PETSc (Portable, Extensible Toolkit for Scientific Computation) (Balay et al., 2008, 2009). Tal ferramenta consiste de um conjunto em bibliotecas, com estruturas de dados e implementações de métodos numéricos para soluções de sistemas lineares e não lineares, com processamento sequencial ou paralelo.

Além disso, o uso do PETSc proporciona maior flexibilidade na solução dos sistemas lineares no Freeflow, pois ele permite que o usuário altere os parâmetros do programa, como o tipo de resolvedor a ser utilizado, o tipo de pré-condicionamento, o tamanho do problema, o valor de tolerância do erro, etc, em tempo de execução.

Nesse trabalho utilizou-se o método BiCGstab (BiConjugate Gradient stabilized) (van der Vorst, 1992) com pré-condicionamento para resolver os sistemas lineares.

\subsection{Algoritmo computacional}

Nas seções anteriores foram descritos os principais procedimentos que compõe a estratégia de solução do GENSMAC para simular o modelo SXPP em três dimensões. Portanto, para estabelecer um algoritmo computacional para a formulação semi-implícita do GENSMAC-SXPP, supõem-se conhecidos, em $t=t_{n}$, os campos de velocidade solenoidal e de pressão, bem como a contribuição não-newtoniana e a posição da superfície livre, o que permite o cálculo da solução em $t_{n+1}=t_{n}+\delta t$. Assim, o algoritmo segue os seguintes passos:

Passo 1: cálculo de $\widetilde{T}^{(n+1)}$ por meio da equação (3.11).

Passo 2: cálculo de $\widetilde{\mathbf{u}}^{(n+1)}$ por meio da equação (3.13).

Passo 3: cálculo da correção da pressão $\psi^{n+1}$ pela solução da equação de Poisson (3.15) com a condição de contorno (3.18) ao longo da superfície livre.

Passo 4: correção do campo de velocidade $\mathbf{u}^{(n+1)}$ pela equação (3.2).

Passo 5: cálculo da correção da pressão $p^{(n+1)}$ pela equação (3.14), no interior do domínio e na superfície livre. 
Passo 6: cálculo de $T^{(n+1)}$ por meio da equação (3.12).

Passo 7: movimentação das partículas marcadoras da superfície livre resolvendo a equação diferencial ordinária

$$
\frac{d \mathbf{x}}{d t}=\mathbf{u}(\mathbf{x}, t)
$$

pelo método de Euler explícito

$$
\frac{\mathbf{x}^{(n+1)}-\mathbf{x}^{(n)}}{\delta t}=\mathbf{u}\left(\mathbf{x}^{(n)}, t_{n+1}\right)
$$

\subsection{Cálculo do passo temporal}

No GENSMAC o passo temporal é adaptativo, ou seja, é calculado a cada ciclo computacional, dependendo da restrição de estabilidade.

Na formulação explícita, o método para integrar a equação da conservação da quantidade de movimento, ocasiona a chamada restrição de estabilidade parabólica. Para o modelo SXPP tal restrição é dada por

$$
\delta t_{v i s c} \leq \beta \frac{R e}{2}\left(\frac{1}{(\delta x)^{2}}+\frac{1}{(\delta y)^{2}}+\frac{1}{(\delta z)^{2}}\right)^{-1} .
$$

Como escoamentos viscoelásticos transcorrem a baixos números de Reynolds, pode ser observado que a restrição de estabilidade (3.21), em vários casos, torna o estudo numérico de alguns modelos inviável. Afim de evitar esse inconveniente, um método de Crank-Nicolson foi empregado para integrar a equação da conservação da quantidade de movimento nesse trabalho.

Independente da estratégia adotada para a integração da equação da conservação da quantidade de movimento, outra limitação é imposta para o cálculo de $\delta t$. Tal limitação é conhecida como "condição CFL" (Courant-Friedrichs-Lewy) (Fletcher, 1991) e visa garantir que uma partícula de fluido percorra no máximo uma célula em cada passo de tempo

$$
\delta t_{C F L}=\min \left\{\delta t_{C F L_{x}}, \delta t_{C F L_{y}}, \delta t_{C F L_{z}}\right\},
$$

em que

$$
\begin{aligned}
\delta t_{C F L_{x}} & \leq \frac{\delta x}{\max \left\{\left|u^{(n)}\right|\right\}}, \\
\delta t_{C F L_{y}} & \leq \frac{\delta y}{\max \left\{\left|v^{(n)}\right|\right\}}, \\
\delta t_{C F L_{z}} & \leq \frac{\delta z}{\max \left\{\left|w^{(n)}\right|\right\}} .
\end{aligned}
$$


Neste ponto, encerramos a definição da metodologia GENSMAC-SXPP para simular escoamentos com superfície livre em três dimensões. Antes de visualizar alguns resultados obtidos ao longo do desenvolvimento desse trabalho, vejamos, no próximo capítulo, os principais aspectos da discretização espacial das equações governantes. 


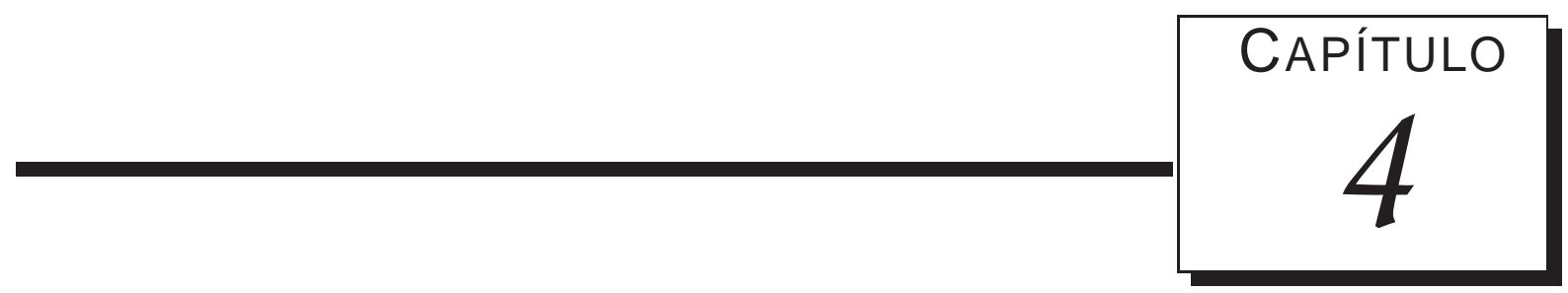

\section{Discretização Espacial}

Definida a estratégia de solução do GENSMAC-SXPP, serão apresentados neste capítulo importantes aspectos da discretização espacial por diferenças finitas em uma malha deslocada.

Como mencionado no capítulo anterior, a metodologia GENSMAC-SXPP não altera a estratégia de solução das equações de conservação da quantidade de movimento e da continuidade do GENSMAC, pelo fato que a contribuição não-newtoniana é inserida na equação de conservação da quantidade de movimento como um termo fonte. Assim, será apresentado apenas a discretização espacial da contribuição não-newtoniana $T$. Detalhes sobre a discretização das equações no GENSMAC podem ser encontrados em Tomé et al. (2001).

Além disso, a discretização de $T$ merece atenção especial, principalmente nas condições de contorno, por diferir de alguns modelos viscoelásticos, como o modelo Oldroyd-B (Tomé et al., 2007b,a; Oishi et al., 2008), por apresentar não linearidades (Aboubacar et al., 2005; Martins, 2009; Oishi et al., 2011). É importante observar que o modelo Oldroyd-B é um caso particular do modelo SXPP, apenas por alguns ajustes nos parâmetros (Martins, 2009).

\subsection{Contribuição não-newtoniana em células [F] e [S]}

Para calcular as componentes de $T$ em células do tipo [F] e [S], as equações (3.11) e (3.12) são discretizadas no centro das células, conforme a metodologia GENSMAC-SXPP.

Para calcular (3.11), é necessário aproximar as componentes de (3.7) no centro das células, como segue 


$$
\begin{aligned}
& F^{x x}\left(\mathbf{u}^{(n)}, T^{(n)}\right)_{i, j, k}=\left\{2\left(\left.\frac{\partial u}{\partial x}\right|_{i, j, k} T_{i, j, k}^{x x}+\left.\frac{\partial u}{\partial y}\right|_{i, j, k} T_{i, j, k}^{x y}+\left.\frac{\partial u}{\partial z}\right|_{i, j, k} T_{i, j, k}^{x z}\right)+\left.2 \xi \frac{\partial u}{\partial x}\right|_{i, j, k}\right. \\
& -\left(\operatorname{conv}_{x}\left(u T^{x x}\right)_{i, j, k}+\operatorname{conv}_{y}\left(v T^{x x}\right)_{i, j, k}+\operatorname{conv}_{z}\left(w T^{x x}\right)_{i, j, k}\right) \\
& -\frac{1}{W e}\left\{f(\lambda, T)_{i, j, k} T_{i, j, k}^{x x}+\xi\left(f(\lambda, T)_{i, j, k}-1\right)\right. \\
& \left.\left.+\frac{\alpha}{\xi}\left[\left(T_{i, j, k}^{x x}\right)^{2}+\left(T_{i, j, k}^{x y}\right)^{2}+\left(T_{i, j, k}^{x z}\right)^{2}\right]\right\}\right\}^{(n)} \text {, } \\
& F^{y y}\left(\mathbf{u}^{(n)}, T^{(n)}\right)_{i, j, k}=\left\{2\left(\left.\frac{\partial v}{\partial x}\right|_{i, j, k} T_{i, j, k}^{x y}+\left.\frac{\partial v}{\partial y}\right|_{i, j, k} T_{i, j, k}^{y y}+\left.\frac{\partial v}{\partial z}\right|_{i, j, k} T_{i, j, k}^{y z}\right)+\left.2 \xi \frac{\partial v}{\partial y}\right|_{i, j, k}\right. \\
& \text { - }\left(\operatorname{conv}_{x}\left(u T^{y y}\right)_{i, j, k}+\operatorname{conv}_{y}\left(v T^{y y}\right)_{i, j, k}+\operatorname{conv}_{z}\left(w T^{y y}\right)_{i, j, k}\right) \\
& -\frac{1}{W e}\left\{f(\lambda, T)_{i, j, k} T_{i, j, k}^{y y}+\xi\left(f(\lambda, T)_{i, j, k}-1\right)\right. \\
& \left.\left.+\frac{\alpha}{\xi}\left[\left(T_{i, j, k}^{x y}\right)^{2}+\left(T_{i, j, k}^{y y}\right)^{2}+\left(T_{i, j, k}^{y z}\right)^{2}\right]\right\}\right\}^{(n)}, \\
& F^{z z}\left(\mathbf{u}^{(n)}, T^{(n)}\right)_{i, j, k}=\left\{2\left(\left.\frac{\partial w}{\partial x}\right|_{i, j, k} T_{i, j, k}^{x z}+\left.\frac{\partial w}{\partial y}\right|_{i, j, k} T_{i, j, k}^{y z}+\left.\frac{\partial w}{\partial z}\right|_{i, j, k} T_{i, j, k}^{z z}\right)+\left.2 \xi \frac{\partial w}{\partial z}\right|_{i, j, k}\right. \\
& -\left(\operatorname{conv}_{x}\left(u T^{z z}\right)_{i, j, k}+\operatorname{conv}_{y}\left(v T^{z z}\right)_{i, j, k}+\operatorname{conv}_{z}\left(w T^{z z}\right)_{i, j, k}\right) \\
& -\frac{1}{W e}\left\{f(\lambda, T)_{i, j, k} T_{i, j, k}^{z z}+\xi\left(f(\lambda, T)_{i, j, k}-1\right)\right. \\
& \left.\left.+\frac{\alpha}{\xi}\left[\left(T_{i, j, k}^{x z}\right)^{2}+\left(T_{i, j, k}^{y z}\right)^{2}+\left(T_{i, j, k}^{z z}\right)^{2}\right]\right\}\right\}^{(n)}, \\
& F^{x y}\left(\mathbf{u}^{(n)}, T^{(n)}\right)_{i, j, k}=\left\{\left.\frac{\partial u}{\partial x}\right|_{i, j, k} T_{i, j, k}^{x y}+\left.\frac{\partial u}{\partial y}\right|_{i, j, k} T_{i, j, k}^{y y}+\left.\frac{\partial u}{\partial z}\right|_{i, j, k} T_{i, j, k}^{y z}+\left.\frac{\partial v}{\partial x}\right|_{i, j, k} T_{i, j, k}^{x x}\right. \\
& +\left.\frac{\partial v}{\partial y}\right|_{i, j, k} T_{i, j, k}^{x y}+\left.\frac{\partial v}{\partial z}\right|_{i, j, k} T_{i, j, k}^{x z}+\xi\left(\left.\frac{\partial u}{\partial y}\right|_{i, j, k}+\left.\frac{\partial v}{\partial x}\right|_{i, j, k}\right) \\
& -\left(\operatorname{conv}_{x}\left(u T^{x y}\right)_{i, j, k}+\operatorname{conv}_{y}\left(v T^{x y}\right)_{i, j, k}+\operatorname{conv}_{z}\left(w T^{x y}\right)_{i, j, k}\right) \\
& \left.-\frac{1}{W e}\left\{f(\lambda, T)_{i, j, k} T_{i, j, k}^{x y}+\frac{\alpha}{\xi}\left[T_{i, j, k}^{x x} T_{i, j, k}^{x y}+T_{i, j, k}^{x y} T_{i, j, k}^{y y}+T_{i, j, k}^{x z} T_{i, j, k}^{y z}\right]\right\}\right\}^{(n)} \\
& F^{x z}\left(\mathbf{u}^{(n)}, T^{(n)}\right)_{i, j, k}=\left\{\left.\frac{\partial u}{\partial x}\right|_{i, j, k} T_{i, j, k}^{x z}+\left.\frac{\partial u}{\partial y}\right|_{i, j, k} T_{i, j, k}^{y z}+\left.\frac{\partial u}{\partial z}\right|_{i, j, k} T_{i, j, k}^{z z}+\left.\frac{\partial w}{\partial x}\right|_{i, j, k} T_{i, j, k}^{x x}\right. \\
& +\left.\frac{\partial w}{\partial y}\right|_{i, j, k} T_{i, j, k}^{x y}+\left.\frac{\partial w}{\partial z}\right|_{i, j, k} T_{i, j, k}^{x z}+\xi\left(\left.\frac{\partial u}{\partial z}\right|_{i, j, k}+\left.\frac{\partial w}{\partial x}\right|_{i, j, k}\right) \\
& -\left(\operatorname{conv}_{x}\left(u T^{x z}\right)_{i, j, k}+\operatorname{conv}_{y}\left(v T^{x z}\right)_{i, j, k}+\operatorname{conv}_{z}\left(w T^{x z}\right)_{i, j, k}\right) \\
& \left.-\frac{1}{W e}\left\{f(\lambda, T)_{i, j, k} T_{i, j, k}^{x z}+\frac{\alpha}{\xi}\left[T_{i, j, k}^{x x} T_{i, j, k}^{x z}+T_{i, j, k}^{x y} T_{i, j, k}^{y z}+T_{i, j, k}^{x z} T_{i, j, k}^{z z}\right]\right\}\right\}^{(n)}
\end{aligned}
$$




$$
\begin{aligned}
F^{y z}\left(\mathbf{u}^{(n)}, T^{(n)}\right)_{i, j, k}= & \left\{\left.\frac{\partial v}{\partial x}\right|_{i, j, k} T_{i, j, k}^{x z}+\left.\frac{\partial v}{\partial y}\right|_{i, j, k} T_{i, j, k}^{y z}+\left.\frac{\partial v}{\partial z}\right|_{i, j, k} T_{i, j, k}^{z z}+\left.\frac{\partial w}{\partial x}\right|_{i, j, k} T_{i, j, k}^{x y}\right. \\
& +\left.\frac{\partial w}{\partial y}\right|_{i, j, k} T_{i, j, k}^{y y}+\left.\frac{\partial w}{\partial z}\right|_{i, j, k} T_{i, j, k}^{y z}+\xi\left(\left.\frac{\partial v}{\partial z}\right|_{i, j, k}+\left.\frac{\partial w}{\partial y}\right|_{i, j, k}\right) \\
& -\left(\operatorname{conv}_{x}\left(u T^{y z}\right)_{i, j, k}+\operatorname{conv}_{y}\left(v T^{y z}\right)_{i, j, k}+\operatorname{conv}_{z}\left(w T^{y z}\right)_{i, j, k}\right) \\
& \left.-\frac{1}{W e}\left\{f(\lambda, T)_{i, j, k} T_{i, j, k}^{y z}+\frac{\alpha}{\xi}\left[T_{i, j, k}^{x y} T_{i, j, k}^{x z}+T_{i, j, k}^{y y} T_{i, j, k}^{y z}+T_{i, j, k}^{y z} T_{i, j, k}^{z z}\right]\right\}\right\}^{(n)},
\end{aligned}
$$

em que as derivadas espaciais são discretizadas por diferenças centradas, da forma

$$
\begin{aligned}
& \left.\frac{\partial u}{\partial x}\right|_{i, j, k}=\frac{u_{i+\frac{1}{2}, j, k}-u_{i-\frac{1}{2}, j, k}}{\delta x},\left.\frac{\partial v}{\partial x}\right|_{i, j, k}=\frac{v_{i+\frac{1}{2}, j, k}-v_{i-\frac{1}{2}, j, k}}{\delta x},\left.\frac{\partial w}{\partial x}\right|_{i, j, k}=\frac{w_{i+\frac{1}{2}, j, k}-w_{i-\frac{1}{2}, j, k}}{\delta x}, \\
& \left.\frac{\partial u}{\partial y}\right|_{i, j, k}=\frac{u_{i, j+\frac{1}{2}, k}-u_{i, j-\frac{1}{2}, k}}{\delta y},\left.\frac{\partial v}{\partial y}\right|_{i, j, k}=\frac{v_{i, j+\frac{1}{2}, k}-v_{i, j-\frac{1}{2}, k}}{\delta y},\left.\frac{\partial w}{\partial y}\right|_{i, j, k}=\frac{w_{i, j+\frac{1}{2}, k}-w_{i, j-\frac{1}{2}, k}}{\delta y}, \\
& \left.\frac{\partial u}{\partial z}\right|_{i, j, k}=\frac{u_{i, j, k+\frac{1}{2}}-u_{i, j, k-\frac{1}{2}}}{\delta z},\left.\frac{\partial v}{\partial z}\right|_{i, j, k}=\frac{v_{i, j, k+\frac{1}{2}}-v_{i, j, k-\frac{1}{2}}}{\delta z},\left.\frac{\partial w}{\partial z}\right|_{i, j, k}=\frac{w_{i, j+\frac{1}{2}}-w_{i, j, k-\frac{1}{2}}}{\delta z} .
\end{aligned}
$$

Os termos $\operatorname{conv}_{x}(), \operatorname{conv}_{y}()$ e $\operatorname{conv}_{z}()$ denotam, respectivamente, as derivadas parciais do termo convectivo ao longo das direções $x, y$ e $z$. Nesse trabalho, os termos convectivos são aproximados pelo esquema CUBISTA (Alves et al., 2003). Mais detalhes sobre esse esquema podem ser encontrados em Ferreira et al. (2007).

Assim, calculado $F\left(\mathbf{u}^{(n)}, T^{(n)}\right)_{i, j, k}, \widetilde{T}_{i, j, k}^{(n+1)}$ é calculado por

$$
\begin{aligned}
& \left(\widetilde{T}^{x x}\right)_{i, j, k}^{(n+1)}=\left(T^{x x}\right)_{i, j, k}^{(n)}+\delta t F^{x x}\left(\mathbf{u}^{(n)}, T^{(n)}\right)_{i, j, k}, \\
& \left(\widetilde{T}^{y y}\right)_{i, j, k}^{(n+1)}=\left(T^{y y}\right)_{i, j, k}^{(n)}+\delta t F^{y y}\left(\mathbf{u}^{(n)}, T^{(n)}\right)_{i, j, k}, \\
& \left(\widetilde{T}^{z z}\right)_{i, j, k}^{(n+1)}=\left(T^{z z}\right)_{i, j, k}^{(n)}+\delta t F^{z z}\left(\mathbf{u}^{(n)}, T^{(n)}\right)_{i, j, k}, \\
& \left(\widetilde{T}^{x y}\right)_{i, j, k}^{(n+1)}=\left(T^{x y}\right)_{i, j, k}^{(n)}+\delta t F^{x y}\left(\mathbf{u}^{(n)}, T^{(n)}\right)_{i, j, k}, \\
& \left(\widetilde{T}^{x z}\right)_{i, j, k}^{(n+1)}=\left(T^{x z}\right)_{i, j, k}^{(n)}+\delta t F^{x z}\left(\mathbf{u}^{(n)}, T^{(n)}\right)_{i, j, k}, \\
& \left(\widetilde{T}^{y z}\right)_{i, j, k}^{(n+1)}=\left(T^{y z}\right)_{i, j, k}^{(n)}+\delta t F^{y z}\left(\mathbf{u}^{(n)}, T^{(n)}\right)_{i, j, k} .
\end{aligned}
$$

Além disso, por (3.10), $T_{i, j, k}^{\left(n+\frac{1}{2}\right)}$ é dado por 


$$
\begin{aligned}
& \left(T^{x x}\right)_{i, j, k}^{\left(n+\frac{1}{2}\right)}=\frac{1}{2}\left(\left(T^{x x}\right)_{i, j, k}^{(n)}+\left(\widetilde{T}^{x x}\right)_{i, j, k}^{(n+1)}\right), \\
& \left(T^{y y}\right)_{i, j, k}^{\left(n+\frac{1}{2}\right)}=\frac{1}{2}\left(\left(T^{y y}\right)_{i, j, k}^{(n)}+\left(\widetilde{T}^{y y}\right)_{i, j, k}^{(n+1)}\right), \\
& \left(T^{z z}\right)_{i, j, k}^{\left(n+\frac{1}{2}\right)}=\frac{1}{2}\left(\left(T^{z z}\right)_{i, j, k}^{(n)}+\left(\widetilde{T}^{z z}\right)_{i, j, k}^{(n+1)}\right), \\
& \left(T^{x y}\right)_{i, j, k}^{\left(n+\frac{1}{2}\right)}=\frac{1}{2}\left(\left(T^{x y}\right)_{i, j, k}^{(n)}+\left(\widetilde{T}^{x y}\right)_{i, j, k}^{(n+1)}\right. \\
& \left(T^{x z}\right)_{i, j, k}^{\left(n+\frac{1}{2}\right)}=\frac{1}{2}\left(\left(T^{x z}\right)_{i, j, k}^{(n)}+\left(\widetilde{T}^{x z}\right)_{i, j, k}^{(n+1)}\right), \\
& \left(T^{y z}\right)_{i, j, k}^{\left(n+\frac{1}{2}\right)}=\frac{1}{2}\left(\left(T^{y z}\right)_{i, j, k}^{(n)}+\left(\widetilde{T}^{y z}\right)_{i, j, k}^{(n+1)}\right) .
\end{aligned}
$$

Observe que em (4.7), algumas velocidades não estão definidas em algumas das faces da célula $C_{i, j, k}$. Para solucionar esse problema, tais velocidade são calculadas por interpolação, utilizando os valores mais próximos, da seguinte forma

$$
\begin{aligned}
& u_{i, j+\frac{1}{2}, k}=\frac{1}{4}\left(u_{i+\frac{1}{2}, j, k}+u_{i-\frac{1}{2}, j, k}+u_{i+\frac{1}{2}, j+1, k}+u_{i-\frac{1}{2}, j+1, k}\right), \\
& u_{i, j, k+\frac{1}{2}}=\frac{1}{4}\left(u_{i+\frac{1}{2}, j, k}+u_{i-\frac{1}{2}, j, k}+u_{i+\frac{1}{2}, j, k+1}+u_{i-\frac{1}{2}, j, k+1}\right), \\
& v_{i+\frac{1}{2}, j, k}=\frac{1}{4}\left(v_{i, j+\frac{1}{2}, k}+v_{i, j-\frac{1}{2}, k}+v_{i+1, j+\frac{1}{2}, k}+v_{i+1, j-\frac{1}{2}, k}\right), \\
& v_{i, j, k+\frac{1}{2}}=\frac{1}{4}\left(v_{i, j+\frac{1}{2}, k}+v_{i, j-\frac{1}{2}, k}+v_{i, j+\frac{1}{2}, k+1}+v_{i, j-\frac{1}{2}, k+1}\right), \\
& w_{i+\frac{1}{2}, j, k}=\frac{1}{4}\left(w_{i, j, k+\frac{1}{2}}+w_{i, j, k-\frac{1}{2}}+w_{i+1, j, k+\frac{1}{2}}+w_{i+1, j, k-\frac{1}{2}}\right), \\
& w_{i, j+\frac{1}{2}, k}=\frac{1}{4}\left(w_{i, j, k+\frac{1}{2}}+w_{i, j, k-\frac{1}{2}}+w_{i, j+1, k+\frac{1}{2}}+w_{i, j+1, k-\frac{1}{2}}\right) .
\end{aligned}
$$

Assim, é definido o procedimento utilizado para aproximar as equações (3.7) e (3.11) no espaço. O mesmo procedimento é utilizado para aproximar a equação (3.12), para o cálculo de $T^{(n+1)} \mathrm{em}$ células $[\mathbf{F}]$ e $[\mathbf{S}]$.

Observação 2 : Na discretização da equação de conservação da quantidade de movimento (3.9), a contribuição não-newtoniana $T$ é discretizada por diferenças centrais. Como exemplo, considere a equação (3.9) na direção x. Dessa forma, a equação (3.10) é discretizada como

$$
\nabla T_{i+\frac{1}{2}, j, k}^{\left(n+\frac{1}{2}\right)}=\left(\frac{T_{i+1, j, k}^{x x}-T_{i, j, k}^{x x}}{\delta x}+\frac{T_{i+\frac{1}{2}, j+\frac{1}{2}, k}^{x y}-T_{i+\frac{1}{2}, j-\frac{1}{2}, k}^{x y}}{\delta y}+\frac{T_{i+\frac{1}{2}, j, k+\frac{1}{2}}^{x z}-T_{i+\frac{1}{2}, j, k-\frac{1}{2}}^{x z}}{\delta z}\right)^{\left(n+\frac{1}{2}\right)}
$$

em que as componentes de T que não estão no centro das células, são aproximadas pela média dos seus vizinhos mais próximos 


$$
\begin{aligned}
& T_{i+\frac{1}{2}, j+\frac{1}{2}, k}^{x y}=\frac{T_{i, j, k}^{x y}+T_{i+1, j, k}^{x y}+T_{i, j+1, k}^{x y}+T_{i+1, j+1, k}^{x y}}{4}, \\
& T_{i+\frac{1}{2}, j, k+\frac{1}{2}}^{x z}=\frac{T_{i, j, k}^{x z}+T_{i+1, j, k}^{x z}+T_{i, j, k+1}^{x z}+T_{i+1, j, k+1}^{x z}}{4} .
\end{aligned}
$$

\section{Observação 3 :}

Uma diferença muito importante na metodologia GENSMAC-SXPP utilizada nesse trabalho, é a respeito da discretização da equação (3.13) em relação ao gradiente de pressão. Na metodologia GENSMAC explícita, a pressão é calculada em todas as células [S] pela condição, (2.40) enquanto que para o restante das células a pressão é definida como sendo nula. Isso faz como que o gradiente de pressão no cálculo da equação de conservação da quantidade de movimento seja eliminado em células [F], sendo calculado apenas nas células vizinhas à célula [S]. O comportamento de tais métodos de projeção sem acréscimo de pressão, foi explorado por Chorin (1968), Kim and Moin (1985) e Perot (1993).

Porém, estudos realizados por Brown et al. (2001) e Guermond et al. (2006), mostraram que a eliminação do gradiente de pressão nos métodos de projeção prejudica a precisão dos resultados quando o passo temporal cresce. Além disso, uma investigação realizada por Oishi (2008), no GENSMAC implícito sem o acréscimo de pressão, mostra que o erro da solução numérica aumenta à medida que o passo de tempo cresce. Por esse fato, na formulação do GENSMAC-SXPP, o gradiente de pressão é empregado no cálculo da equação de conservação da quantidade de movimento.

As condições de contorno para a contribuição não-newtoniana em células [I] e [O] são aproximadas pela discretização das condições impostas na seção 2.3. A discretização de tais condições, por serem idênticas às do modelo Oldroyd-B, podem ser encontradas em Mompean and Deville (1997) e Tomé et al. (2002).

Dessa forma, falta aproximar $T$ em paredes rígidas. Vejamos como isso é feito na seção seguinte.

\subsection{Contribuição não-newtoniana em células [B]}

A discretização espacial de $T$ no modelo SXPP difere de outros modelos viscoelásticos em células $[\mathbf{F}]$ e $[\mathbf{S}$ ] por não ser possível realizar simplificações na equação que define a contribuição não-newtoniana, como em Tomé et al. (2002)e Silva (2003). Além disso, nos trabalhos anteriores, o cálculo de $T$ nas células [B] é feito obtendo-se uma aproximação para $T$ na face da célula [B] em contato com célula $[\mathbf{F}]$ ou $[\mathbf{S}]$ e, em seguida, utiliza-se extrapolação linear para aproximar $T$ no centro da célula $[\mathbf{B}]$. Porém, devido às não linearidades presentes no modelo SXPP, é utilizada extrapolação quadrática para determinar $T$ no centro da célula [B].

Assim, estendendo para o caso tridimensional o procedimento descrito em Martins (2009), o cálculo de $T$ em células [B] é feito da seguinte forma. Supondo um contorno rígido paralelo ao plano $x y$ (vide figura 4.1), pelas condições de impermeabilidade e de não escorregamento apresentadas na 
seção 2.3, as equações que definem $T$ em tais contornos são dadas por (2.29)-(2.33). Reescrevendo essas equações na forma (3.6) e, discretizando-as na face comum das células [B] e [F/S], obtemos

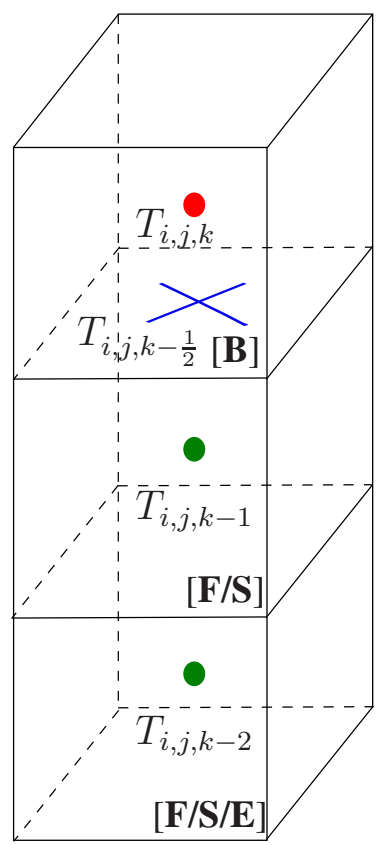

Figura 4.1: Ilustração de uma fronteira rígida paralela ao plano $x y$.

$$
\begin{aligned}
& F^{x x}\left(\mathbf{u}^{(n)}, T^{(n)}\right)_{i, j, k-\frac{1}{2}}=\left.2 \frac{\partial u}{\partial z}\right|_{i, j, k-\frac{1}{2}} T_{i, j, k-\frac{1}{2}}^{x z} \\
& -\frac{1}{W e}\left\{f(\lambda, T)_{i, j, k-\frac{1}{2}} T_{i, j, k-\frac{1}{2}}^{x x}+\xi\left(f(\lambda, T)_{i, j, k-\frac{1}{2}}-1\right)\right. \\
& \left.+\frac{\alpha}{\xi}\left[\left(T_{i, j, k-\frac{1}{2}}^{x x}\right)^{2}+\left(T_{i, j, k-\frac{1}{2}}^{x y}\right)^{2}+\left(T_{i, j, k-\frac{1}{2}}^{x z}\right)^{2}\right]\right\} \text {, } \\
& F^{y y}\left(\mathbf{u}^{(n)}, T^{(n)}\right)_{i, j, k-\frac{1}{2}}=\left.2 \frac{\partial v}{\partial z}\right|_{i, j, k-\frac{1}{2}} T_{i, j, k-\frac{1}{2}}^{y z} \\
& -\frac{1}{W e}\left\{f(\lambda, T)_{i, j, k-\frac{1}{2}} T_{i, j, k-\frac{1}{2}}^{y y}+\xi\left(f(\lambda, T)_{i, j, k-\frac{1}{2}}-1\right)\right. \\
& \left.+\frac{\alpha}{\xi}\left[\left(T_{i, j, k-\frac{1}{2}}^{x y}\right)^{2}+\left(T_{i, j, k-\frac{1}{2}}^{y y}\right)^{2}+\left(T_{i, j, k-\frac{1}{2}}^{y z}\right)^{2}\right]\right\} \text {, } \\
& F^{z z}\left(\mathbf{u}^{(n)}, T^{(n)}\right)_{i, j, k-\frac{1}{2}}=-\frac{1}{W e}\left\{f(\lambda, T) T_{i, j, k-\frac{1}{2}}^{z z}+\xi\left(f(\lambda, T)_{i, j, k-\frac{1}{2}}-1\right)\right. \\
& \left.+\frac{\alpha}{\xi}\left[\left(T_{i, j, k-\frac{1}{2}}^{x z}\right)^{2}+\left(T_{i, j, k-\frac{1}{2}}^{y z}\right)^{2}+\left(T_{i, j, k-\frac{1}{2}}^{z z}\right)^{2}\right]\right\} \text {, }
\end{aligned}
$$




$$
\begin{aligned}
F^{x y}\left(\mathbf{u}^{(n)}, T^{(n)}\right)_{i, j, k-\frac{1}{2}}= & \left.\frac{\partial u}{\partial z}\right|_{i, j, k-\frac{1}{2}} T_{i, j, k-\frac{1}{2}}^{y z}+\left.\frac{\partial v}{\partial z}\right|_{i, j, k-\frac{1}{2}} T_{i, j, k-\frac{1}{2}}^{x z} \\
& -\frac{1}{W e}\left\{f(\lambda, T)_{i, j, k-\frac{1}{2}} T_{i, j, k-\frac{1}{2}}^{x y}\right. \\
& \left.+\frac{\alpha}{\xi}\left[T_{i, j, k-\frac{1}{2}}^{x x} T_{i, j, k-\frac{1}{2}}^{x y}+T_{i, j, k-\frac{1}{2}}^{x y} T_{i, j, k-\frac{1}{2}}^{y y}+T_{i, j, k-\frac{1}{2}}^{x z} T_{i, j, k-\frac{1}{2}}^{y z}\right]\right\}, \\
F^{x z}\left(\mathbf{u}^{(n)}, T^{(n)}\right)_{i, j, k-\frac{1}{2}}= & \left.\frac{\partial u}{\partial z}\right|_{i, j, k-\frac{1}{2}}\left(T_{i, j, k-\frac{1}{2}}^{z z}+\xi\right)-\frac{1}{W e}\left\{f(\lambda, T)_{i, j, k-\frac{1}{2}} T_{i, j, k-\frac{1}{2}}^{x z}\right. \\
& \left.+\frac{\alpha}{\xi}\left[T_{i, j, k-\frac{1}{2}}^{x x} T_{i, j, k-\frac{1}{2}}^{x z}+T_{i, j, k-\frac{1}{2}}^{x y} T_{i, j, k-\frac{1}{2}}^{y z}+T_{i, j, k-\frac{1}{2}}^{x z} T_{i, j, k-\frac{1}{2}}^{z z}\right]\right\}, \\
F^{y z}\left(\mathbf{u}^{(n)}, T^{(n)}\right)_{i, j, k-\frac{1}{2}}= & \left.\frac{\partial v}{\partial z}\right|_{i, j, k-\frac{1}{2}}\left(T_{i, j, k-\frac{1}{2}}^{x x}+\xi\right)-\frac{1}{W e}\left\{f(\lambda, T)_{i, j, k-\frac{1}{2}} T_{i, j, k-\frac{1}{2}}^{y z}\right. \\
& \left.+\frac{\alpha}{\xi}\left[T_{i, j, k-\frac{1}{2}}^{x y} T_{i, j, k-\frac{1}{2}}^{x z}+T_{i, j, k-\frac{1}{2}}^{y y} T_{i, j, k-\frac{1}{2}}^{y z}+T_{i, j, k-\frac{1}{2}}^{y z} T_{i, j, k-\frac{1}{2}}^{z z}\right]\right\} .
\end{aligned}
$$

As derivadas espaciais na direção de $z$, são calculadas por diferenças centradas,

$$
\begin{aligned}
& \left.\frac{\partial u}{\partial z}\right|_{i, j, k-\frac{1}{2}}=\frac{u_{i, j, k}-u_{i, j, k-1}}{\delta z} \\
& \left.\frac{\partial v}{\partial z}\right|_{i, j, k-\frac{1}{2}}=\frac{v_{i, j, k}-v_{i, j, k-1}}{\delta z}
\end{aligned}
$$

em que

$$
\begin{aligned}
u_{i, j, k} & =\frac{1}{2}\left(u_{i+\frac{1}{2}, j, k}+u_{i-\frac{1}{2}, j, k}\right), \\
v_{i, j, k} & =\frac{1}{2}\left(v_{i, j+\frac{1}{2}, k}+v_{i, j-\frac{1}{2}, k}\right) .
\end{aligned}
$$

Dessa forma, com o valor atualizado de $F(\mathbf{u}, T)_{i, j, k-\frac{1}{2}}$, calcula-se $T_{i, j, k-\frac{1}{2}}$ e, em seguida, utiliza-se extrapolação quadrática para obter o valor de $T_{i, j, k}$ na célula [B]. Esta extrapolação é dada por

$$
T_{i, j, k}=\frac{8}{3} T_{i, j, k-\frac{1}{2}}-2 T_{i, j, k-1}+\frac{1}{3} T_{i, j, k-2} .
$$

Assim, definimos a procedimento utilizado para aproximar a contribuição não-newtoniana em fronteiras rígidas paralelas ao plano $x y$. Para as fronteiras paralelas aos planos $x z$ e $y z$, o procedimento é análogo.

Além disso, existe outra situação a ser considerada: quando existe quina na fronteira rígida. Tal 
situação envolve dois casos importantes.

No primeiro, considera-se duas faces da célula $[\mathbf{B}]$, em contato com células $[\mathbf{F}]$ ou $[\mathbf{S}]$, conforme mostrado na figura 4.2. Para aproximar $T$ nesse caso, calcula-se $T_{i, j+\frac{1}{2}, k}$ e $T_{i, j, k+\frac{1}{2}}$ em cada uma das faces utilizando o procedimento definido anteriormente. Por fim, calcula-se a média das extrapolações em cada direção por

$$
T_{i, j, k}=\frac{1}{2}\left[\left(\frac{8}{3} T_{i, j, k+\frac{1}{2}}-2 T_{i, j, k+1}+\frac{1}{3} T_{i, j, k+2}\right)+\left(\frac{8}{3} T_{i, j+\frac{1}{2}, k}-2 T_{i, j+1, k}+\frac{1}{3} T_{i, j+2, k}\right)\right] .
$$

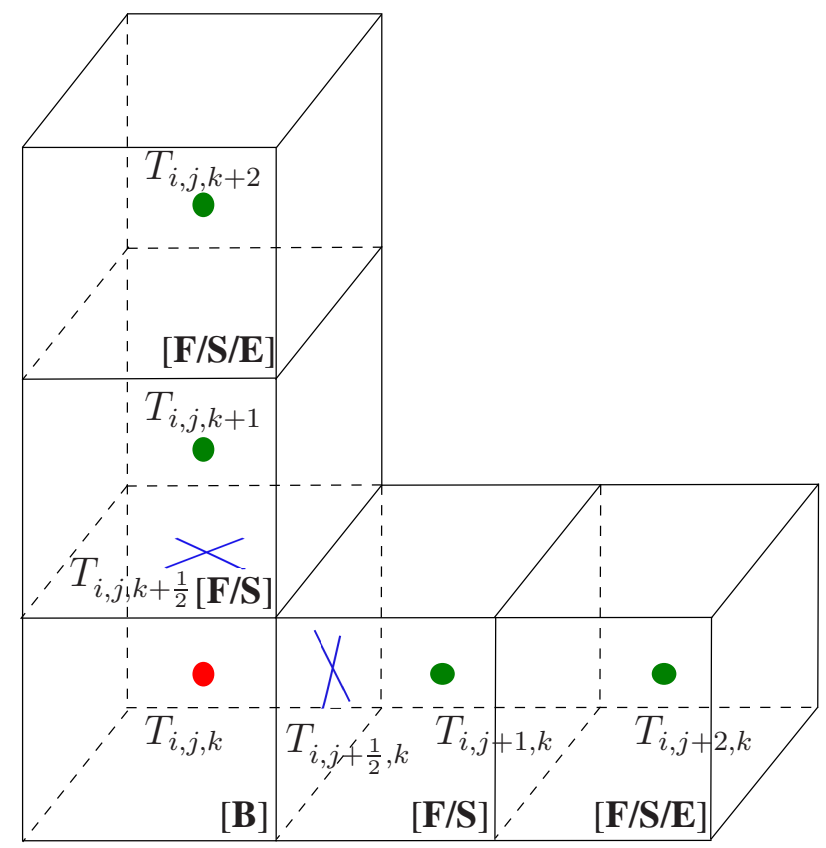

Figura 4.2: Ilustração de uma fronteira rígida com quina, paralela aos plano $x y$ e $y z$.

No segundo caso, considera-se três faces da célula $[\mathbf{B}]$, em contato com células $[\mathbf{F}]$ ou $[\mathbf{S}]$, conforme ilustrado na figura 4.3. Da mesma forma que no caso anterior, são obtidos os valores de $T$ nas faces de $[\mathbf{B}]$ em contato com células $[\mathbf{F}]$ ou $[\mathbf{S}]$ independentemente e calcula-se a média das extrapolações em cada direção. Para esse caso, temos que

$$
\begin{aligned}
T_{i, j, k}= & \frac{1}{2}\left[\left(\frac{8}{3} T_{i, j, k+\frac{1}{2}}-2 T_{i, j, k+1}+\frac{1}{3} T_{i, j, k+2}\right)+\left(\frac{8}{3} T_{i, j+\frac{1}{2}, k}-2 T_{i, j+1, k}+\frac{1}{3} T_{i, j+2, k}\right)\right. \\
& \left.+\left(\frac{8}{3} T_{i+\frac{1}{2}, j, k}-2 T_{i+1, j, k}+\frac{1}{3} T_{i+2, j, k}\right)\right] .
\end{aligned}
$$

Assim, foram apresentados os principais aspectos da discretização espacial, em uma malha deslocada, para o caso tridimensional do GENSMAC-SXPP. Como esperado, no próximo capítulo serão apresentados alguns resultados numéricos utilizando o modelo SXPP. 


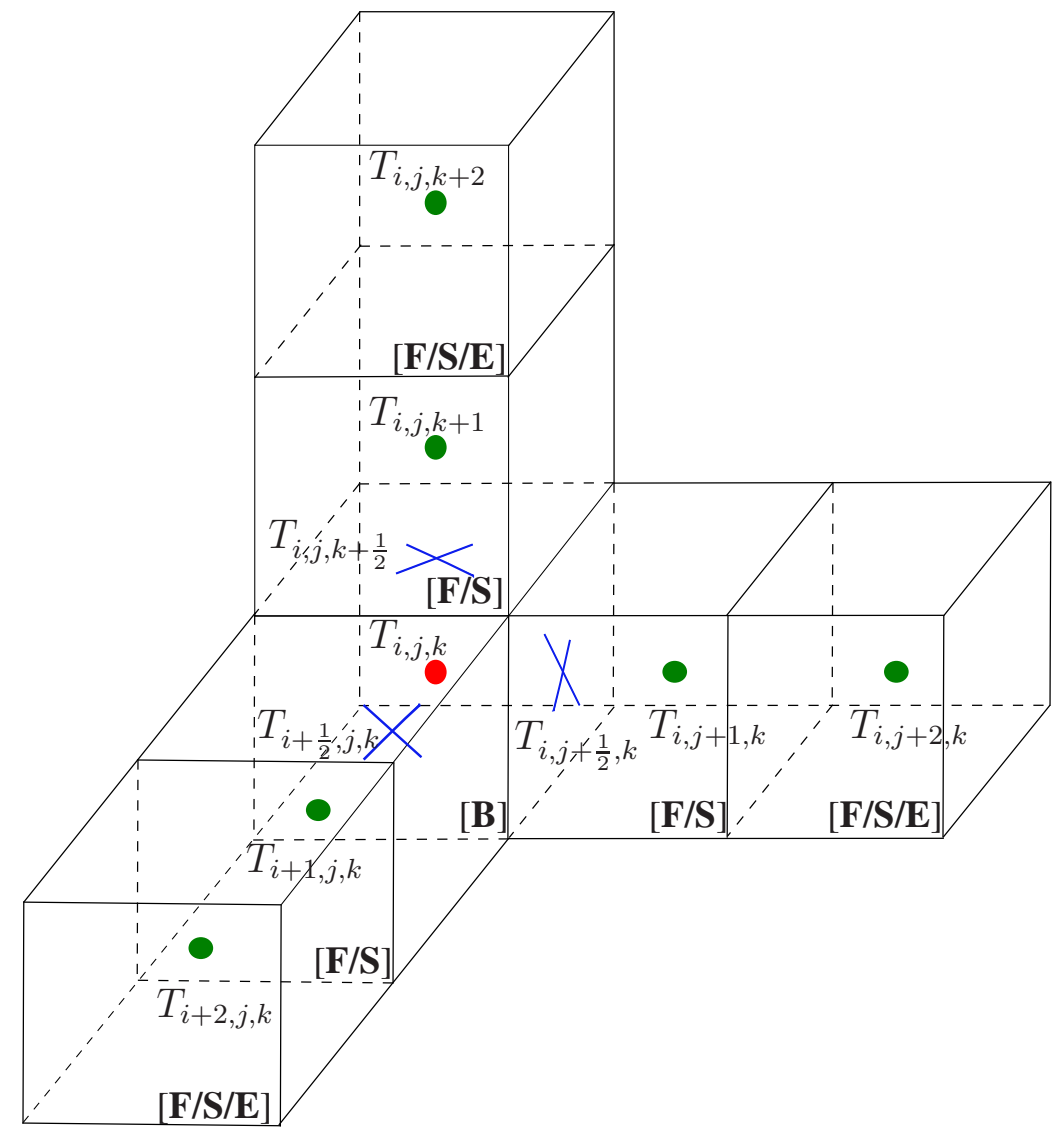

Figura 4.3: Ilustração de uma fronteira rígida com quina, paralela aos plano $x y, x z \mathrm{e} y z$. 


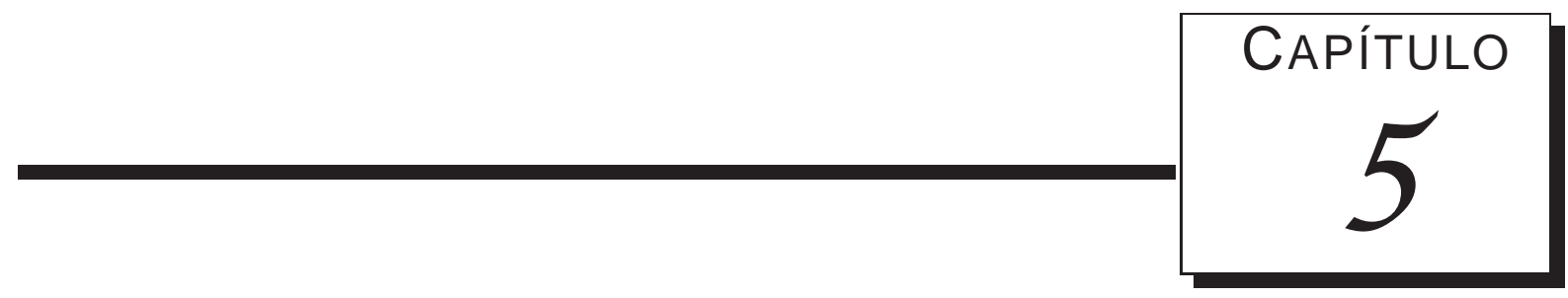

\section{Resultados}

\subsection{Verificação do método numérico}

Nos capítulos anteriores foram definidas as equações que modelam um escoamento com o modelo de fluido SXPP, a metodologia GENSMAC-SXPP para solucionar tais equações e os principais aspectos da discretização espacial. Assim, nessa seção será descrito o estudo realizado para verificação do método numérico.

Em problemas transientes, o modelo SXPP não possui solução analítica para a velocidade e nem para as componentes do tensor não-newtoniano $T$. Dessa forma, para verificar o método numérico implementado no sistema Freeflow3D, foi realizado um estudo de convergência da solução numérica utilizando diferentes tamanhos de malhas. Para isso, foi considerado um escoamento em um tubo de raio $R$ e comprimento $10 R$ como ilustrado na figura 5.1.

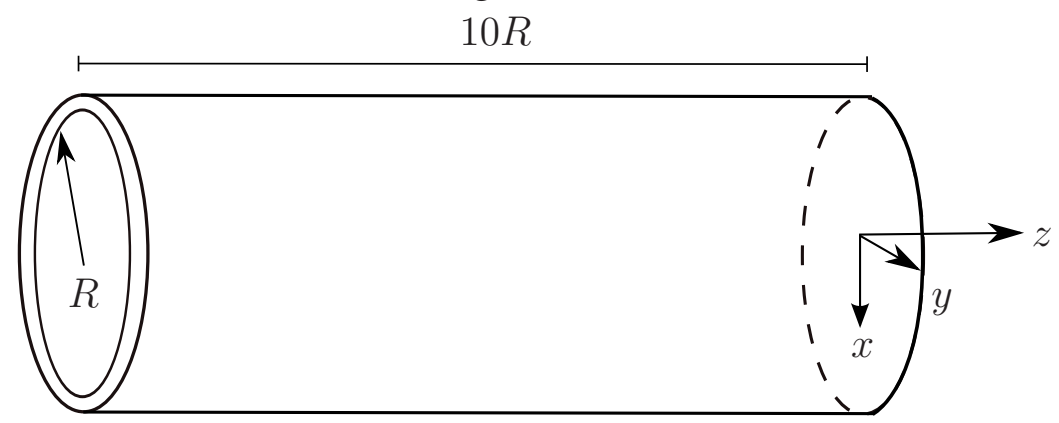

Figura 5.1: Ilustração do domínio para simulação do escoamento em um tubo.

$\mathrm{Na}$ entrada do tubo foi imposto um perfil de velocidade parabólico, com condição de contorno para o tensor não-newtoniano $T$ dada pela equação (2.36). Em contornos rígidos utilizou-se condição de aderência completa (no-slip), enquanto que nos ejetores utilizou-se condição de Neumann homogênea 
tanto para a velocidade quanto para a contribuição não-newtoniana. Na superfície livre, adotou-se condições de contorno dadas pelas equações (2.37), (2.38) e (2.39).

Os parâmetros de entrada utilizados neste experimento foram: $R=1 \mathrm{~m}, R e=1, W e=2$, $\alpha=0.2, \beta=0.5, \gamma=\frac{\lambda_{2}}{\lambda_{1}}=0.5, Q Q_{0}=2$ e gravidade $g=0$. Para analisar a convergência do método foram adotadas as seguintes malhas: $M 1: 10 \times 10 \times 50$ células $(\delta h=0.2), M 2: 14 \times 14 \times 70$ células $(\delta h=0.1428), M 3: 22 \times 22 \times 110$ células $(\delta h=0.0909)$ e $M 4: 38 \times 38 \times 190$ células $(\delta h=0.0526)$. O sistema linear resultante da equação de Poisson foi resolvido pelo método BiCGstab (BiConjugate Gradient stabilized), enquanto o sistema linear resultante da equação da quantidade de movimento foi resolvido pelo método dos Gradientes Conjugados. Foi considerada uma tolerância $\epsilon=1.0 \times 10^{-10}$ para resolver todos os sistemas lineares.

Como a solução analítica do modelo SXPP não é conhecida, considerou-se a solução da malha mais fina $M 4$ como a solução de referência.

Inicialmente, o tubo está vazio e injeta-se fluido na região de entrada até que o escoamento atinja o estado estacionário. No estado estacionário, para calcular o erro relativo do método, consideramos uma seção transversal com a distância de $\frac{3}{4}$ do comprimento do tubo em relação ao injetor, ou seja, mais próxima do ejetor. Isso é necessário, pois no inflow é imposto para o tensor $T$ o perfil desenvolvido do modelo Oldroyd-B e, de acordo com Aboubacar et al. (2005); Aguayo et al. (2004); Martins (2009), o tensor $T$ se desenvolve ao longo do canal, o que leva à obtenção do perfil do modelo SXPP. Assim, para o estudo desse modelo, é necessário que haja um domínio computacional longo, para possibilitar o desenvolvimento do tensor.

Na figura 5.2 são apresentadas as soluções numéricas obtidas para a velocidade $w$, alguns tensores não-newtonianos e o parâmetro $\lambda$, em uma seção transversal do tubo, em $z=7.5 R$ e $x=R$, no tempo $t=60$.

Para verificar a convergência do método numérico, foram utilizados os resultados obtidos com as malhas $M 1, M 2$ e $M 3$, sendo os resultados da malha $M 4$ a solução de referência. O erro relativo é calculado utilizando-se a norma 2 , da seguinte forma

$$
\|E\|_{2}=\sqrt{\frac{\sum_{i j k}\left(S O L_{r e f}-S O L_{n u m}\right)^{2}}{\sum_{i j k}\left(S O L_{r e f}\right)^{2}}},
$$

em que $S O L_{\text {ref }}$ denota a solução obtida com a malha $M 4$ e $S O L_{\text {num }}$ denota as soluções obtidas com as malhas $M 1-M 3$. A tabela 5.1 apresenta o cálculo do erro relativo utilizando as malhas $M 1, M 2$ e $M 3$. Observa-se que os erros decrescem com o refinamento da malha, evidenciando a convergência do método numérico.

Além disso, pode-se estimar a ordem de convergência $\left(N_{i}\right)$ do cálculo da velocidade no método implícito, utilizando os dados da tabela 5.1 e a fórmula

$$
N_{i}=\frac{\log \left(\frac{E(w)_{M_{i+1}}}{E(w)_{M_{i}}}\right)}{\log \left(\frac{\delta h_{i+1}}{\delta h_{i}}\right)}, \quad i=1,2
$$


a)

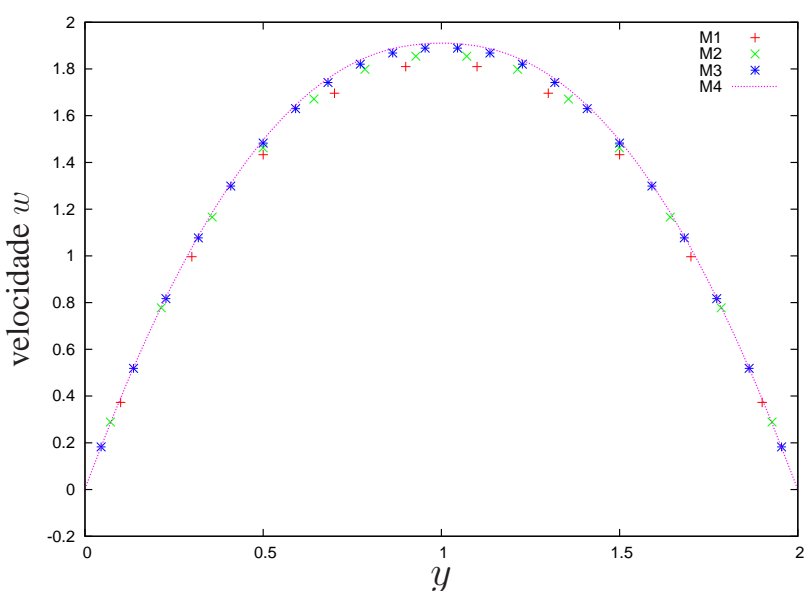

c)

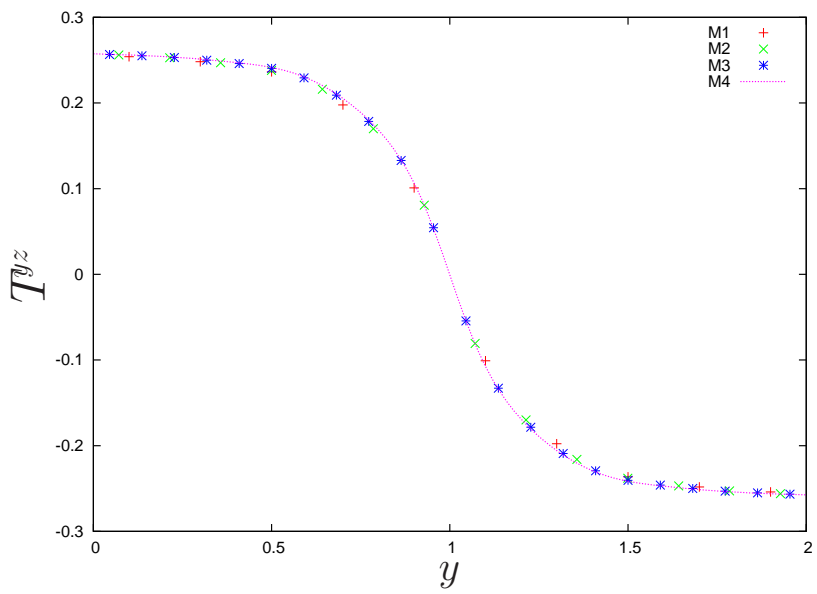

b)

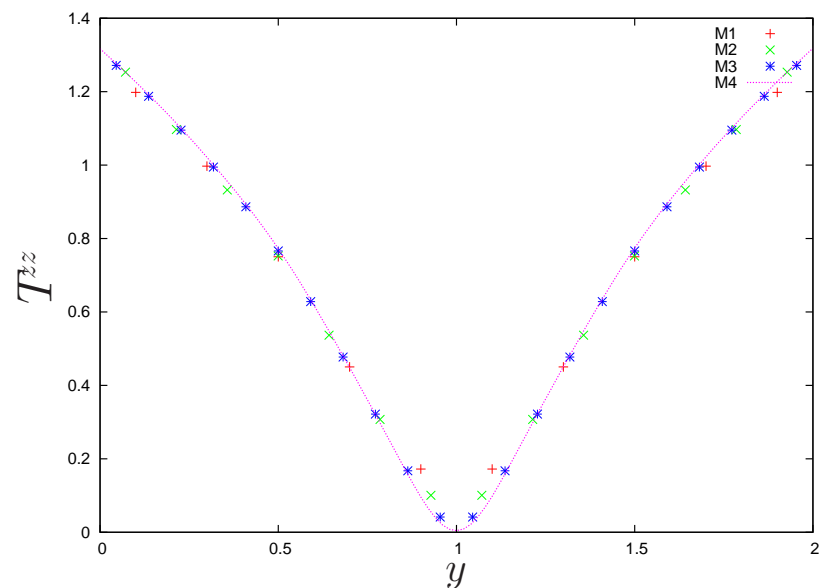

d)

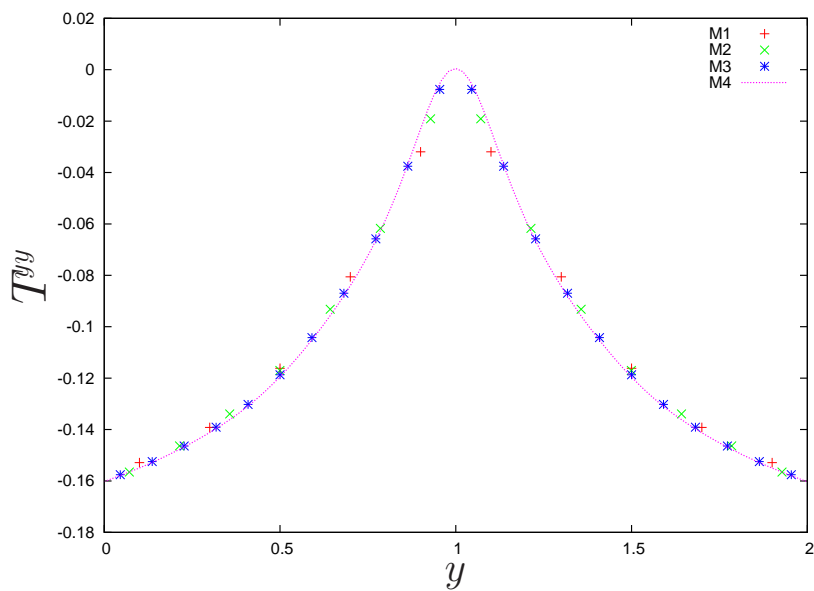

e)

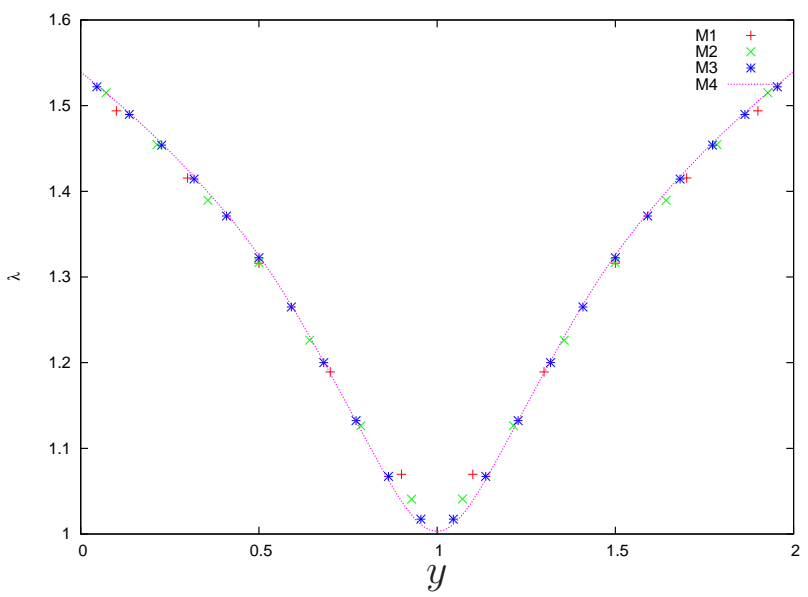

Figura 5.2: Solução numérica do escoamento em um tubo com o modelo SXPP. Comparação entre as soluções obtidas com as malhas $M 1, M 2$ and $M 3$ em relação à solução obtida com a malha $M 4$. a) w, b) $\left.T^{z z}, c\right) T^{y z}$, d) $\left.T^{y y}, e\right) \lambda$.

Dessa forma, foram obtidos $N_{1}=1.81$ e $N_{2}=2.18$, resultando em $N_{m}=\frac{N_{1}+N_{2}}{2} \simeq 2.0$. 
Tabela 5.1: Erros nas malhas $M 1, M 2$ e $M 3$ para o escoamento em um tubo com fluido SXPP.

\begin{tabular}{cccccc}
\hline Malhas & $E(w)$ & $E\left(T^{z z}\right)$ & $E\left(T^{y z}\right)$ & $E\left(T^{y y}\right)$ & $E(\lambda)$ \\
\hline$M 1$ & $4.4372 \times 10^{-2}$ & $5.1176 \times 10^{-2}$ & $2.0483 \times 10^{-2}$ & $6.1409 \times 10^{-2}$ & $1.2782 \times 10^{-2}$ \\
$M 2$ & $2.4101 \times 10^{-2}$ & $2.8762 \times 10^{-2}$ & $1.1951 \times 10^{-2}$ & $3.4373 \times 10^{-2}$ & $7.2270 \times 10^{-3}$ \\
$M 3$ & $8.9730 \times 10^{-3}$ & $9.9690 \times 10^{-3}$ & $7.0070 \times 10^{-3}$ & $1.5686 \times 10^{-2}$ & $2.4660 \times 10^{-3}$ \\
\hline
\end{tabular}

\subsection{Aplicações}

Com a verificação do método numérico apresentada na seção anterior, foi possível realizar alguns experimentos com o modelo SXPP com superfície livre em três dimensões. Nessa seção, serão apresentados os resultados obtidos ao longo desse trabalho: o inchamento do extrudado e o jato oscilante.

\subsubsection{Inchamento do extrudado}

O problema do inchamento do extrudado (extrudate swell problem) é um fenômeno comum em escoamentos com fluidos viscoelásticos, que ocorre em várias aplicações industriais que envolvem processos de extrusão. O problema consiste em um jato de fluido dentro de um tubo, que ao ser expelido se expande. Esse comportamento também é conhecido como efeito de Barus.

$\mathrm{Na}$ literatura exitem poucos trabalhos com resultados em três dimensões sobre o inchamento do extrudado para fluidos viscoelásticos, por exemplo Normandin et al. (1999); Mu et al. (2010); Antonietti et al. (2010), entre outros. O estudo desse problema é muito importante para analisar o comportamento da superfície livre em diferentes tempos de processamento. Bonito et al. (2006); Tomé et al. (2008, 2010); Mompean et al. (2011); Ganvir et al. (2011) apresentaram resultados sobre a análise da superfície livre para os modelos de fluido Oldroyd-B, Upper-Convected Maxwell e Phan Thien Tanner.

Nesse trabalho, como uma verificação adicional do método numérico, foi realizado um estudo sobre a convergência da superfície livre utilizando refinamento de malha. Até onde conhecemos, esse é o primeiro trabalho a realizar uma análise tridimensional do inchamento do extrudado com o modelo SXPP.

Os parâmetros de entrada do modelo SXPP utilizados na análise da convergência da superfície livre foram $L=0.005 \mathrm{~m}, U=0.5 \mathrm{~m} / \mathrm{s}, R e=1, W e=1, \alpha=0.01, \gamma=0.8, Q=4$ e $\beta=0.5$. A força da gravidade foi adotada na direção $z$ e dada por $g=-9.81 \mathrm{~m} / \mathrm{s}^{2}$. Considerou-se um injetor em um tubo de diâmetro $2 L$ e comprimento $5 L$, com distância $10 L$ do ejetor (vide figura 5.3). As malhas adotadas para essa análise foram: $M 5: 24 \times 24 \times 40$ células $(\delta h=0.00125), M 6: 36 \times 36 \times 60$ células $(\delta h=0.000833)$ e $M 7: 48 \times 48 \times 80$ células $(\delta h=0.000625)$.

A figura 5.4 mostra a convergência da superfície livre utilizando refinamento da malha nos tempos adimensionais $t=0.04, t=0.06$ e $t=0.4$. Pode ser observado a convergência da malha mais grossa para a malha mais fina, evidenciando o bom funcionamento do método numérico implementado no sistema Freeflow3D. 


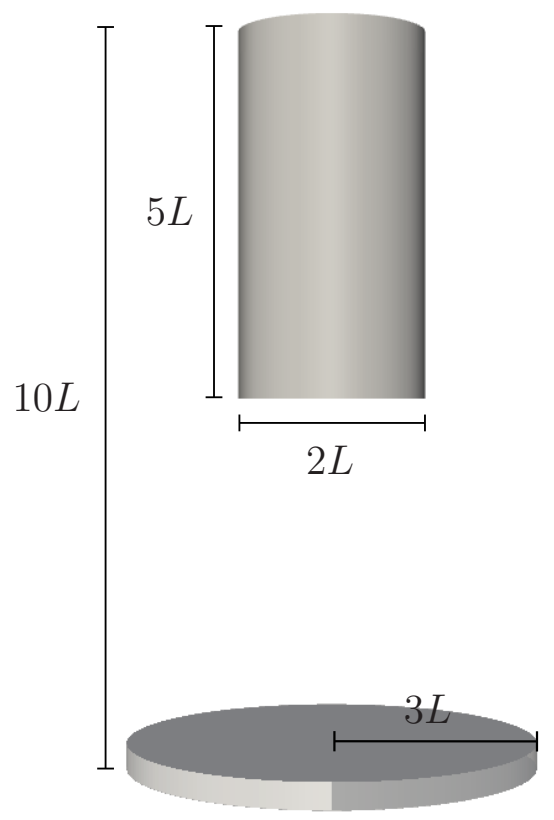

Figura 5.3: Definição do domínio para simulação do inchamento do extrudado.

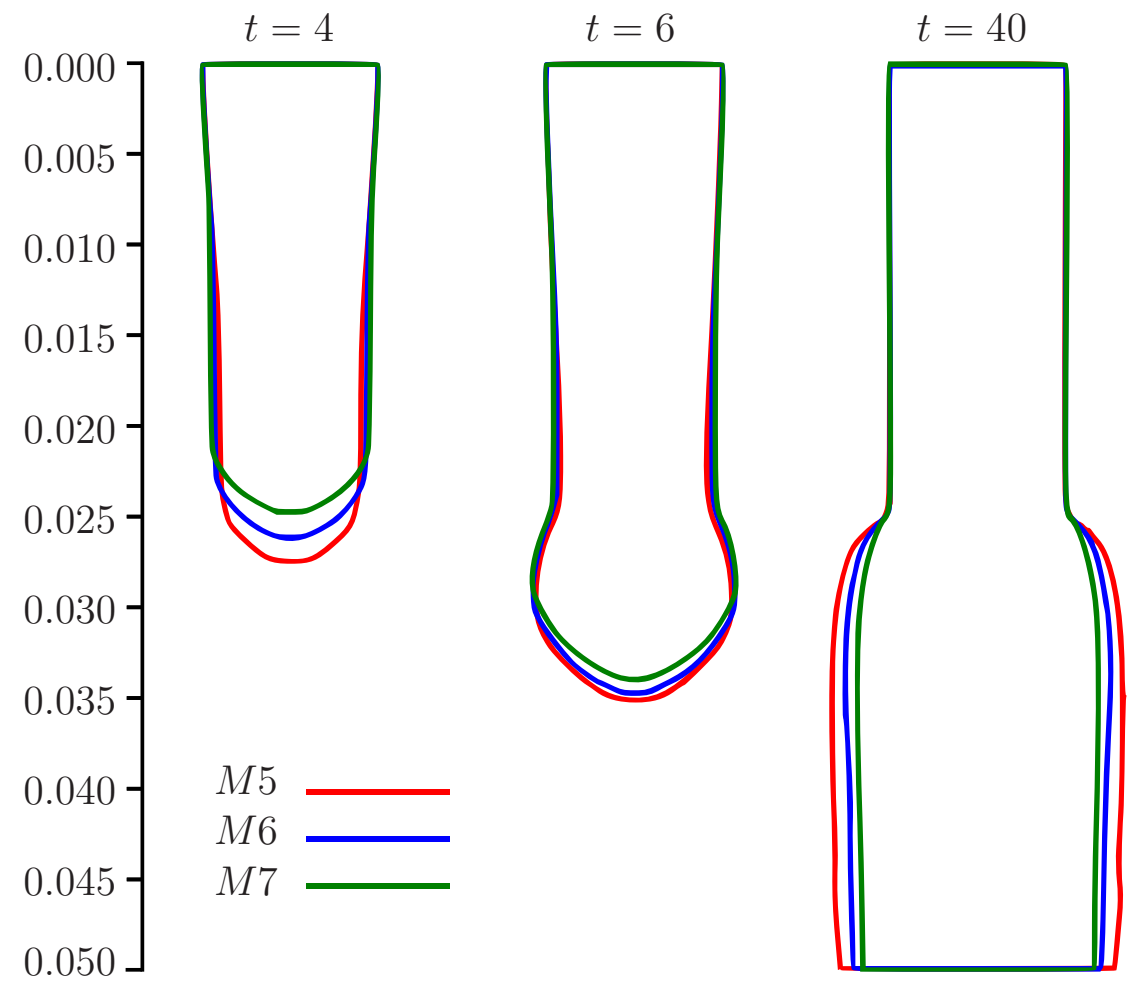

Figura 5.4: Convergência da superfície livre em uma seção transversal $y=0.015$ nas malhas $M 5, M 6$ e $M 7$ em diferentes tempos.

Além disso, podemos observar, na figura 5.5, o comportamento da velocidade $v$ durante o processo de extrusão na malha $M 7$. Observa-se também a simetria na velocidade $v$, que é uma característica 
do problema.

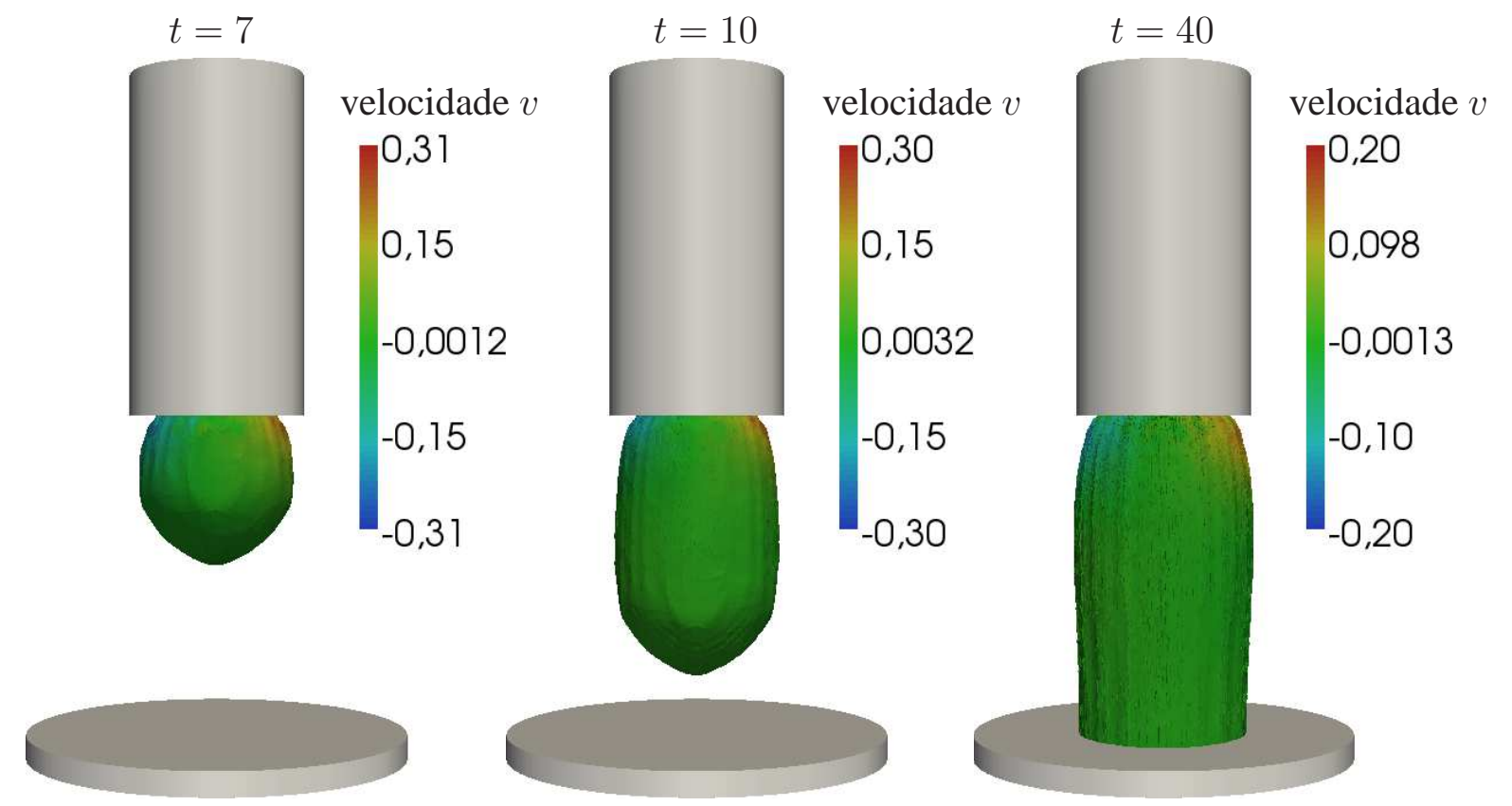

Figura 5.5: Resultado numérico do inchamento do extrudado: velocidade na direção $y$ na malha $M 7$ em diferentes tempos.

Outro estudo realizado com o inchamento do extrudado nesse trabalho foi a análise do comportamento do problema em relação à influência dos parâmetros do modelo SXPP. Esse estudo foi realizado por Oishi et al. (2011) para o caso bidimensional. A métrica utilizada para investigar a influência dos parâmetros foi a razão de inchamento, definida como

$$
S_{r}=\frac{D_{\max }}{D_{\text {tube }}}
$$

em que $D_{\max }$ é o diâmetro máximo do fluido ao sair do tubo e $D_{\text {tube }}$ é o diâmetro do tubo.

Considerando a mesma geometria adotada para o estudo da convergência da superfície livre e a malha $M 6$, foi analisado o comportamento da influência dos parâmetros.

Primeiramente, foi feita a análise da influência do parâmetro $\alpha$. Para tal, os demais parâmetros foram fixados com os seguintes valores: $W e=10, R e=0.1, Q=4, \gamma=0.8$ e $\beta=0.5$. A figura 5.6 mostra o razão de inchamento para $\alpha=0.01,0.05,0.1,0.2,0.3$ e 0.4 .

De acordo com a figura 5.6, pode-se notar que à medida que o valor de $\alpha$ aumenta, a razão de inchamento decresce. Este parâmetro representa a anisotropia do material e uma boa descrição de seu comportamento pode ser encontrada em Baltussen et al. (2010b).

Em seguida, foi efetuado o estudo da influência do parâmetro $\beta$. Os seguintes parâmetros foram mantidos fixos $W e=10, R e=0.1, Q=4, \gamma=0.5$ e $\alpha=0.02$, enquanto $\beta$ assumiu os seguintes valores: $\beta=0.3,0.4,0.6,0.7,0.8$, e 0.9 . A figura 5.7 ilustra o comportamento da razão de inchamento no estudo da influência de $\beta$. De acordo com essa figura, o valor mínimo para $S_{r}$ foi obtido para o 


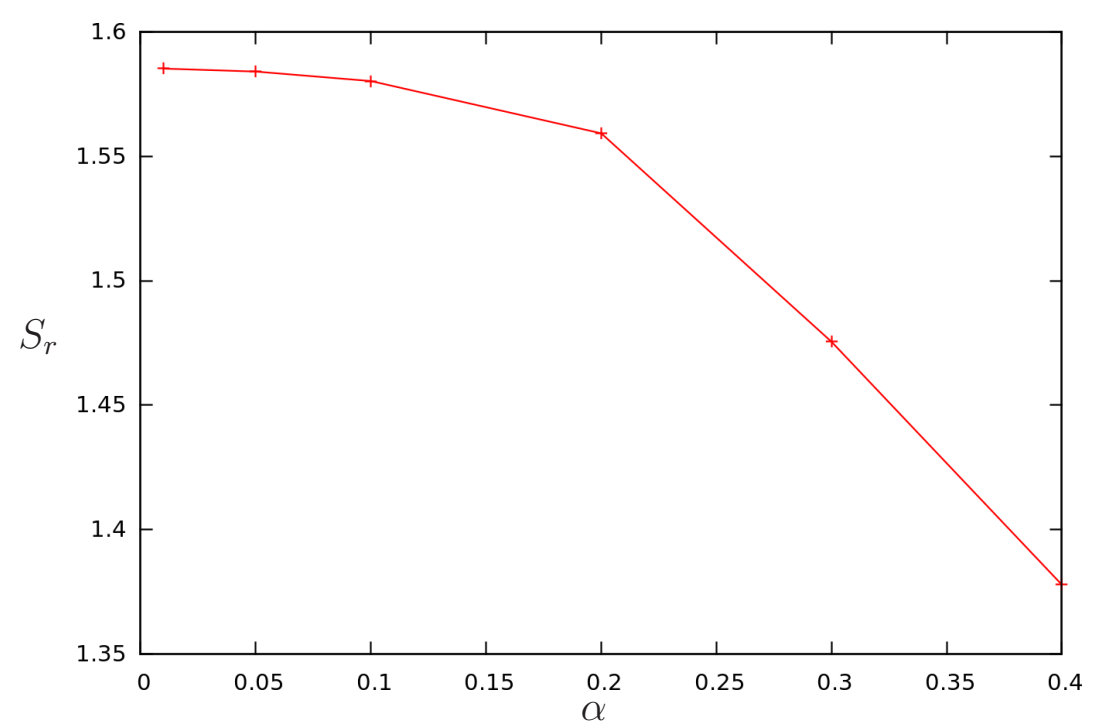

Figura 5.6: Razão de inchamento $\times$ influência de $\alpha$.

maior valor de $\beta$. Estudos realizados por Aboubacar et al. (2005) mostram que quando $\beta$ tende para 1, o modelo SXPP irá se comportar com um fluido newtoniano.

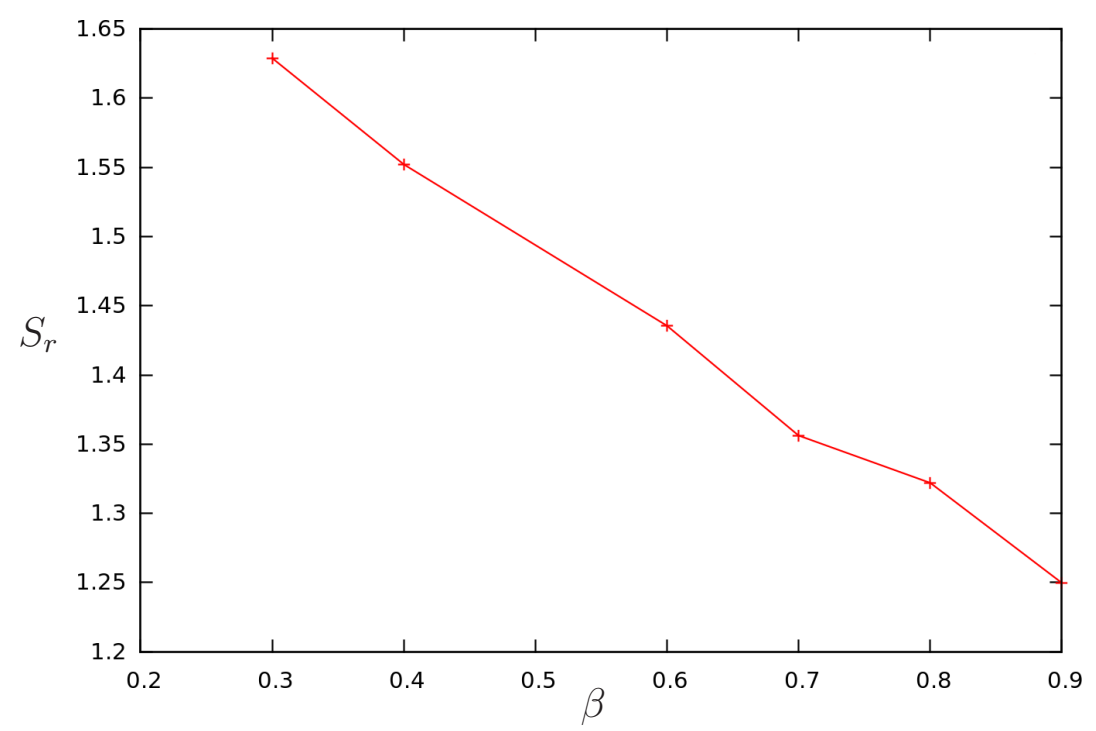

Figura 5.7: Razão de inchamento $\times$ influência de $\beta$.

Outro parâmetro analisado foi o parâmetro $\gamma$, que representa a razão entre os tempos de relaxação do modelo. Para o estudo da influência desse parâmetro, fixou-se $W e=10, \operatorname{Re}=0.1, Q=4$, $\alpha=0.02$ e $\beta=0.5$ e considerou-se $\gamma$ com os seguintes valores $0.2,0.3,0.4,0.5,0.7$ e 0.9 . A figura 5.8 mostra a influência de $\gamma$ sobre o comportamento do $S_{r}$. Pode ser observado que, quanto maior $\gamma$, maior será a elasticidade do fluido e, portanto, maior será o $S_{r}$. Tais resultados estão em boa concordância com a literatura (Oishi et al., 2011; Russo and Phillips, 2010).

O estudo da influência do parâmetro $Q$, que define o número de ramificações nas extremidades da molécula polimérica, foi realizado fixando $W e=10, R e=0.1, \alpha=0.01, \beta=0.5$ e $\gamma=0.5$. Os valores de $Q$ considerados para este caso foram: 1, 2, 3, 5, 6 e 7 . Na figura 5.9 é apresentado o 


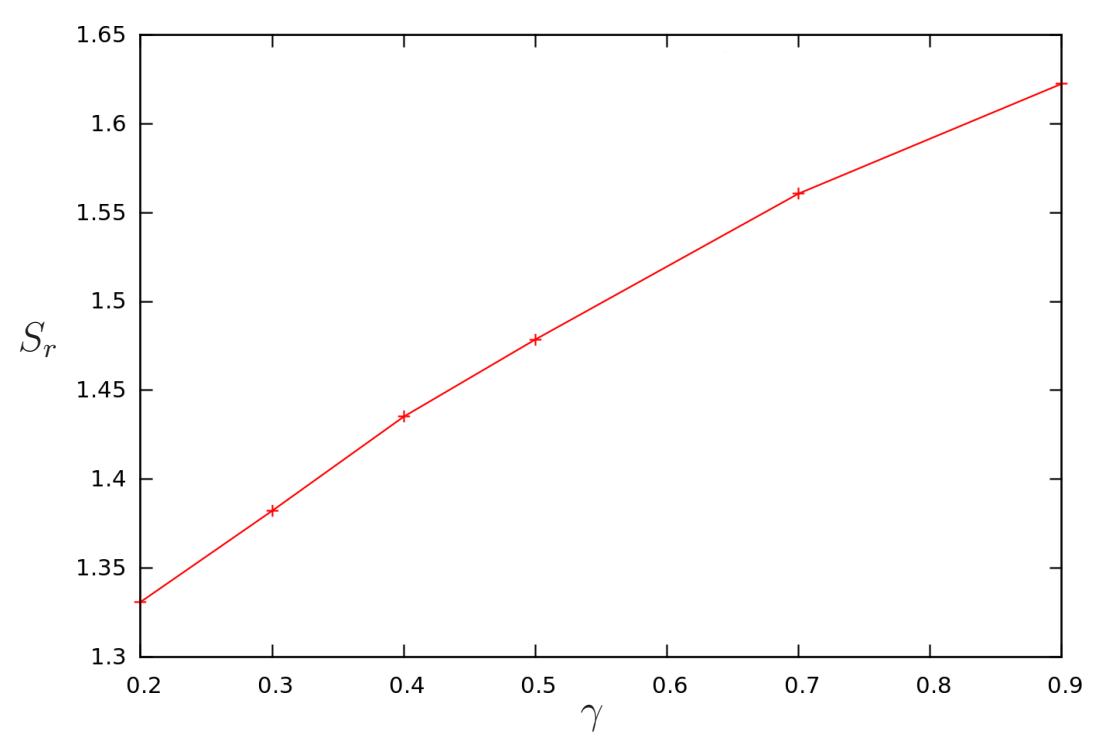

Figura 5.8: Razão de inchamento $\times$ influência de $\gamma$.

comportamento de $S_{r}$ em função do valor de $Q$. Como pode ser observado nesta figura, à medida que o número de ramificações da molécula polimérica aumenta, a razão de inchamento $S_{r}$ cresce, concordando com os resultados apresentados por Oishi et al. (2011).

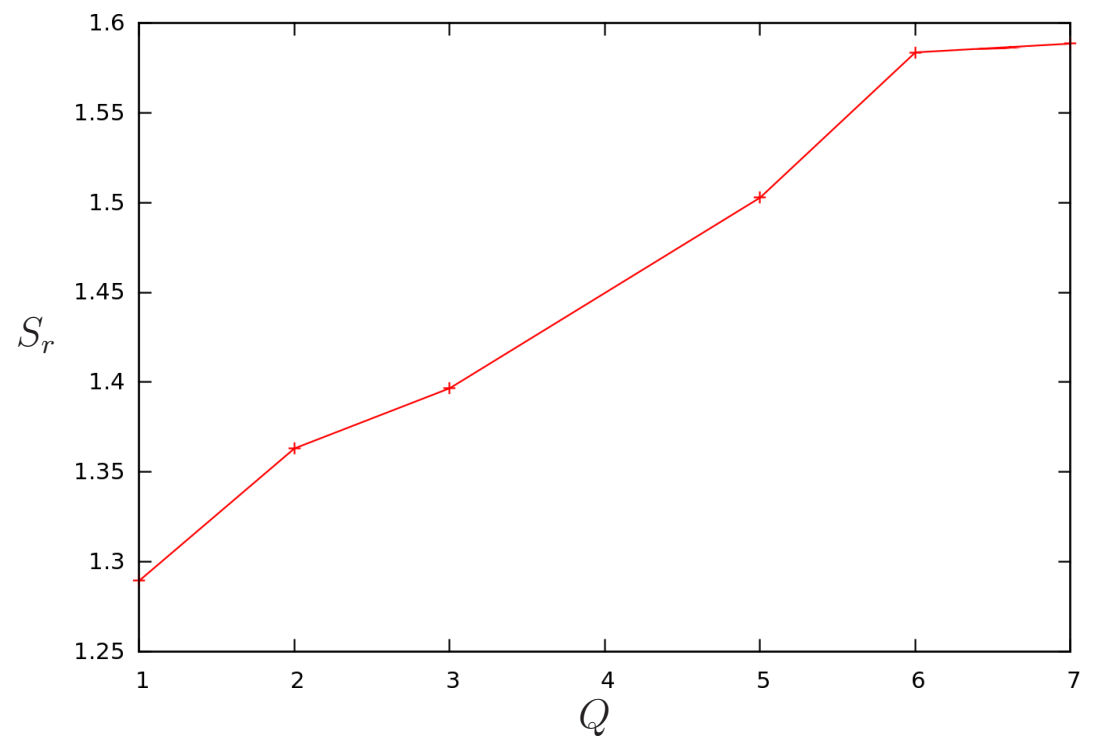

Figura 5.9: Razão de inchamento $\times$ influência de $Q$.

O comportamento da razão de inchamento, influenciada por $W e$, pode ser observado na figura 5.10. Observa-se que $S_{r}$ cresce à medida que $W e$ aumenta. Isso deve à característica do número de Weissenberg, pois quando maior, mais viscoelástico. Os parâmetros utilizados para esse estudo foram: $R e=0.1, \alpha=0.01, \beta=0.5, Q=5, \gamma=0.8$ e $W e=0.5,1,2,4,6$ e 8 .

Por fim, foi analisada a influência do número de Reynolds. Nesse caso, foram fixados os seguintes parâmetros: $W e=20, \alpha=0.01, \beta=0.5, Q=5, \gamma=0.8$, enquanto os valores de $R e$ considerados foram: $0.025,0.05,0.1,0.2,0.3$ e 0.5 .

A figura 5.11 mostra a variação de $S_{r}$ com $R e$. Observa-se que quanto menor o número de 


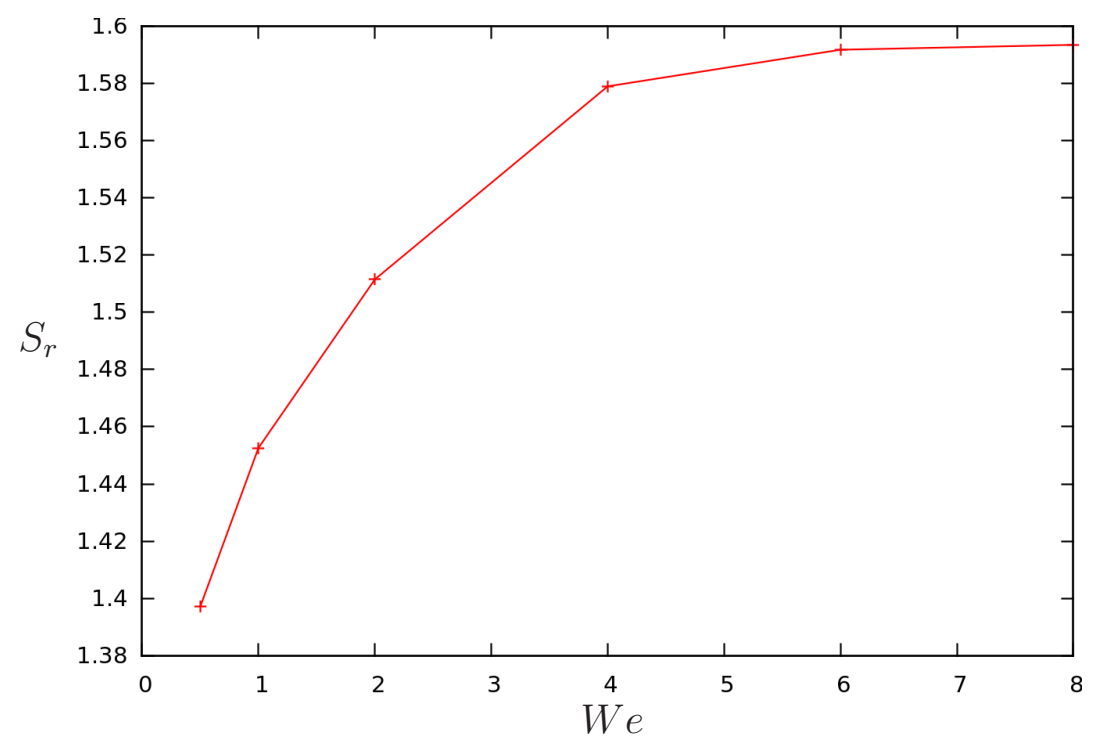

Figura 5.10: Razão de inchamento $\times$ influência de $W e$.

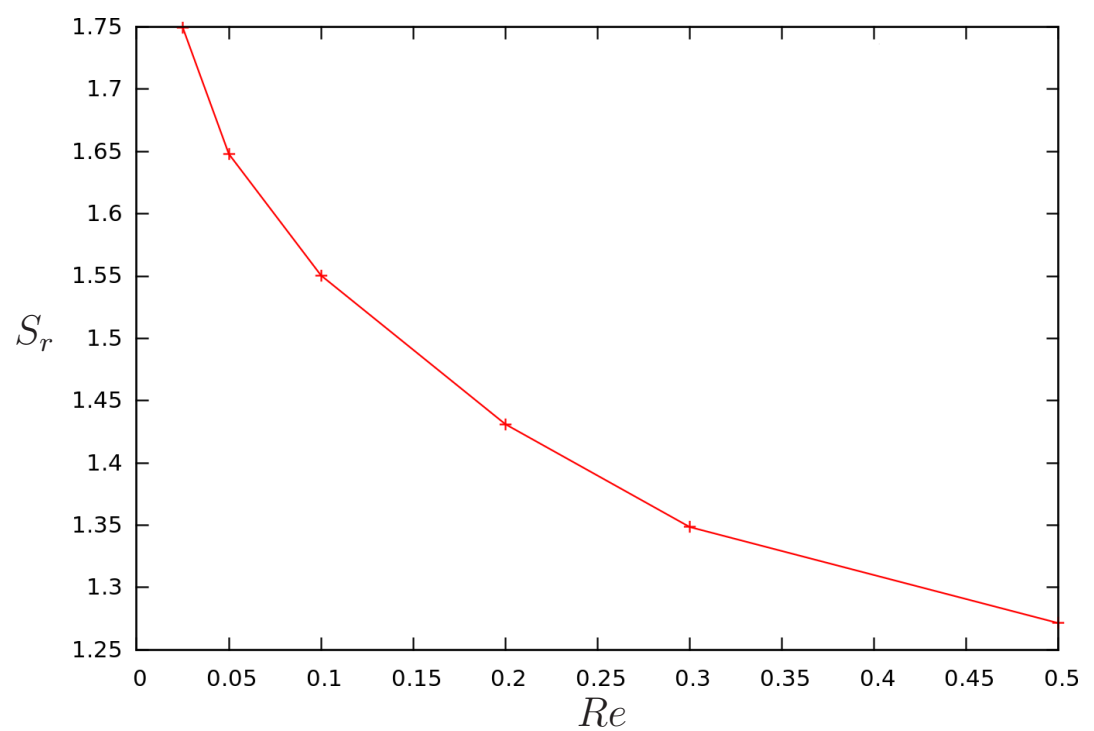

Figura 5.11: Razão de inchamento $\times$ influência de Re.

Reynolds, maior a razão de inchamento. Tal comportamento ocorre devido ao fato que quanto menor o número de Reynolds, mais viscoelástico é o fluido.

Todos os resultados numéricos obtidos nesse trabalho para a análise do comportamento da razão de inchamento, apresentaram boa concordância com os resultados apresentados em Oishi et al. (2011) e Russo and Phillips (2010), para o caso bidimensional.

A seguir, serão apresentados obtidos para a simulação do jato oscilante.

\subsubsection{Jato oscilante}

O fenômeno do jato oscilante (jet buckling phenomenon) consiste em um fluido sendo injetado de uma certa distância em uma parede rígida. Ao atingir a parede rígida, o fluido começa a se acumular e inicia-se a ocorrência de oscilações toroidais, que caracterizam tal fenômeno. 
Esse fenômeno recebeu muita atenção nas últimas décadas, principalmente em escoamentos com fluidos viscosos. Estudos realizados por Cruickshank (1980, 1988); Cruickshank and Munson (1981, 1983); Mahadevan et al. (1998) conseguiram determinar dois parâmetros críticos responsáveis pelo efeito oscilante. Recentemente, Nóbrega et al. (2007) realizou uma comparação entre dados experimentais e resultados numéricos, obtidos com o Freeflow3D. Ville et al. (2010) propôs um método level set convected para resolver escoamentos com superfície livre e apresentou resultados em duas e três dimensões desse fenômeno.

Para os modelos de fluidos viscoelásticos Oldroyd-B, Upper-Convected Maxwell, Phan Thien Tanner e K-BKZ, estudos recentes do jato oscilante para os casos bi e tridimensionais, foram apresentados por Araujo et al. (2005); Bonito et al. (2006); de Paulo et al. (2007); Tomé et al. (2008, 2009, 2010). Já para o modelo SXPP, o único estudo desse fenômeno foi apresentado por Martins (2009), para o caso bidimensional.

Nesse trabalho, foi simulado o fenômeno do jato oscilante, variando-se os parâmetros do modelo SXPP para verificar a ocorrência de oscilações. A geometria adotada para esse estudo considerou uma caixa de dimensões $1 \mathrm{~m} \times 1 \mathrm{~m} \times 0.5 \mathrm{~m}$ e um injetor de diâmetro $D=0.16 \mathrm{~m}$, à distância de $H=1 \mathrm{~m}$ do fundo da caixa, como mostrado na figura 5.12.

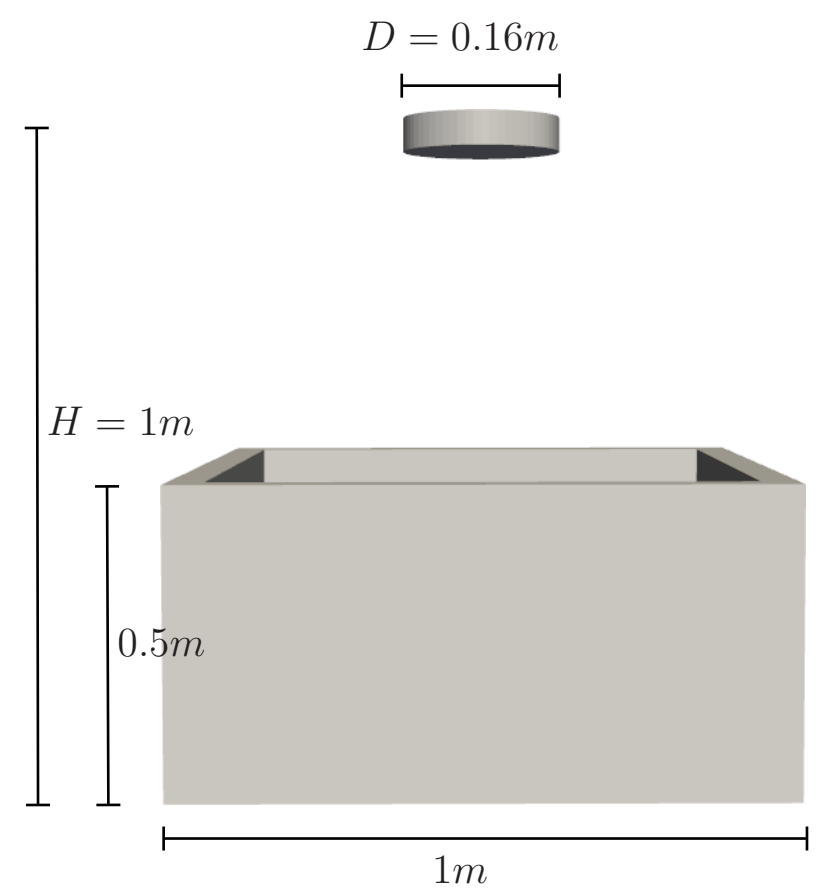

Figura 5.12: Geometria do jato oscilante.

Na tabela 5.2 são apresentados os parâmetros e a ocorrência do fenômeno do jato oscilante. Observa-se que os resultados para os casos em que os valores do número de Reynolds são menores ou iguais a 4, o efeito da oscilação sempre ocorre. Vale ressaltar que os valores dos parâmetros do modelo adotados para essas simulações diminui a viscoelasticidade do fluido. Já para os resultados com $R e=8$, os parâmetros do modelo foram ajustados de maneira a se obter um fluido mais viscoelástico. Porém, o efeito oscilatório não ocorreu. 
Tabela 5.2: Ocorrência de oscilação para o problema do jato oscilante, com diversos parâmetros do modelo SXPP e com $W e=0.1$.

\begin{tabular}{cccccc}
\hline$R e$ & $\alpha$ & $\beta$ & $\gamma$ & $Q$ & Oscilação \\
\hline 2 & 0.5 & 0.9 & 0.1 & 1 & Sim \\
4 & 0.5 & 0.9 & 0.1 & 1 & Sim \\
5 & 0.5 & 0.9 & 0.1 & 1 & Não \\
5 & 0.43 & 0.8 & 0.2 & 2 & Não \\
5 & 0.36 & 0.7 & 0.3 & 3 & Sim \\
5 & 0.29 & 0.6 & 0.4 & 4 & Sim \\
5 & 0.22 & 0.5 & 0.5 & 5 & Sim \\
5 & 0.15 & 0.4 & 0.6 & 6 & Sim \\
5 & 0.08 & 0.3 & 0.7 & 7 & Sim \\
5 & 0.01 & 0.2 & 0.8 & 8 & Sim \\
6 & 0.5 & 0.9 & 0.1 & 1 & Não \\
6 & 0.01 & 0.3 & 0.8 & 8 & Sim \\
8 & 0.5 & 0.9 & 0.1 & 1 & Não \\
8 & 0.2 & 0.6 & 0.5 & 4 & Não \\
\hline
\end{tabular}

Por outro lado, para as simulações com $R e=5$ e 6 , foi possível variar os parâmetros de forma a obter casos em que ocorreram oscilações e casos em que não ocorreram. Pode-se notar que quando os parâmetros estavam ajustados para o caso mais viscoelástico, observou-se a presença de oscilações; enquanto que para os parâmetros que definiam uma configuração de fluido menos viscoelástico, o efeito oscilatório não foi observado.

A figura 5.13 apresenta os resultado do problema do jato oscilante para os seguintes parâmetros: $R e=6, W e=0.1, \alpha=0.5, \beta=0.9, \gamma=0.1$ e $Q=1$. Observa-se que não ocorre o efeito oscilatório.
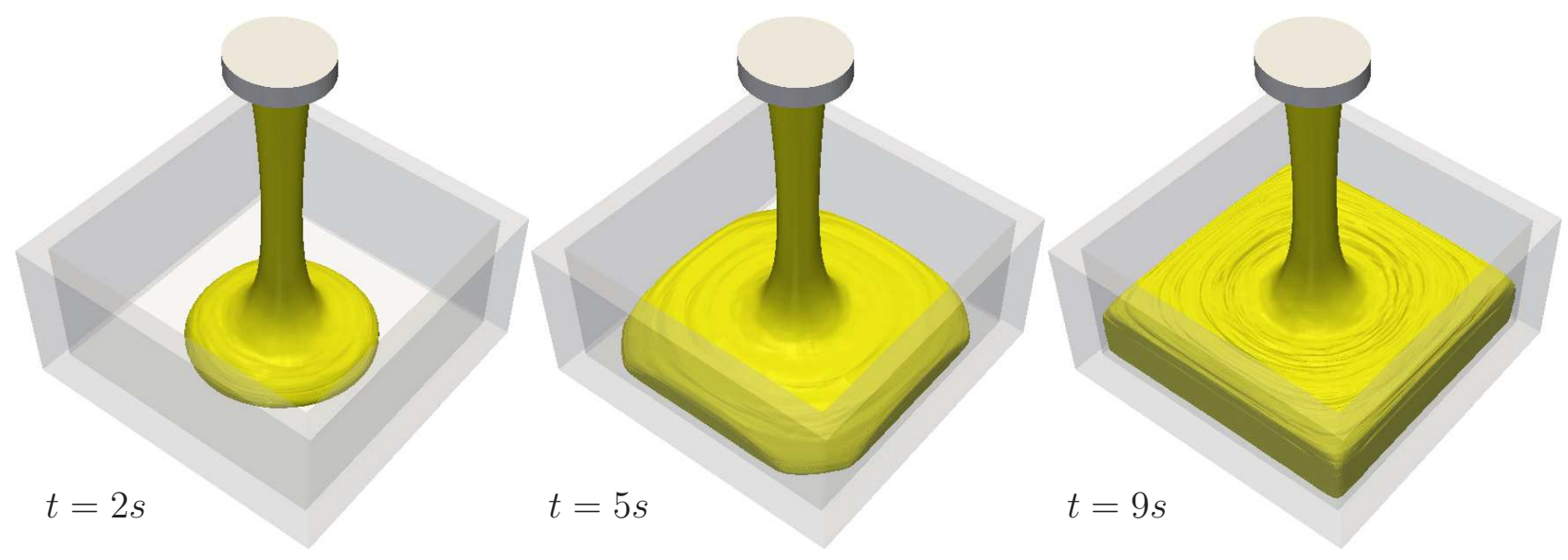

Figura 5.13: Jato oscilante nos tempos $t=2 s, t=5 s$ e $t=9 s$ para os seguintes parâmetros: $R e=6$, $W e=0.1, \alpha=0.5, \beta=0.9, \gamma=0.1$ e $Q=1$.

As figuras 5.14, 5.15, 5.16 e 5.17 apresentam alguns dos resultados onde ocorreram o efeito 
oscilatório. Os parâmetros utilizados na figura 5.14 foram $R e=6, W e=0.1, \alpha=0.01, \beta=0.3$, $\gamma=0.8$ e $Q=8$. Para a figura 5.15 foram considerados os seguintes parâmetros: $R e=5, W e=0.1$, $\alpha=0.08, \beta=0.3, \gamma=0.7$ e $Q=7$ e para simulação da figura 5.16, os parâmetros foram $R e=4$, $W e=0.1, \alpha=0.5, \beta=0.9, \gamma=0.1$ e $Q=1$. E finalmente, para a figura 5.17 considerou-se $R e=2, W e=0.1, \alpha=0.5, \beta=0.9, \gamma=0.1$ e $Q=1$.
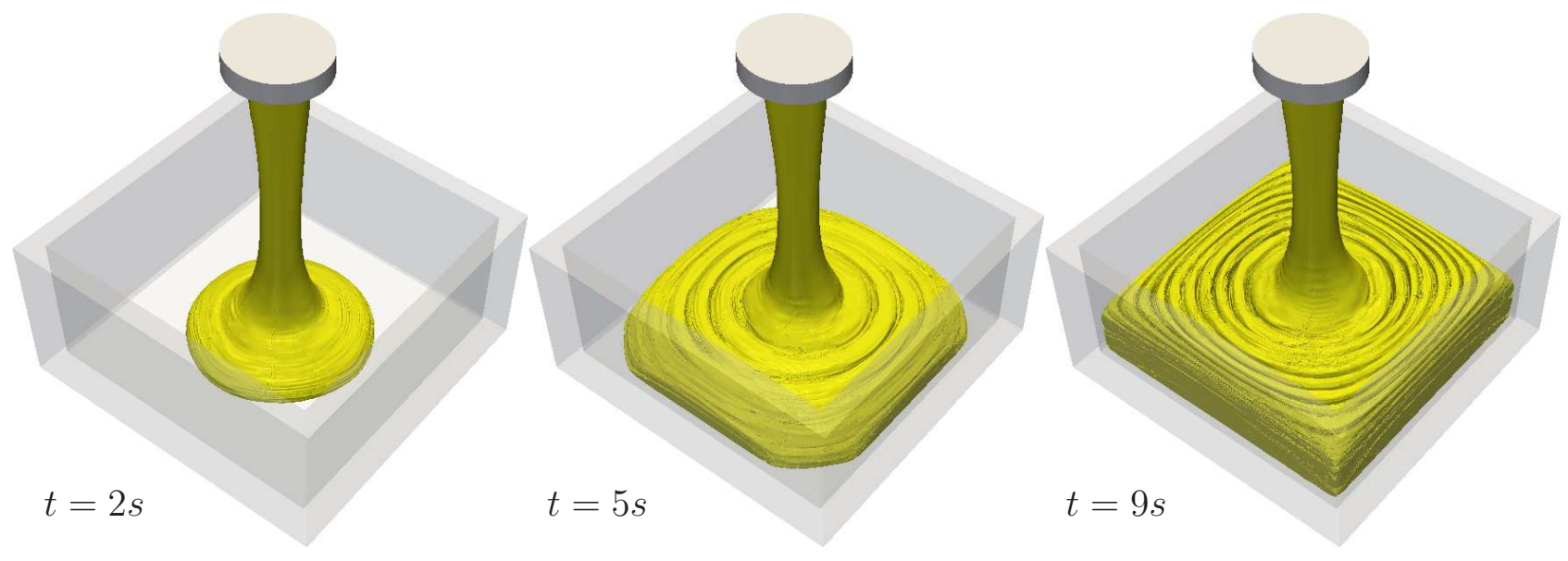

Figura 5.14: Jato oscilante nos tempos $t=2 s, t=5 s$ e $t=9 s$ para os seguintes parâmetros: $R e=6$, $W e=0.1, \alpha=0.01, \beta=0.3, \gamma=0.8$ e $Q=8$.
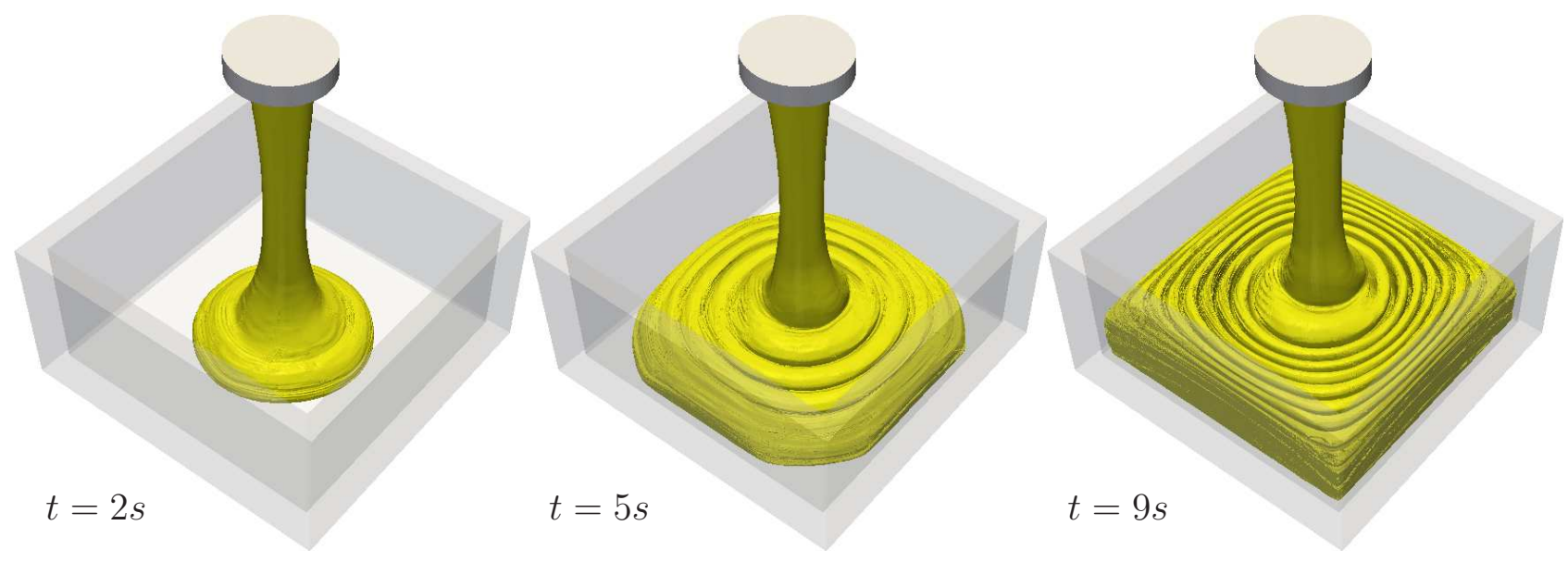

Figura 5.15: Jato oscilante nos tempos $t=2 s, t=5 \mathrm{~s}$ e $t=9 \mathrm{~s}$ para os seguintes parâmetros: $R e=5$, $W e=0.1, \alpha=0.08, \beta=0.3, \gamma=0.7$ e $Q=7$.

Pode-se observar que nas figuras 5.14 e 5.15, a oscilação do jato é mais sutil, enquanto que, nas figuras 5.16 e 5.17, o efeito oscilatório mostra-se mais evidente.

É notável a influência do número de Reynolds na ocorrência de oscilação nos resultados apresentados. Pois, como observado anteriormente, os parâmetros $\alpha, \beta, \gamma \mathrm{e} Q$, para as simulações com $R e=2$ e 4 , foram escolhidos de forma a tornar o fluido menos viscoelástico. Por outro lado, para os resultados das figuras 5.14 e 5.15, esses parâmetros foram empregados para definir um fluido mais viscoelástico. Mais detalhes sobre esses parâmetros podem ser encontrados na seção 5.2 .1 ou em Oishi et al. (2011); Russo and Phillips (2010). 


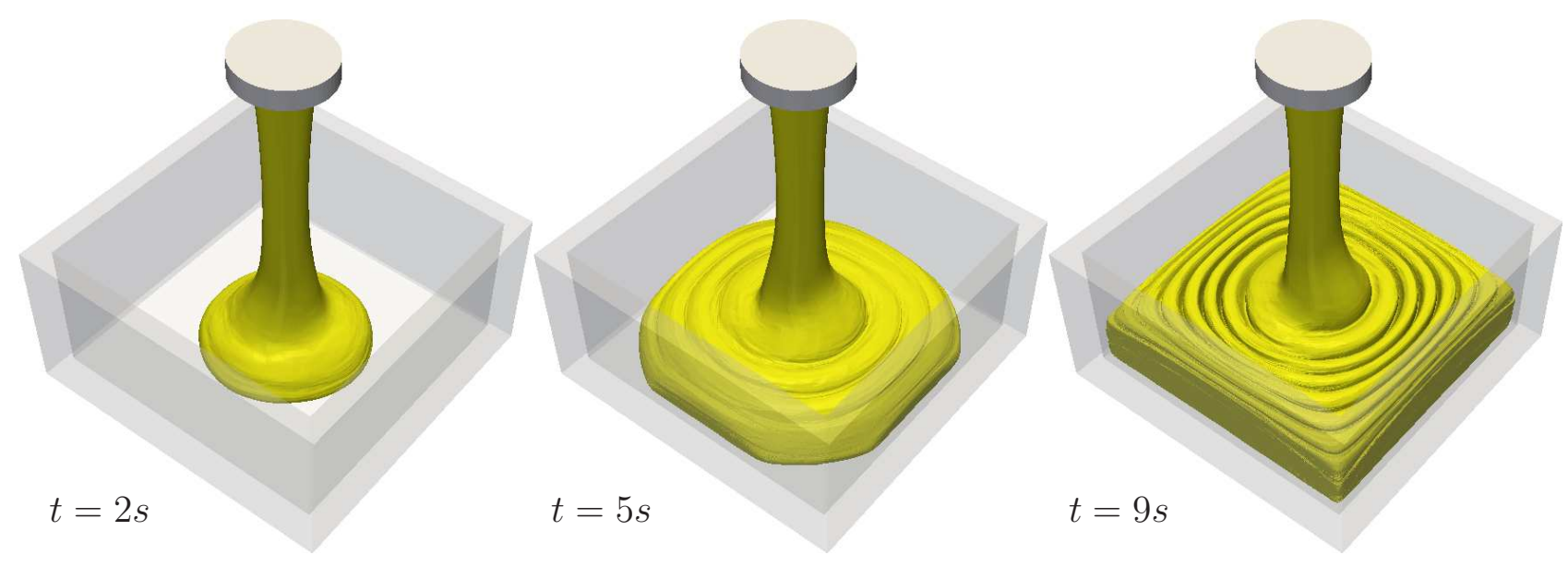

Figura 5.16: Jato oscilante nos tempos $t=2 s, t=5 s$ e $t=9 s$ para os seguintes parâmetros: $R e=4$, $W e=0.1, \alpha=0.5, \beta=0.9, \gamma=0.1$ e $Q=1$.
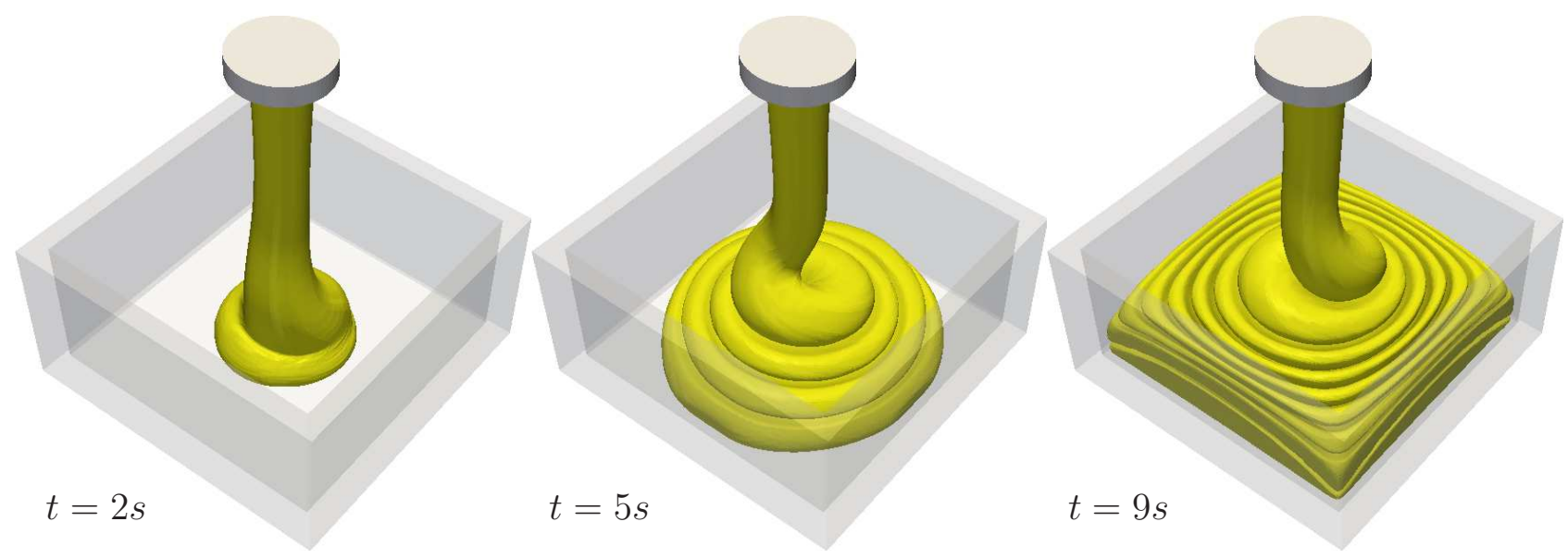

Figura 5.17: Jato oscilante nos tempos $t=2 s, t=5 s$ e $t=9 s$ para os seguintes parâmetros: $R e=2$, $W e=0.1, \alpha=0.5, \beta=0.9, \gamma=0.1$ e $Q=1$. 


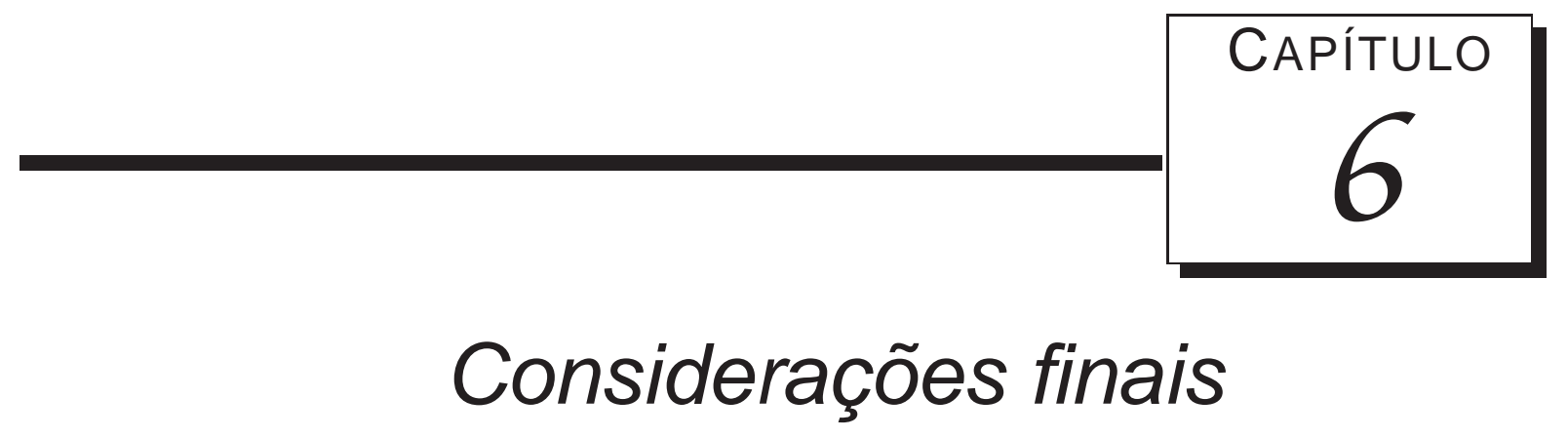

Esse trabalho foi uma extensão do trabalho realizado pelo aluno Fernando Pacanelli Martins no grupo de pesquisa do LCAD/ICMC-USP (Laboratório de Computação de Alto Desempenho), no qual foi apresentada uma análise do comportamento do modelo SXPP para o caso bidimensional (Martins, 2009).

$\mathrm{Na}$ primeira parte desse trabalho, foram apresentadas as equações governantes e constitutiva do modelo SXPP, assim como as condições iniciais e de contorno. O método numérico utilizado para resolver tais equações foi desenvolvido no grupo de pesquisa do LCAD/ICMC-USP, pelo aluno Cassio Machiaveli Oishi (Oishi et al., 2006a). Tal método combina um método de projeção com uma técnica implícita para aproximar as equação da pressão na superfície livre. No estudo de fluidos viscoelásticos, tal método é muito robusto, pois elimina a restrição de estabilidade parabólica e permite adotar um passo temporal maior, diminuindo assim, o custo computacional. Mais detalhes podem ser encontrados no capítulo 3.

As equações governantes e constitutiva foram aproximadas pelo método de diferenças finitas, em uma malha deslocada, e o método numérico foi implementado no sistema Freeflow para resolver essas equações.

O método numérico foi validado considerando um escoamento em um canal. Por não conhecer a solução analítica do modelo, foi utilizado refinamento de malha para sua verificação. Verificou-se também a ordem de convergência espacial para a velocidade. Por fim, para finalizar o estudo da validação do método numérico, foi realizado um estudo sobre a convergência da superfície livre para diferentes malhas, utilizando o problema do inchamento do extrudado.

Verificado o método numérico, foi realizado um estudo de dois problemas clássicos em escoamentos viscoelásticos com superfície livre: o inchamento do extrudado e o jato oscilante. No problema do inchamento do extrudado, estudou-se a influência dos parâmetros do modelo SXPP no comporta- 
mento da razão de inchamento. Todos os resultados apresentaram boa concordância com resultados na literatura para o caso bidimensional.

Para o problema do jato oscilante, foi realizada uma análise da influência dos parâmetros sobre a ocorrência de oscilações no problema. Também foi apresentada uma tabela com os parâmetros adotados e a conclusão dos resultados. Esse estudo nunca foi realizado antes para o modelo SXPP.

Os resultados desse trabalho irão contribuir muito para o grupo de pesquisa do LCAD/ICMC-USP, para o sistema Freeflow e, além de tudo, para a comunidade científica de mecânica dos fluidos computacional. 


\section{Referências Bibliográficas}

Aboubacar, M., Aguayo, J. P., Phillips, P. M., Phillips, T. N., Tamaddon-Jahromi, H. R., Snigerev, B. A., \& Webster, M. F., 2005. Modelling Pom-Pom type models with high-order finite volume schemes. Journal of Non-Newtonian Fluid Mechanics, vol. 126, n. 2-3, pp. 207-220. Annual European Rheology Conference 2003.

Aguayo, J., Phillips, P., Phillips, T., Tamaddon-Jahromi, H., Snigerev, B., \& Webster, M., 2007. The numerical prediction of planar viscoelastic contraction flows using the Pom-Pom model and higher-order finite volume schemes. Journal of Computational Physics, vol. 220, n. 2, pp. 586 611.

Aguayo, J., Tamaddon-Jahromi, H., \& Webster, M., 2006. Extensional response of the Pom-Pom model through planar contraction flows for branched polymer melts. Journal of Non-Newtonian Fluid Mechanics, vol. 134, n. 1-3, pp. 105 - 126. 2nd Annual European Rheology Conference.

Aguayo, J. P., Phillips, P. M., Phillips, T. N., Snigerev, B. A., Tamaddon-Jahromi, H. R., \& Webster, M., 2004. The numerical prediction of viscoelastic flows using the pom-pom model and high-order finite volume schemes. In Proc. XIVth Int. Congr. on Rheology, Seoul, Korea.

Aloku, G. \& Yuan, X., 2010. Numerical simulation of polymer foaming process in extrusion flow. Chemical Engineering Science, vol. 65, n. 12, pp. 3749-3761.

Alves, M. A., Oliveira, P. J., \& Pinho, F. T., 2003. A convergent and universally bounded interpolation scheme for the treatment of advection. International Journal for Numerical Methods in Fluids, vol. 41 , pp. 47-75.

Antonietti, P. F., Fadel, N. A., \& Verani, M., 2010. Modelling and numerical simulation of the polymeric extrusion process in textile products. Communications in Applied and Industrial Mathematics, vol. 1, pp. 1-13. 
Araujo, M., Tomé, M. F., Cuminato, J. A., Castelo, A., \& Ferreira, V. G., 2005. A numerical technique for simulating viscoelastic free surface flows using the $\mathrm{K}-\mathrm{BKZ}$ integral constitutive equation. Mecánica Computacional, vol. 24, pp. 117-136.

Balay, S., Buschelman, K., Eijkhout, V., Gropp, W. D., Kaushik, D., Knepley, M. G., McInnes, L. C., Smith, B. F., \& Zhang, H., 2008. PETSc - Portable, Extensible Toolkit for Scientific Computation - Users Manual. Technical Report ANL-95/11 - Revision 3.0.0, Argonne National Laboratory.

Balay, S., Buschelman, K., Gropp, W. D., Kaushik, D., Knepley, M. G., McInnes, L. C., Smith, B. F., \& Zhang, H., acesso em 09/2009. PETSc - Portable, Extensible Toolkit for Scientific Computation - web page. http://www.mcs.anl.gov/petsc.

Baltussen, M., Hulsen, M., \& Peters, G., 2010a. Numerical simulation of the fountain flow instability in injection molding. Journal of Non-Newtonian Fluid Mechanics, vol. 165, n. 11-12, pp. $631-$ 640.

Baltussen, M., Verbeeten, W., Bogaerds, A., Hulsen, M., \& Peters, G., 2010b. Anisotropy parameter restrictions for the extended pom-pom model. Journal of Non-Newtonian Fluid Mechanics, vol. 165, n. 19-20, pp. 1047 - 1054.

Batchelor, G. K., 1967. An Introduction to Fluid Dynamics. Cambridge University Press.

Bird, R. B., Armstrong, R. C., \& Hassager, O., 1987. Dynamics of polymeric liquids. Vol. 1: Fluid mechanics. John Wiley and Sons Inc., New York, NY.

Bishko, G. B., Harlen, O. G., McLeish, T. C. B., \& Nicholson, T. M., 1999. Numerical simulation of the transient flow of branched polymer melts through a planar contraction using the 'Pom-Pom' model. Journal of Non-Newtonian Fluid Mechanics, vol. 82, n. 2-3, pp. 255 - 273.

Bogaerds, A. C. B., Grillet, A. M., P., G. W. M., \& Baaijens, F. P. T., 2002. Stability analysis of polymer shear flows using the extended Pom-Pom constitutive equations. Journal of Non-Newtonian Fluid Mechanics, vol. 108, n. 1-3, pp. 187 - 208.

Bonito, A., Picasso, M., \& Laso, M., 2006. Numerical simulation of 3D viscoelastic flows with free surfaces. Journal of Computational Physics, vol. 215, pp. 691-716.

Brown, D. L., Cortez, R., \& Minion, M. L., 2001. Accurate projection methods for the incompressible Navier-Stokes equations. Journal of Computational Physics, vol. 168, pp. 464-499.

Butcher, J., 2003. Numerical Methods for Ordinary Differential Equations. Wiley.

Castelo, A. F., Tomé, M. F., Cesar, M. L., Cuminato, J. A., \& Mckee, S., 2000. Freeflow: an integrated simulation system for three-dimensional free surface flows. Computing and Visualization in Science, vol. 2, pp. 199-210. 
Chorin, A. J., 1967. A numerical method for solving incompressible viscous flow problems. Journal of Computational Physics, vol. 2, n. 1, pp. 12-26.

Chorin, A. J., 1968. Numerical solution of the navier-stokes equations. Mathematics of Computation, vol. 22, n. 104, pp. 745-762.

Chorin, A. J. \& Marsden, J. E., 2000. A mathematical introduction to fluid mechanics. Springer.

Clemeur, N., Rutgers, R. P., \& Debbaut, B., 2003. On the evaluation of some differential formulations for the Pom-Pom constitutive model. Rheologica acta, vol. 42, n. 3, pp. 217-231.

Clemeur, N., Rutgers, R. P. G., \& Debbaut, B., 2004. Numerical simulation of abrupt contraction flows using the Double Convected Pom-Pom model. Journal of Non-Newtonian Fluid Mechanics, vol. 117, n. 2-3, pp. $193-209$.

Cruickshank, J. O., 1980. Viscous fluid buckling: A theoretical and experimental analysis with extensions to general fluid stability. PhD thesis, Iowa State University.

Cruickshank, J. O., 1988. Low-Reynolds-number instabilities in stagnating jet flows. Journal of Fluid Mechanics, vol. 193, pp. 111-127.

Cruickshank, J. O. \& Munson, B. R., 1981. Viscous fluid buckling of plane and axisymmetric jets. Journal of Fluid Mechanics, vol. 113, pp. 221-239.

Cruickshank, J. O. \& Munson, B. R., 1983. A theoretical prediction of the fluid buckling frequency. Physics of Fluids, vol. 26, pp. 928-930.

de Paulo, G., Tomé, M., \& McKee, S., 2007. A Marker-And-Cell approach to viscoelastic free surface flows using the PTT model. Journal of Non-Newtonian Fluid Mechanics, vol. 147, n. 3, pp. 149 174.

Debbaut, B. \& Marchal, T., 2008. Numerical simulation of extrusion process and die design for industrial profile, using multimode Pom-Pom model. Plastics, rubber and composites, vol. 37, n. 2-4, pp. 142-150.

Dressler, M. \& Edwards, B., 2006. Channel, tube, and Taylor-Couette flow of complex viscoelastic fluid models. Rheologica acta, vol. 46, n. 1, pp. 59-82.

Favero, J., Secchi, A., Cardozo, N., \& Jasak, H., 2010. Viscoelastic flow analysis using the software OpenFOAM and differential constitutive equations. Journal of Non-Newtonian Fluid Mechanics, vol. 165, n. 23-24, pp. 1625 - 1636.

Ferreira, V. G., Brandi, A. C., Kurokawa, F. A., Seleghim Junior, P., Castelo, A., \& Cuminato, J. A., 2007. Incompressible Turbulent Flow Simulation Using the $\kappa-\epsilon$ Model and Upwind Schemes. Mathematical Problems in Engineering, vol. 2007, pp. 1-27. 
Fletcher, C. A. J., 1991. Computational techniques for fluid dynamics: Fundamental and general techniques. Springer.

Fortuna, A. O., 2000. Técnicas computacionais para dinâmica dos fluidos: conceitos básicos e aplicações. Edusp.

Ganvir, V., Gautham, B., Pol, H., Bhamla, M. S., Sclesi, L., Thaokar, R., Lele, A., \& Mackley, M., 2011. Extrudate swell of linear and branched polyethylenes: ALE simulations and comparison with experiments. Journal of Non-Newtonian Fluid Mechanics, vol. 166, n. 1-2, pp. 12 - 24.

Guermond, J., Minev, P., \& Shen, J., 2006. An overview of projection methods for incompressible flows. Computer Methods in Applied Mechanics and Engineering, vol. 195, n. 44-47, pp. 6011-6045.

Harlow, F. H. \& Welch, J. E., 1965. Numerical calculation of time-dependent viscous incompressible flow of fluid with free surface. Physics of Fluids, vol. 8, pp. 2182-2189.

Inkson, N. \& Phillips, T., 2007. Unphysical phenomena associated with the extended Pom-Pom model in steady flow. Journal of Non-Newtonian Fluid Mechanics, vol. 145, n. 2-3, pp. 92 - 101.

Inkson, N., Phillips, T., \& van Os, R., 2009. Numerical simulation of flow past a cylinder using models of XPP type. Journal of Non-Newtonian Fluid Mechanics, vol. 156, n. 1-2, pp. 7 - 20.

Jiang, T., Ouyang, J., Zhang, L., \& Li, X., 2011. Improved SPH approach to branched polymer free surface flows based on the XPP model. Polymer-Plastics Technology and Engineering, vol. 50, n. 2, pp. 203-215.

Khorsand, M., Rashidi, F., Goharpey, F., Mirzazadeh, M., \& Amani, E., 2011. Numerical predictions of viscoelastic fluid in pipe flow using extended Pom-Pom model. Journal of the Society of Rheology, vol. 39, pp. 75-85.

Kim, J. \& Moin, P., 1985. Application of a fractional-step method to incompressible Navier-Stokes equations. Journal of Computational Physics, vol. 59, pp. 308-323.

Lambert, J. D., 1973. Computational methods in ordinary differential equations. Wiley London.

Mahadevan, L., Ryu, W. S., \& Samuel, A. D., 1998. Fluid 'rope trick' investigated. Nature, vol. 392, pp. 140-141.

Martins, F. P., 2009. Desenvolvimento de um método numérico implícito para a simulação de superfícies livres. Master's thesis, Universidade de São Paulo - São Carlos.

McLeish, T. C. B. \& Larson, R. G., 1998. Molecular constitutive equations for a class of branched polymers: The Pom-Pom polymer. Journal of rheology, vol. 42, pp. 101-110. 
Mompean, G. \& Deville, M., 1997. Unsteady finite volume simulation of Oldroyd-B fluid through a three-dimensional planar contraction. Journal of Non-Newtonian Fluid Mechanics, vol. 72, n. 2-3, pp. 253-279.

Mompean, G., Thais, L., Tomé, M., \& Castelo, A., 2011. Numerical prediction of three-dimensional time-dependent viscoelastic extrudate swell using differential and algebraic models. Computers \& Fluids, vol. 44, n. 1, pp. $68-78$.

Mu, Y., Zhao, G., \& Zhang, C., 2010. Numerical investigation of die geometry effect on LDPE annular extrudate swell. Journal of Applied Polymer Science, vol. 117, n. 1, pp. 91-109.

Normandin, M., Clermont, J., Guillet, J., \& Raveyre, C., 1999. Three-dimensional extrudate swell experimental and numerical study of a polyethylene melt obeying a memory-integral equation. Journal of Non-Newtonian Fluid Mechanics, vol. 87, n. 1, pp. 1 - 25.

Nóbrega, J., Carneiro, O., Pinho, F., Paulo, G., Tomé, M., Castelo, A., \& Cuminato, J., 2007. The phenomenon of jet buckling: experimental results and numerical predictions. In Proceedings of the Polymer Processing Society, 23rd Annual Meeting. Citeseer.

Oishi, C. M., 2004. Análise e implementação de métodos implícitos no sistema Freeflow2D. Master’s thesis, Universidade de São Paulo - São Carlos.

Oishi, C. M., 2008. Análise e implementação de métodos implícitos e de projeção para escoamentos com superfície livre. PhD thesis, Universidade de São Paulo - São Carlos.

Oishi, C. M., Cuminato, J. A., Ferreira, V. G., Tomé, M. F., Castelo, A., Mangiavacchi, N., \& McKee, S., 2006a. A stable semi-implicit method for free surface flows. Journal of Applied Mechanics, vol. 73, pp. 940-947.

Oishi, C. M., Ferreira, V. G., \& Cuminato, J. A., 2006b. A semi-implicit finite difference method for 3D incompressible free surface flow simulation. In Proceedings of II LNCC Meeting on Computational Modelling, Petrópolis / RJ.

Oishi, C. M., Martins, F. P., Tomé, M. F., Cuminato, J. A., \& McKee, S., 2011. Numerical solution of the eXtended Pom-Pom model for viscoelastic free surface flows. Journal of Non-Newtonian Fluid Mechanics, vol. 166, n. 3-4, pp. 165-179.

Oishi, C. M., Tomé, M. F., Cuminato, J. A., \& McKee, S., 2008. An implicit technique for solving 3D low reynolds number moving freesurface flows. Journal of Computational Physics, vol. 227, n. 16, pp. 7446-7468.

Oliveira, J., 1999. Desenvolvimento de um sistema de simulação de escoamentos de fluidos com superfícies livres bidimensionais. Master’s thesis, Universidade de São Paulo - São Carlos. 
Perot, J. B., 1993. An analysis of the fractional step method. Journal of Computational Physics, vol. 108, n. 1, pp. 51-58.

Puangkird, B., Belblidia, F., \& Webster, M., 2009. Numerical simulation of viscoelastic fluids in cross-slot devices. Journal of Non-Newtonian Fluid Mechanics, vol. 162, n. 1-3, pp. 1 - 20.

Qiang, L., Ouyang, J., Yang, B., \& Jiang, T., 2011. Modelling and simulation of moving interfaces in gas-assisted injection moulding process. Applied Mathematical Modelling, vol. 35, n. 1, pp. 257 275.

Rajagopalan, D., Armstrong, R. C., \& Brown, R. A., 1990. Finite element methods for calculation of steady, viscoelastic flow using constitutive equations with a Newtonian viscosity. Journal of Non-Newtonian Fluid Mechanics, vol. 36, pp. 159-192.

Rubio, P. \& Wagner, M. H., 2000. LDPE melt rheology and the Pom-Pom model. Journal of Non-Newtonian Fluid Mechanics, vol. 92, n. 2-3, pp. 245 - 259.

Russo, G. \& Phillips, T., 2010. Numerical prediction of extrudate swell of branched polymer melts. Rheologica acta, vol. 49, n. 6, pp. 657-676.

Silva, G. F., 2003. Simulação numérica de escoamentos viscoelástico com superfície livre usando o ambiente Freeflow2D. Master's thesis, Universidade de São Paulo - São Carlos.

Sirakov, I., Ainser, A., Haouche, M., \& Guillet, J., 2005. Three-dimensional numerical simulation of viscoelastic contraction flows using the Pom-Pom differential constitutive model. Journal of Non-Newtonian Fluid Mechanics, vol. 126, n. 2-3, pp. 163 - 173. Annual European Rheology Conference 2003.

Soulages, J., Hütter, M., \& Öttinger, H. C., 2006. Thermodynamic admissibility of the eXtended Pom-Pom model for branched polymers. Journal of Non-Newtonian Fluid Mechanics, vol. 139, n. 3 , pp. $209-213$.

Tenchev, R., Gough, T., Harlen, O., Jimack, P., Klein, D., \& Walkley, M., 2011. Three dimensional finite element analysis of the flow of polymer melts. Journal of Non-Newtonian Fluid Mechanics, vol. 166, n. 5-6, pp. $307-320$.

Tomé, M., Castelo, A., Ferreira, V., \& McKee, S., 2008. A finite difference technique for solving the Oldroyd-B model for 3D-unsteady free surface flows. Journal of Non-Newtonian Fluid Mechanics, vol. 154, n. 2-3, pp. $179-206$.

Tomé, M., Silva, R., Oishi, C., \& McKee, S., 2009. Numerical solution of the Upper-Convected Maxwell model for three-dimensional free surface flows. Communications in Computational Physics, vol. 6, pp. 367-395. 
Tomé, M. F., 1993. GENSMAC: a multiple free surface fluid flow solver. PhD thesis, Department of Mathematics - University of Atrathclyde.

Tomé, M. F., Castelo, A., Cuminato, J. A., Mangiavacchi, N., \& McKee, S., 2001. GENSMAC3D: a numerical method for solving unsteady three-dimensional free surface flows. International Journal for Numerical Methods in Fluids, vol. 37, pp. 747-796.

Tomé, M. F., Doricio, J. L., Castelo, A., Cuminato, J. A., \& McKee, S., 2007a. Solving viscoelastic free surface flows of a second-order fluid using a Marker-And-Cell approach. International Journal for Numerical Methods in Fluids, vol. 53, n. 4, pp. 599-627.

Tomé, M. F., Grossi, L., Castelo, A., Cuminato, J. A., McKee, S., \& Walters, K., 2007b. Die-swell, splashing drop and a numerical technique for solving the Oldroyd-B model for axisymmetric free surface flows. Journal of Non-Newtonian Fluid Mechanics, vol. 141, n. 2-3, pp. 148-166.

Tomé, M. F., Mangiavacchi, N., Cuminato, J. A., Castelo, A., \& McKee, S., 2002. A finite difference technique for simulating unsteady viscoelastic free surface flows. Journal of Non-Newtonian Fluid Mechanics, vol. 106, n. 2-3, pp. 61-106.

Tomé, M. F., McKee, S., Barratt, L., Jarvis, D. A., \& Patrick, A. J., 1999. An experimental and numerical investigations of container filling with viscous liquids. International Journal for Numerical Methods in Fluids, vol. 31, pp. 1333-1353.

Tomé, M. F., Paulo, G. S., Pinho, F. T., \& Alves, M. A., 2010. Numerical solution of the PTT constitutive equation for unsteady three-dimensional free surface flows. Journal of Non-newtonian Fluid Mechanics, vol. 165, pp. 247-262.

van der Vorst, H. A., 1992. Bi-CGSTAB: A fast and smoothly converging variant of Bi-CG for the solution of nonsymmetric linear systems. SIAM Journal on Scientific and Statistical Computing, vol. 13, pp. 631-644.

van Os, R. M. \& Phillips, T., 2005. Efficient and stable spectral element methods for predicting the flow of an XPP fluid past a cylinder. Journal of Non-Newtonian Fluid Mechanics, vol. 129, n. 3, pp. $143-162$.

Verbeeten, W. M. H., P., G. W. M., \& Baaijens, F. P. T., 2002. Viscoelastic analysis of complex polymer melt flows using the eXtended Pom-Pom model. Journal of Non-Newtonian Fluid Mechanics, vol. 108 , n. 1-3, pp. $301-326$.

Verbeeten, W. M. H., P., G. W. M., \& Baaijens, F. P. T., 2004. Numerical simulations of the planar contraction flow for a polyethylene melt using the XPP model. Journal of Non-Newtonian Fluid Mechanics, vol. 117, n. 2-3, pp. 73 - 84. 
Verbeeten, W. M. H., Peters, G. W. M., \& Baaijens, F. P. T., 2001. Differential constitutive equations for polymer melts: the eXtended Pom-Pom model. Journal of rheology, vol. 45, pp. 823-843.

Ville, L., Silva, L., \& Coupez, T., 2010. Convected level set method for the numerical simulation of fluid buckling. International Journal for numerical methods in fluids, vol. 66, n. 3, pp. 324-344.

Wang, W., Li, X., \& Han, X., 2010. A numerical study of constitutive models endowed with Pom-Pom molecular attributes. Journal of Non-Newtonian Fluid Mechanics, vol. 165, n. 21-22, pp. 1480 1493.

Wapperom, P. \& Keunings, R., 2001. Numerical simulation of branched polymer melts in transient complex flow using Pom-Pom models. Journal of Non-Newtonian Fluid Mechanics, vol. 97, n. 2-3, pp. $267-281$.

Yang, B., Ouyang, J., Li, Q., Zhao, Z., \& Liu, C., 2010. Modeling and simulation of the viscoelastic fluid mold filling process by level set method. Journal of Non-Newtonian Fluid Mechanics, vol. 165, n. 19-20, pp. 1275-1293. 